\title{
Household survey to evaluate the Zambia-led Prevention Initiative: Baseline report
}

Zambia-led Prevention Initiative

Follow this and additional works at: https://knowledgecommons.popcouncil.org/departments_sbsr-hiv

Part of the Demography, Population, and Ecology Commons, Health Policy Commons, Immune System Diseases Commons, International Public Health Commons, Medicine and Health Commons, Public Health Education and Promotion Commons, and the Virus Diseases Commons How does access to this work benefit you? Let us know!

\section{Recommended Citation}

Zambia-led Prevention Initiative. 2012. "Household survey to evaluate the Zambia-led Prevention Initiative: Baseline report." Lusaka: USAID. 


\section{HOUSEHOLD SURVEY TO EVALUATE THE ZAMBIA-LED PREVENTION INITIATIVE}

\section{BASELINE REPORT}

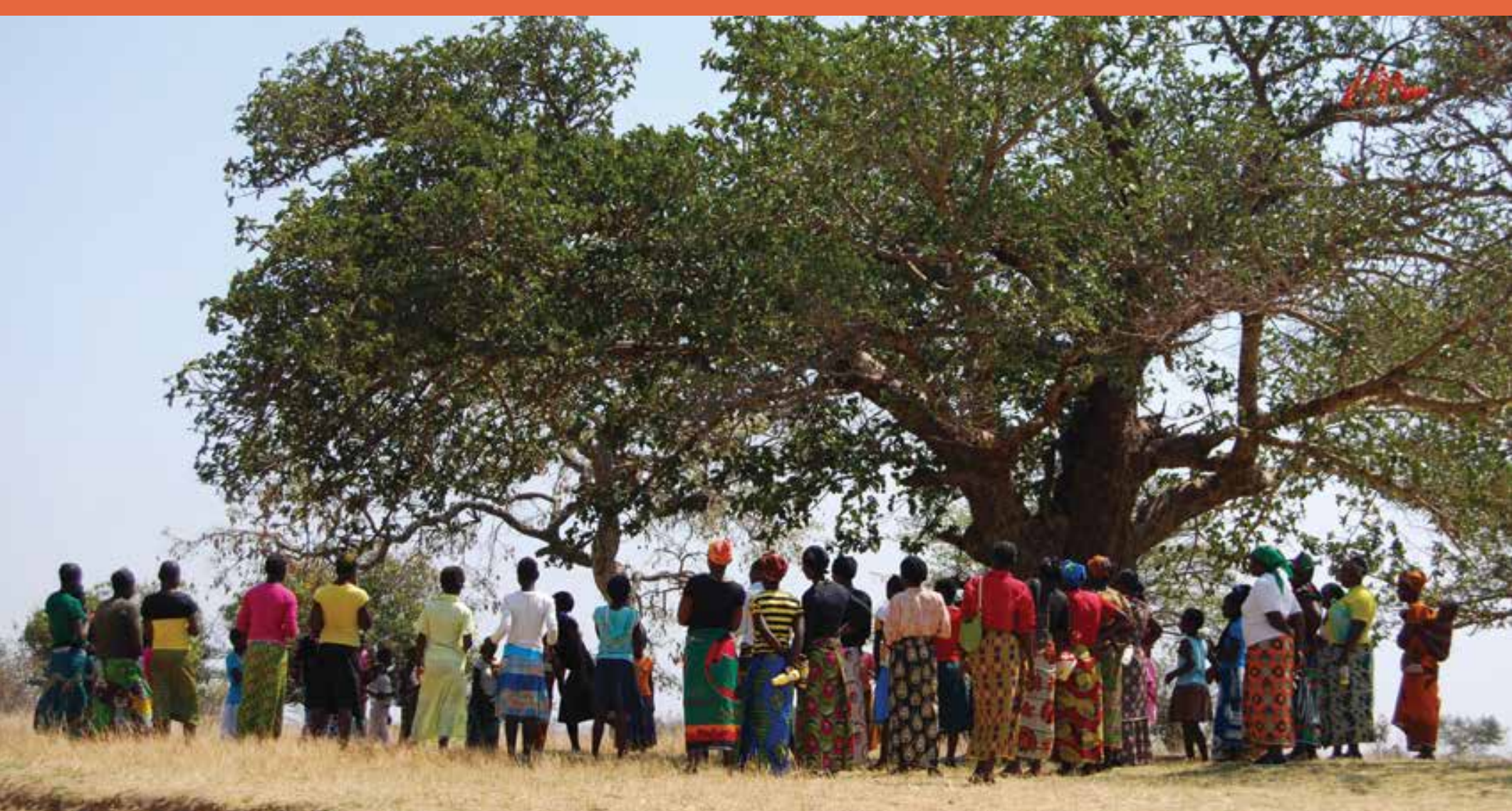

ZAMBIA-LED PREVENTION INITIATIVE 



\section{HOUSEHOLD SURVEY TO \\ EVALUATE THE ZAMBIA-LED \\ PREVENTION INITIATIVE}

\section{BASELINE REPORT}

\section{Zambia-led Prevention Initiative}

\section{Investigators}

Samuel Kalibala MD ${ }^{1}$

Jill Keesbury, $\mathrm{PhD}^{2}$

Waimar Tun $\mathrm{PhD}^{3}$

\section{Co-Investigators}

Tina Moyo ${ }^{2}$ (Study Coordinator)

Meredith Sheehy ${ }^{4}$

Chileshe Chilangwa ${ }^{5}$

Robert Haloba ${ }^{5}$

${ }^{1}$ Population Council, Nairobi, Kenya

${ }^{2}$ Population Council, Lusaka, Zambia

${ }^{3}$ Population Council, Washington, DC

${ }^{4}$ Population Council, New York

${ }^{5} \mathrm{FHI360}$, Lusaka, Zambia
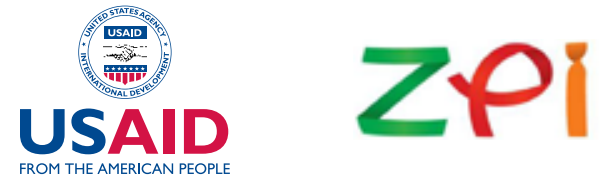

Zambia-led

Prevention Initiative 


\section{ACKNOWLEDGEMENTS}

The Zambia-led Prevention Initiative (ZPI) acknowledges the efforts of all those who contributed to the successful conduct of the baseline survey and report. In particular, ZPI appreciates the efforts of Principal Investigators Drs. Sam Kalibala and Jill Keesbury for initiating this evaluation, and Dr. Waimar Tun for leading the analysis and writing of this report.

Special thanks to Tina Nanyangwe Moyo for overseeing the data collection efforts, Chabu Kangale and Benjamin Kayungwa for programming the handheld computers for data collection, Kumbutso Dzekedzeke for his input regarding mapping activities and selection of sampling units, Meredith Sheehy and Alyssa Westerman for their assistance with the writing of the report, and Dr. Jessica Price for her review and assistance with the interpretation of results and dissemination of the findings to stakeholders. ZPI also extends its appreciation to Chileshe Chilangwa, Robert Haloba, Earnest Myunda, Felly Simmonds, and Chad Rathner for their thorough review of and input into this report.

The contributions of Patrick Chilumba and Mutale Mwaba of Crystal Consulting, the organization contracted to conduct the survey, and the data collectors are appreciated. We are also grateful to all the respondents who gave their time to participate in the study.

In addition, we gratefully acknowledge the United States Agency for International Development (USAID) for supporting the project.

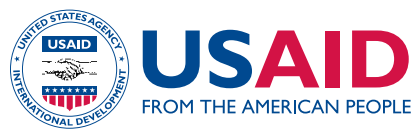

This document was made possible by the support provided by the American people through the United States Agency for International Development (USAID) under the terms of Contract No. GHS-I-02-07-00008-00. The contents are the responsibility of the authors and do not necessarily reflect the views of USAID or the United States Government.

Suggested citation: Zambia-led Prevention Initiative. 2012. "Household survey to evaluate the Zambia-led Prevention Initiative: Baseline report.” Lusaka, Zambia: USAID.

Published in October 2012.

Copyright (C2012 Population Council.

Cover photo by Natalie Jackson, courtesy of the Population Council.

This document may be reproduced in whole or in part without permission of USAID provided full source citation is given and the reproduction is not for commercial purposes. 


\section{TABLE OF CONTENTS}

Acronyms

Executive Summary 1

Introduction 1

Methodology 1

Study Population Characteristics $\quad 2$

Key Findings and Implications $\quad 2$

$\begin{array}{ll}\text { Conclusion } & 7\end{array}$

Introduction $\quad 8$

Background $\quad 8$

ZPI Objectives and Project Design 11

Evaluation of ZPI 12

Methods 13

Study Design 13

Study Population $\quad 15$

Sample Size 15

Data Collection 16

Data Analysis 17

$\begin{array}{ll}\text { Limitations } & 18\end{array}$

$\begin{array}{ll}\text { Results } & 19\end{array}$

$\begin{array}{ll}\text { Background Characteristics } & 19\end{array}$

Knowledge about HIV and AIDS 19

HIV Testing $\quad 22$

Sexual Behaviors $\quad 26$

Condom Accessibility $\quad 34$

Gender Relations 36

Alcohol and Drugs $\quad 43$

Contraception and Pregnancy 45

Male Circumcision $\quad 48$

Economic Empowerment $\quad 51$ 


\section{ACRONYMS}

\begin{tabular}{|c|c|}
\hline AED & Academy for Educational Development \\
\hline ANC & Antenatal care \\
\hline ART & Antiretroviral therapy \\
\hline ARV & Antiretrovirals \\
\hline $\mathrm{BCC}$ & Behavior change communication \\
\hline CAGE & $\begin{array}{l}\text { Cutting down, annoyance by criticism, guilty feeling, and eye-openers } \\
\text { (alcohol abuse assessment) }\end{array}$ \\
\hline CBO & Community-based organization \\
\hline CHAMP & Comprehensive HIV/AIDS Management Program \\
\hline CMMB & Catholic Medical Mission Board \\
\hline GRS & Grass Roots Soccer \\
\hline CSO & Central Statistical Office \\
\hline DHS & Demographic Health Survey \\
\hline FHI360 & Family Health International 360 \\
\hline GEM & Gender equitable men \\
\hline GBV & Gender-based violence \\
\hline GRZ & Government of Republic of Zambia \\
\hline $\mathrm{HH}$ & Household \\
\hline HIV & Human immunodeficiency virus \\
\hline HTC & HIV testing and counseling \\
\hline KAP & Knowledge, attitudes, and practices \\
\hline LAN & Local area network \\
\hline $\mathrm{MC}$ & Male circumcision \\
\hline MCP & Multiple and concurrent partnerships \\
\hline MOT & Modes of transmission \\
\hline NAC & National AIDS Council \\
\hline NGO & Non-governmental organization \\
\hline $\mathrm{PCl}$ & Project Concern International \\
\hline PDA & Personal Digital Assistant \\
\hline РMTCT & Prevention of mother-to-child transmission \\
\hline PLA & Participatory learning and action \\
\hline PRA & Participatory rural appraisal \\
\hline RCT & Randomized clinical trial \\
\hline
\end{tabular}




$\begin{array}{ll}\text { SEA } & \text { Standard enumeration areas } \\ \text { SES } & \text { Socio-economic status } \\ \text { STI } & \text { Sexually transmitted infections } \\ \text { TBA } & \text { Traditional birth attendant } \\ \text { UNZA } & \text { University of Zambia } \\ \text { VCT } & \text { Voluntary counseling and testing } \\ \text { VSU } & \text { Victim Support Unit } \\ \text { ZDHS } & \text { Zambia Demographic Health Survey } \\ \text { ZHECT } & \text { Zambia Health Education and Communication Trust } \\ \text { ZPI } & \text { Zambia-led Prevention Initiative } \\ \text { ZSBS } & \text { Zambia Sexual Behavioral Survey }\end{array}$




\section{Introduction}

With an estimated HIV prevalence of 14.3 percent among men and women age 15-49, Zambia is one of the sub-Saharan African countries most affected by the HIV and AIDS pandemic (Zambia Demographic Health Survey [ZDHS] 2007). For this reason, it is important that interventions that have an intensive prevention focus are implemented. The Zambia-led Prevention Initiative Program (ZPI) was developed by a consortium ${ }^{1}$ led by FHI360, with the Population Council as the evaluation partner. ZPI focuses on mobilizing stakeholders, generating an evidence base for diffusion of effective prevention interventions, and building local capacity. ZPI works on increasing utilization of community-level interventions through a targeted approach and provides technical leadership and expertise on comprehensive, effective, community-based prevention efforts. As part of a multi-pronged approach to ZPI monitoring and evaluation, the Population Council conducted a community-based survey to assess baseline values on key indicators related to HIV knowledge and risk, gender and gender-based violence (GBV), and reproductive health.

The evaluation will determine the effect of the ZPI intervention on knowledge and behavioral outcomes related to HIV, reproductive health, and GBV using a repeated cross-sectional household $(\mathrm{HH})$ survey conducted at baseline, midline, and endline. The purpose of this report is to discuss the results of the baseline $\mathrm{HH}$ survey that was conducted July to August 2011.

\section{Methodology}

The baseline survey was conducted in eight districts in four provinces (two districts per province): Copperbelt and Eastern provinces, where activities were initiated in Year 1; Luapula, where activities will be initiated in Year 2; and Western, where activities will be initiated in Year 3 of the ZPI. Districts were randomly selected from those where ZPI activities will be initiated. Half of the selected districts were predominantly rural and the other half had a significant urban or peri-urban population; all of the districts had a limited number of HIV activities. Households and household members were randomly selected. The eligibility criteria included being a permanent resident of the sampling area and being female aged 15-49 years or male aged 15-59 years. Face-to-face interviews were conducted using handheld computers (Personal Digital Assistants [PDA]). In all, 2,760 individuals (1,060 males and 1,700 females) were interviewed; data on 2,439 respondents ( 88 percent) were included in the analysis due to data failing to be captured on the PDAs for some initial participants.

${ }^{1}$ FHI360 as lead, Afya Mzuri, Comprehensive HIV AIDS Management Programme (CHAMP), Hodi, Zambia Health Education and Communication Trust (ZHECT), Catholic Medical Mission Board (CMMB), Grass Roots Soccer (GRS), and the Population Council. 


\section{Study Population Characteristics}

Overall, the study population was young (median age: 28 for males and 26 for females) with the majority having some primary or secondary education. Only a small percentage of respondents (5.9 percent of males and 11.4 percent of females) had received no education. Sixty-two percent of the respondents reported being currently married or cohabiting with a sex partner. Sixty-five percent of individuals in the sample resided in rural areas, and 41 percent fell into the lowest two quintiles of the Demographic Health Survey's (DHS) wealth index. Wealth did not vary between males and females, but varied greatly across provinces. Copperbelt province had the largest proportion of both males (39.0 percent) and females (38.3 percent) in the highest tier of the wealth index.

\section{Key Findings and Implications}

\section{HIV prevention and transmission knowledge}

Using the DHS five-question indicator of "comprehensive HIV knowledge," the ZPI baseline shows that comprehensive knowledge was low (39 percent) and varied significantly across provinces for both males and females. Females had significantly lower comprehensive knowledge than males (35 percent versus 47 percent; $p<0.05$ ). These knowledge rates were very similar to findings in the 2007 ZDHS. Individuals from Eastern province had particularly low comprehensive knowledge levels ( 25 percent) compared to other provinces.

Bivariate and multivariate analyses do not show any significant associations between comprehensive HIV knowledge and sexual risk variables (having multiple, non-regular sex partners, or condom use). Therefore, having correct HIV knowledge is unlikely sufficient for practicing HIV preventive behaviors.

\section{Programmatic implications}

- Behavior change communication (BCC) must go beyond improving knowledge alone. This is reflected in ZPI's BCC approach based on stages of change theory: from awareness of an issue, contemplation of relevance to Self, taking protective behavioral action, and maintaining the safer behaviors. There is a need to critically assess communication messages and approaches with a view to improving BCC effectiveness as a process of change.

\section{Sexual risk}

Early sexual onset (before 15 years of age): Statistically significant differences were found across provinces, with especially high rates of early sexual onset in Western province (30 percent compared to 18 percent for the whole sample). No differences were found between females and males.

Multiple sex partners (having two or more partners in the last 12 months): Having multiple partners was more common among males than females. About 1 in 5 males had multiple partners in the past 12 months, compared to less than 1 in 10 females $(p<.05)$. Further, for all provinces except Luapula, rates of multiple partnering appeared to be substantially higher compared to findings reported in the 2007 ZDHS. 
Non-regular sex partners (non-marital /non-cohabiting sex partner in the past 12 months): While men (31 percent) were significantly more likely to have non-regular partners, women also had non-regular partners (24 percent). Significant differences were found across provinces $(p<.05)$, with much greater prevalence in Western (approximately 50 percent of both males and females) compared to all provinces. Having non-regular partners was more common among younger persons, those with more education, with early sexual debut, and who had multiple partners in the past 12 months.

Condom use: Condom use (at last sexual act) among persons with multiple sex partners is overall low, but higher in females (20 percent) compared to males ( 5 percent). Similarly, condom use with the last non-regular partner is lower in males (24 percent) compared to females (38 percent). Multivariate analyses revealed that simply knowing where to get a condom is not sufficient for condom use. Rather, having confidence that he/she could obtain a condom if he/she wanted to was the greatest predictor of condom use.

\section{Programmatic implications}

- There is a need for programs that reduce sexual risk behaviors for both men and women, with an extra emphasis on male-centered interventions.

- More and better communication specifically about how and where one can obtain condoms when needed is crucial.

- Also indicated is a need for critical analysis and utilization of BCC theory for practice.

\section{Attitudes toward and perceived norms around abstinence and faithfulness}

The apparent disconnect between knowledge and risk behavior is consistent with apparent contradictions in responses to value statements and perceived social norms around abstinence and faithfulness. For example, more than 80 percent agreed to the statement "Young men should wait until they are married to have sex." However, less than 15 percent agreed to "Most young men I know wait until they are married to have sex." There were similar findings for parallel statements about women and about faithfulness.

\section{Programmatic implications}

- BCC messages need to be re-evaluated and must be made more persuasive and address psychosocial processes such as the cognitive dissonance using such proven techniques as: motivational interviewing, cognitive-behavioral approaches, harm and risk reduction interventions, etc.

\section{HIV testing}

A significantly greater proportion of females than males knew where to get tested and reported having ever been tested and receiving their results (69 percent versus 53 percent; $p<.05)$. This is not surprising given the added exposure to testing within ANC clinics. The lowest HIV testing rates were observed in Western province (55 percent). HIV testing rates in this study were higher than that in the 2007 ZDHS (which was 20 percent in males and 35 percent in females). This likely is due to huge HIV testing campaigns throughout the country since 2007. Despite the increase in HIV testing, there is still a need to increase testing rates, particularly among men. 


\section{Programmatic implications}

- All provinces should consider conducting male-centered information and testing campaigns.

- HIV testing services should be evaluated to determine whether they are meeting the unique needs of men for HIV testing and sexual health.

\section{Gender equitable attitudes}

Using a validated scale to measure gender attitudes (Gender Equitable Men Scale), the survey found that overall, 37 percent of respondents supported gender inequitable norms. There was wide variability across the provinces with Copperbelt having the lowest proportion supporting inequitable norms (22 percent) and Luapula having the highest (55 percent). Further, in contrast to the trend in all three of the other provinces of males having lower gender equitable attitudes compared to females, in Luapula females have substantially lower gender equitable attitudes compared to males from the same province (60 percent versus 46 percent; $p<0.05)$.

Low gender equitable attitudes seem to be associated with higher risk. Low gender equitable attitudes is highly correlated with high risk sexual partnering $(p<.001)$ and also significantly correlated with being drunk at last sex $(p<.05)$.

\section{Programmatic implications}

- ZPI has developed a specific Gender Strategy, and all ZPI interventions have been designed to be gender-sensitive and take into account the impact gender has on becoming infected with HIV as well as on access to treatment, care, and support.

\section{Sexual and physical abuse and rape myths}

Female respondents in all provinces reported high rates of ever having experiencing sexual abuse (39 percent) or physical abuse (35 percent). Significant differences exist across provinces $(p<.05)$ with the highest rates of sexual abuse reported in Copperbelt (51 percent) and physical abuse reported in Eastern (42 percent). Rural residence was associated with higher rates of ever having been sexually or physically abused $(p<.05)$. Currently or ever married also is highly associated with ever having experienced abuse $(p<.01)$.

Among females who reported having experienced abuse, very few sought help (15 percent overall); those who most often turned to a family member (60 percent turning to her own family and 24 percent to an in-law).

Underlying the violent behaviors are myths that blame women for rape. Sixty-two percent of all respondents supported one or more of four rape myths such as "When a woman is raped, she usually did something careless to put her in that situation." Fourteen percent of the sample support all four rape myth statements. The pervasiveness of these rape myths in the community makes it difficult for women to find and seek support after GBV experiences. 


\section{Programmatic implications}

- Programs for survivors of GBV should help women know where else they can turn for help besides family members. However, programs should also simultaneously work to improve family response to abuse. Providers at health facilities must be sensitized and doctors and nurses need to be trained to provide services for survivors of GBV.

- Linkages should be developed between local hospitals/health centers and the police in order to facilitate referrals for victims. Even more appropriate would be to have such support services based at the police stations so as not to lose people during the referral process. Counselors could be available at police stations to help victims obtain the appropriate care they need right there and then. This includes emergency contraceptive, improved psychosocial counseling, STI testing and treatment, and post-exposure prophylaxis to prevent HIV.

\section{PMTCT}

A high percentage of both men (48 percent) and women (35 percent) did not know that there were drugs to reduce mother to child transmission of HIV during pregnancy $(p<0.05)$. However, it was encouraging that the majority of women had received antenatal care (ANC) for their last pregnancy (95 percent), and three-quarters of these women received HIV testing and results. However, Luapula and Western provinces had lower HIV testing rates during ANC with 29-34 percent not having been tested or receiving test results. Further, in Luapula, a large proportion of women saw traditional birth attendants rather than doctors, nurse/midwives, or clinical officers for ANC services, unlike women in other provinces.

\section{Programmatic implications}

- Traditional birth attendants can be trained to provide HIV testing or they should facilitate women getting tested.

- Ensure that ANC providers are educating women about ways in which women can prevent HIV transmission to their babies.

\section{Alcohol use}

Two key indicators ascertain levels of alcohol abuse: drunk in the last four weeks and a standard measure of a clinically significant alcohol problem. Males were significantly more likely than females to have been drunk in the last four weeks and to have an alcohol problem (as measured by the CAGE questionnaire items). Further, those in Copperbelt and Eastern provinces fared worse on both of these indicators. Being drunk at last sex (either self or partner) was found to be significantly associated with having multiple partners in the past year.

\section{Programmatic implications}

- There is a need for prevention programs to include or intensify alcohol risk reduction counseling as an integral part of HIV counseling and testing. At a minimum, alcohol problem should be assessed of all people accessing HIV counseling and testing. PMTCT, and male circumcision (MC), and appropriate referrals should be made. 


\section{Unintended pregnancy and contraceptive use}

Fifty percent of women reported unintended pregnancy in relation to their last birth (i.e., did not want to become pregnant or wanted to wait to become pregnant). Copperbelt has the highest rate of unintended pregnancy (67 percent) and Luapula the lowest (34 percent). Young, single women had especially high rates of unintended pregnancy. Among women under the age of 25, 77 percent and 85 percent of those who have never been married or are divorced, respectively, reported unintended pregnancy compared to much lower rates of 50 percent unintended pregnancy in older women or young married women.

In addition to high rates of unintended pregnancy, the baseline showed overall low rates of current use of any family planning method (25 percent overall). Among contraceptive users, pills and injectibles were the most common methods ( 85 percent). Only 4 percent of women reported using implants, and no other long-acting or permanent method use is reported.

The majority (97 percent) of respondents had never heard of emergency contraception, which is a key component of the Zambia national family planning method approach. Emergency contraceptive use could lower the rates of unintended pregnancies.

\section{Programmatic implications}

- There is an urgent need to understand the dynamics of access to family planning for young, single women (i.e., whether younger unmarried women are self-denying access to family planning services or whether health providers are denying them access or both).

- Awareness of and access to emergency contraceptive need to be improved.

\section{ANC coverage}

While attendance at one or more ANC visit for a pregnancy was high (over 90 percent), a high proportion of women (one-third) did not complete the four recommended ANC visits. The proportion was as high as one-half in Eastern province. It was also Eastern province that had the highest percentage of women who gave birth to a live child who later died (35.4 percent) compared to other provinces.

\section{Programmatic implications}

- Strategies are needed to improve continuation of antenatal care throughout pregnancy, particularly in Eastern province.

- This low rate of ANC coverage and the high proportion of deaths urgently need further investigation in Eastern province.

\section{Male circumcision}

Except for Western province (47 percent), reported male circumcision is low (18 percent overall). Further, among those circumcised, about one-half occurred at less than 13 years of age. Sixty percent of the circumcisions were performed by traditional circumcisers. Multivariate analysis showed that those who were circumcised had lower comprehensive knowledge of HIV and were significantly more likely to have had multiple partners in the past year. It is 
important to know whether there is greater sexual risk taking due to a false sense of security in thinking that one is protected from HIV infection due to circumcision.

\section{Programmatic implications}

- Apart from male condoms, medical male circumcision is one of the best known methods to reduce the risk for acquiring HIV in men. As barriers to circumcision may vary across provinces, tailored strategies to increase uptake of medical male circumcision is needed for different provinces.

\section{Women's Economic Empowerment}

Based on questions related to family financial decisions, Luapula appears to have the greatest equity in that the province had the highest proportion (approximately $60-80$ percent) of participants who indicated that decisions about earnings, health care, daily purchases, food and clothing, and large investments were made jointly. Interestingly, however, Luapula was also the only province in which a very high proportion of men (51 percent) indicated that they had no earnings (in money) unlike other provinces where approximately only 13-35 percent of men had no earnings. It is very likely that the men are earning their wage in other forms of compensations such as food and lodging.

Eastern province had the lowest women's economic empowerment based on family financial decision making. It had the highest proportion of respondents (33-43 percent) who indicated that the male partner had the final say with regard to earnings and other household decisions.

\section{Programmatic implications}

- In all provinces, there is still a need for women's economic empowerment as decisions regarding daily purchases and large investments are more likely to be made by the male partner. Interventions should focus on improving women's financial literacy and their ability to make financial management decisions.

- It is worth further exploration into how household decisions are made in Luapula in order to achieve this kind of decision making equity in other provinces. What are the unique socio-cultural and economic factors in Luapula whereby family financial decisions are able to be made jointly?

\section{Conclusion}

This study determined baseline levels of key indicators related to HIV, GBV, and reproductive health. Additionally, the baseline findings provided critical insights into key areas for interventions in Zambia and highlighted variability in the populations across provinces and between males and females that provide valuable guidance for programming. 


\section{Background}

The Zambia-Led Prevention Initiative Program (ZPI) is a USAID-funded initiative designed to increase the delivery and uptake of community-led HIV prevention interventions and to generate an evidence base for diffusion of effective approaches. ZPI is implemented by a consortium of organizations ${ }^{2}$ led by the FHI360, which acquired Academy for Educational Development (AED) in July 2011. A partner in the consortium, the Population Council, is tasked with conducting targeted operational research and ZPI program evaluation. This report describes the methods and findings from the baseline survey conducted as part of ZPI's evaluation.

\section{Zambia's epidemic and state of HIV prevention science}

With an estimated HIV prevalence of 14.3 percent among men and women age 15-49, Zambia is one of the sub-Saharan African countries most affected by the HIV and AIDS pandemic (Zambia Demographic Health Survey [ZDHS] 2007). Of the 12.9 million people living in Zambia, an estimated 1.1 million people live with HIV, and 15.4 percent know their HIV status (National AIDS Council 2010). As in other highly affected African countries, Zambia's epidemic is shaped by a complex set of social and behavioral factors. Recent research in Zambia and elsewhere has advanced our understanding of these factors and their contribution to the spread of HIV (Zablotska et al. 2006; Malhotra and Yang 2011; Singh et al. 2011).

Sexual behavior and partnerships: High rates of partner change and multiple concurrent sexual partners (MCP) have both been implicated in high HIV prevalence rates in many African countries (Morris and Kretzschmar 1997; Halperin and Epstein 2004; Mah and Halperin 2008; Morris et al. 2010). The Zambia's Modes of Transmission (MOT) study (National AIDS Council 2009) estimates that individuals whose partners have casual heterosexual sex contribute most to HIV incidence and are responsible for 37 percent of total annual HIV incidence in Zambia, followed by individuals reporting casual heterosexual sex, who contribute 34 percent of the annual HIV incidence in Zambia. Thus the behavior of individuals concurrently having more than one sexual partner is considered to be the most important behavior driving the epidemic in Zambia. The 2007 ZDHS reported that 1.6 percent of women and 19.0 percent of men had had sex with at least two sexual partners in the past twelve months. ${ }^{3}$ Additionally, only 33.1 percent of women and 27.2 percent of men who had had sex with at least two sexual partners in the past twelve months used a condom at their last sexual act. Further evidence finds a positive correlation between being drunk during sexual intercourse and HIV infection, which is due to increased sexual risk taking, including MCP behaviors and lower rates of condom use (Zablotska et al. 2006; Malhotra and Yang 2011; Singh et al. 2011).

${ }^{2}$ FHI360 as lead, Afya Mzuri, Comprehensive HIV AIDS Management Programme (CHAMP), Hodi, Zambia Health Education and Communication Trust (ZHECT), Catholic Medical Mission Board (CMMB), Grass Roots Soccer (GRS), and the Population Council.

${ }^{3}$ We note a limitation to the survey in its exclusive focus on heterosexual behaviors. 
Sexual risk and HIV knowledge among young people: Successive ZDHS results since 1992 generally show positive trends in sexual risk, with decreasing proportions of males and females age 15-24 years reporting having had sexual intercourse by the age of 15, having had sexual intercourse with more than one partner in the past 12 months, and, of those who have had more than one partner in the past 12 months, increasing reported condom use during the last sex act (Gouws et al. 2008; International Group on Analysis of Trends in HIV Prevalence and Behaviours in Young People in Countries most Affected by HIV 2010). However, trends in knowledge on HIV transmission seem to be worsening; the 2009 Zambia Sexual Behavioral Survey (ZSBS) finds that from 2005 to 2009 a decreased proportion of respondents rejected misconceptions regarding HIV transmission, with fewer rural respondents refuting the myths.

Sexual risk and alcohol use: Observational data are beginning to associate alcohol use with HIV transmission behavior (Zablotska et al. 2006; Singh et al. 2011). A review of studies on alcohol use and sexual risk behaviors in sub-Saharan Africa showed an association between unsafe sex and high quantities of alcohol consumption (Kalichman et al. 2007). In Zambia, the 2007 ZDHS showed that among young people aged 15 to 24 years, 0.9 percent of females and 4.7 percent of males had had sexual intercourse when drunk. The ZDHS also showed that in the same age group, 7.8 percent of the females compared to 4.8 percent of the males had had sexual intercourse when they or their sexual partners were drunk. This data suggest that, for females, their alcohol-related risk is more likely due to the drunkenness of their partners than of themselves. Malhotra and Yang (2011) found that respondents who, along with their sexual partner, were drunk the last three times they had sexual intercourse were more likely to be HIV positive, which is primarily due to an increase in risky behavior.

Gender-based violence (GBV): More studies are showing that GBV also has an association with high HIV prevalence. A study from South Africa reported that women with violent partners had a 50 percent greater risk of acquiring HIV than women without violent partners (Dunkle et al. 2004). In a study of women attending an HIV counseling and testing clinic in Tanzania, young HIV-positive women were 10 times more likely to report violence than HIV-negative women (Maman et al. 2002). In Zambia, the 2007 ZDHS showed that 51.9 percent of women had ever experienced either physical or sexual violence in their life time.

Male circumcision (MC): Other studies have shown that MC reduces the risk of HIV acquisition by men by approximately 60 percent (Auvert et al. 2005; Bailey et al. 2007; Gray et al. 2007). According to the 2007 ZDHS, the rate of male circumcision was 12.7 percent overall but it varied between provinces. While there are some exceptions, provinces where the HIV prevalence among men was above the national average of 12.3 percent, such as Central (12.6 percent), Lusaka (19.0 percent), Luapula (15.3 percent) and Southern (13.2 percent), tended to have rates of $\mathrm{MC}$ that are 10 percent and below.

Sexually transmitted infections (STIs): While still inconclusive, there is strong evidence that STIs are associated with a higher risk of HIV transmission (Steen et al. 2009). The 2007 ZDHS data showed that 4.8 percent of women and 5.7 percent of men reported having had an STI in the past 12 months. The ZSBS reports a lower incidence of STIs in Zambian men and women. In 2009, the ZSBS documented that 2.7 percent of all male respondents 
and 2.4 percent of all female respondents had experienced an STI symptom in the past 12 months. For females this was an increase from 2000, but for males this was a decrease (ZSBS 2009).

Internal mobility and labor migration: Other significant drivers of the HIV epidemic in Zambia include high levels of internal mobility and labor migration. The 2007 ZDHS found HIV prevalence was highest among respondents who slept away from home five or more times within one year.

Socio-economic status: A growing body of work globally has explored associations between socio-economic status (SES) and HIV prevalence. While some clear trends are emerging, trends in Zambia remain difficult to disentangle (ZDHS 2007). For example, on the relationship between wealth and HIV risk, Mishra et al. (2007) reviewed data from Demographic Health Surveys (DHS) conducted between 2003 and 2005 in Kenya, Ghana, Burkina Faso, Cameroon, Tanzania, Lesotho, Malawi, and Uganda and concluded that in most cases wealthier adults remain at least as likely as poorer adults to be infected with HIV. But the 2007 DHS in Zambia clearly showed that HIV prevalence was 8 percent among respondents in the lowest wealth quintile and it rose to 21 percent among those in the fourth quintile; it was only slightly lower in the fifth quintile (18 percent). Based on a multivariate regression analysis of the 2007 ZDHS, Malhotra and Yang (2011) also found a strong positive relationship between wealth status and HIV prevalence. Singh et al. (2011), however, discovered that women in Mongu, Zambia were more likely to partake in sexually risky behavior, such as MCP and transactional sex, if they were unemployed or looking for work, which could signal either poverty or a desire for advancement. Gabrysch et al. (2008) analyzed the influence of neighborhood-level SES on HIV prevalence and found that women age 15-24 living in neighborhoods of lower or middle SES had higher HIV prevalence than those from higher SES neighborhoods.

Education: Gillespie et al. (2007) report that most studies suggest that education is increasingly associated with less risky behaviors. However, the 2007 ZDHS showed that the HIV prevalence among people with no education was 10 percent but the prevalence increased with the level of education, i.e., 14 percent among those with a primary education, 15 percent among people with a secondary education, and 19 percent among people who have more than secondary education. Stephenson (2010) found that in Chad, Malawi, Nigeria, Uganda, and Zambia men living in communities with more equal ratios of women to men with at least a primary education were less likely to report extramarital sexual activity, but there was no significant relationship between education and extramarital sexual risk-taking among men. To further illustrate the conflicting nature of the results, other studies have found that the relationship between education and HIV prevalence is not statistically significant (Malhotra and Yang 2011; Singh et al. 2011).

Mother-to-child transmission: Vertical transmission from mother-to-child has also contributed to Zambia's high HIV prevalence. While the scaling up of prevention of mother-to-child transmission (PMTCT) programs has steadily reduced the estimated number of children born with HIV, there are inadequate linkages and integration of PMTCT in reproductive health and antiretroviral therapy (ART) services; one out of 10 new infections still occurs in children aged 
0-14 years. Torpey et al. (2010) found that PMTCT interventions work in program settings, but postnatal transmission, especially after six months remains a problem; the transmission rate from mother to child was 6.5 percent when both mother and infant received interventions, compared with 20.9 percent when no intervention was given. Furthermore, Stringer et al. (2005) found that despite a seemingly robust PMTCT program in Lusaka, only 30 percent of seropositive mother-infant pairs in the study population received both a maternal and infant dose of nevirapine.

\section{ZPI's contribution to the response}

The ZPI project attempts to intervene in these multiple prevention opportunities. The present baseline study combined with two planned follow-on studies-at mid-point and end-point-are designed to evaluate the project's effectiveness, contribute to the understanding of the HIV epidemic in Zambia, and explore variability of protective and risky behaviors across different socio-demographic groups and ZPI project sites. Study results will also help to indentify best practices and needed revisions to those that are found to be ineffective.

\section{ZPI Objectives and Project Design}

The purpose of ZPI is to increase utilization of community-level interventions through a targeted approach and provide technical leadership and expertise on comprehensive, effective, community-based prevention efforts aimed at reducing HIV transmission in Zambia. ZPI pilots and evaluates HIV prevention interventions, including structural and economic development interventions; facilitates increased coverage, access, and uptake of these interventions; and strengthens the capacity and engagement of Government of Republic of Zambia (GRZ) and the private sector to direct, manage, and sustain these interventions as part of a broader response to the HIV epidemic in Zambia. The main objectives of ZPI are to:

1. Build capacity in communities affected by HIV/AIDS to access more effective, gender-sensitive, higher-quality HIV prevention programs, including HIV testing and counseling, male circumcision, and PMTCT;

2. Strengthen the continuity and coordination of, as well as commitment to, effective, efficient, and sustainable HIV prevention, including HIV testing and counseling, male circumcision, and PMTCT;

3. Design efficient, sustainable, and locally owned responses to HIV/AIDS, including increased engagement with the private sector; and

4. Provide community-based family planning and reproductive health services as an adjunct to effective prevention of HIV/AIDS.

Working through a consortium of international and national technical assistance partners ${ }^{4}$ and in close collaboration with multi-sectoral government services at all levels, ZPI engages communities in processes aimed at empowering members to generate locally relevant responses. Drawing upon the collective resources of community members, service providers, leaders, and private sector actors, ZPI implements a variety of cross-cutting interventions

${ }^{4}$ FHI360 as lead, Afya Mzuri, CHAMP, Hodi, Zambia Health Education and Communication Trust (ZHECT), Catholic Medical Mission Board (CMMB), Grass Roots Soccer (GRS), and the Population Council. 
and services that target behaviors and structural factors affecting the epidemic (e.g., gender norms, sexual abuse, mental health issues, alcohol abuse, and violence) and that promote an enabling environment for healthy behaviors and social norms.

ZPI is planned as a four and half-year project to be expanded in three phases. In year 1, the project was initiated in five provinces-Eastern, Southern, North-Western, Lusaka, and Copperbelt-covering four to seven districts in each for a total of 28 districts. In year 2 the project will expand to Luapula and Central provinces. In year 3 , the project will be initiated in the remaining two provinces of Zambia, Northern and Western, and will be implemented in at least 50 percent of all districts nationwide.

On key areas of risk and vulnerability, ZPI project performance is monitored both through routine process and output indicators collected in project implementation and through data collected in this baseline and follow-up household $(\mathrm{HH})$ surveys.

\section{Evaluation of ZPI}

The ZPI evaluation is designed to measure program coverage and outcomes at the individual level and generate data that assess the effect of the ZPI interventions on HIV prevention and reproductive health behaviors and related outcomes, in addition to contributing to the further understanding of the HIV epidemic in Zambia. Data from this study enables ZPI partners to judge to what extent they are meeting their targets, and to identify barriers and ways to address them.

Objectives of the ZPI evaluation:

1. Measure changes in project outcome indicators including male norms, alcohol use, and other standard HIV knowledge, attitudes and practices (KAP) indicators.

2. Estimate HIV infections averted as a result of the interventions.

3. Measure change in respondents' perception of coverage and availability of essential HIV prevention services including their knowledge of and experiences in using services.

Key evaluation questions answered by the household survey:

1. What is the effect of the ZPI program on HIV prevention indicators, including positive and negative male norms towards GBV, alcohol use and abuse, traditional norms associated with HIV risk, and other HIV KAP indicators?

2. What is the estimate of HIV infections averted by the ZPI program calculated from behavioral indicators through modeling?

\section{Purpose and objectives of the baseline household survey}

The baseline survey established the baseline levels for the indicators of the ZPI project shown in Appendix 1, which includes targets for Years 1 and 3 and findings from the 2007 ZDHS. The baseline survey also documented baseline levels of service utilization including the community members' knowledge about the services (i.e., HIV testing, ANC, contraception, condoms). In order to measure change after the intervention, data will be collected at midline and endline and compared to baseline levels. Lastly, the baseline survey will enable explora- 
tion of variability in the study population. The findings of the baseline HH survey will guide ZPI stakeholders to design and implement appropriate interventions.

Furthermore, results of the baseline $\mathrm{HH}$ survey will be used in conjunction with the endline results to estimate the probability of infection in the 12 months before the baseline, midline, and endline by using the Bernoulli-process model. Thus, the difference between the baseline and endline estimates will be the HIV infections averted by the intervention.

\section{Ethical review}

This study was approved by the Population Council Institutional Review Board in New York and the University of Zambia (UNZA) Ethics Committee.

\section{METHODS}

\section{Study Design}

This is a cross-sectional study design with repeated HH surveys that measure HIV behavioral indicators at three time points in three groups of communities: communities where ZPI interventions were initiated in year 1; communities where ZPI interventions will be initiated in year 2; and communities where ZPI interventions will be initiated in year 3 . The evaluation surveys are carried out at three points: baseline, midline (18 months after), and endline (another 18 months after).

As shown in Table 1, the baseline was conducted in months 10 to 12 when activities had been running for about three months in the year 1 initiated provinces, but no activities had taken place in the rest of the provinces. Further, the midline survey will be conducted in months 28 to 30 when activities will have been running for 21 months in the year 1 initiated provinces, 15 months in the year 2 initiated provinces, and three months in the year 3 initiated provinces. Finally, the third survey (endline) will be carried out in months 46 to 48 when activities will have been implemented for 39 months in the year 1 initiated provinces, 33 months in the year 2 initiated provinces, and 21 months in the year 3 initiated provinces. Thus throughout the three rounds of surveys it will be possible to compare outcomes in relation to the duration of the intervention. 


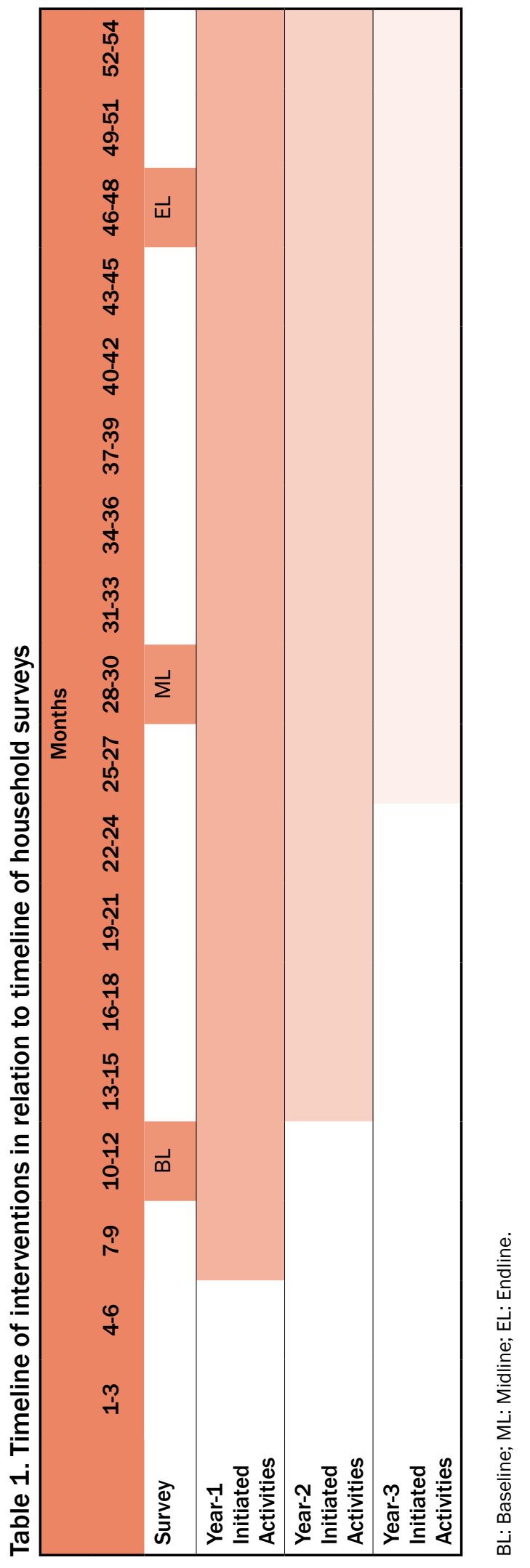




\section{Study Population}

The study population for the baseline HH survey was the population that is currently or will be covered by the ZPI interventions. By year 3 , the project will be conducted in all nine provinces of Zambia, and within each province between two and four districts will have been selected, totalling 28 districts (40 percent of all districts). This is the population from which all three rounds of survey will be drawn. Districts were randomly selected from among those where ZPI activities will be initiated. Half of the selected districts were predominantly rural, and the other half had a significant urban or peri-urban population; all of the districts had a limited number of HIV activities. Out of this universe, we randomly selected a manageable number of geographical areas known as standard enumeration areas (SEA) within which the study was carried out.

Eligibility criteria of respondents: For the baseline $\mathrm{HH}$ survey, the survey team recruited and interviewed female and male residents in $\mathrm{HH}$ in the selected SEA using the following inclusion criteria:

- Females aged 15 to 49 years.

- Males aged 15 to 59 years.

- Being a permanent resident of a household or having spent the night before in the household.

\section{Sample Size}

The sample size was calculated to detect a one-tenth reduction in high-risk sexual behavior between baseline and midline and between midline and endline. The 2007 ZDHS defined higher-risk intercourse as sexual intercourse with a non-marital, non-cohabiting partner, and the data showed that 16.9 percent of female respondents and 35.4 percent of males reported this behavior; this indicator was used to determine the minimum sample size for the behavioral survey. A target sample size of 2,700 respondents $(1,800$ women and 900 men) was determined to be able to detect a one-tenth reduction in high-risk sexual behavior between rounds of surveys.

Given limited resources, the ZPI study is only conducted in four randomly selected provinces: Copperbelt and Eastern among the Year 1 initiated; Luapula among the Year 2 initiated; and Western among the Year 3 initiated. Within each of these four provinces, districts where intervention activities were to occur were selected; districts were diversified by rural and urban/ peri-urban characteristics. Households and household members were randomly selected from standard enumeration areas (SEAs), which are the lowest geographic cluster used by the Central Statistical Office (CSO) of the Government of Zambia in demographic surveys. The actual sample size allocated to each province was proportionate to the population of the province.

The baseline survey interviewed a total sample of 2,760 people (1,060 men and 1,700 women). However, the study initially faced some technological challenges with the use of the personal digital assistant (PDA). The complexity of the sexual behavior section of the questionnaire caused the loss of some data for some respondents. Twenty percent of males 
and 6 percent of females only had data on sexual behaviors. They were excluded from the analytic sample. Additionally, 25 percent of males and 25 percent of females had missing data on sexual behaviors. However, since these latter respondents had all other data, they were included in the analytic sample for all other variables except the sexual behaviors. The analytic sample for all variables except sexual behaviors included 845 men ( 80 percent) and 1,594 women (94 percent). The sample for sexual behavior variables included 580 men (55 percent) and 1,174 women (69 percent).

\section{Data Collection}

\section{Preparatory phase before data collection}

Community buy-in: Community consultations and briefings were conducted with elected and traditional community leaders and district and provincial officials to ensure community buy-in of the survey by ZPI project staff who already had established rapport with the community leadership. Officials provided the study manager with a letter of introduction of the study to the traditional chiefs of the respective communities. The study team used this letter to introduce the study to the chiefs, who then provided a guide to introduce the team to the head of each $\mathrm{HH}$ during data collection.

Updating household lists and maps: Maps and household listings of the SEAs in the districts of operation of ZPI were obtained from the CSO. A team of enumerators made advance visits to the randomly selected SEAs to update the $\mathrm{HH}$ listings. The statistician randomly selected the $\mathrm{HH}$ and, within each $\mathrm{HH}$, selected the eligible female and male respondent to be interviewed using the updated lists. Since the required sample size of females was twice that of males, a female respondent was randomly selected from each randomly selected $\mathrm{HH}$ and a male respondent was randomly selected from every other $\mathrm{HH}$ that was randomly selected.

Interviewer training: Interviewers comprised current university students and recent graduates. Interviewer supervisors were university degree holders who had had prior experience in $\mathrm{HH}$ surveys including the DHS. They underwent a two week training conducted by the PI and Co-PI as well as other senior members of the research team. The training program included ethical procedures, interview techniques, a review of the questionnaires, and the use of PDAs, as well as role plays in interviewing using local languages. Following the training the interviewers did a pilot test of the tools.

Pilot testing: Survey instruments and methodology of approaching households were pilot tested. This included testing the process of seeking permission to talk to respondents, identifying the designated head of the $\mathrm{HH}$ who answered the HH questionnaire, identifying the selected respondents for the male and female questionnaires, and administering the informed consent. The pilot testing took place in districts where ZPI was not being implemented.

\section{Survey instruments}

The baseline HH survey consisted of three questionnaires. One was the general HH questionnaire that was administered to the adult identified as the head of the $\mathrm{HH}$. The general 
$\mathrm{HH}$ questionnaire asked about characteristics of the $\mathrm{HH}$. When the head of the $\mathrm{HH}$ was one of the respondents pre-selected for the individual male or female questionnaire, this person answered two questionnaires, the general one and the individual one. In HHs where the head of the $\mathrm{HH}$ was not pre-selected for the individual male or female questionnaire, the head of the $\mathrm{HH}$ answered only the general $\mathrm{HH}$ questionnaire. The second questionnaire was administered to the pre-selected female aged 15 to 49 years and the third was administered to the pre-selected male aged 15 to 59 years.

\section{Interviews}

The data were collected using face to face interviews administered by trained interviewers who read questions from a PDA and entered responses on the same PDA. The teams of interviewers were formed by local language and deployed to the provinces and districts that used that language as a majority language, and were introduced to $\mathrm{HHs}$ by a local guide. The guide, the team leader, and two interviewers, one male and one female, explained the purpose of their visit as well as the procedure of the consent and interview process, using the consent form for the study. In the case of legal minors (under 16 years of age in Zambia), consent for their participation in the study was obtained from their parents or legal guardians followed by the minor's assent.

\section{Data Analysis}

Data was analyzed in STATA version 9.0. Continuous variables were compared using Student's $t$-test and categorical variables with Pearson's chi-square test. Variables were considered significant at $p<0.05$ (two-tailed). Logistic regression was used to calculate unadjusted and adjusted odds ratios with 95 percent confidence intervals for the relationship of selected independent variables with dependent variables. Dependent variables include: i) sex with non-regular partners in the last 12 months; ii) having two or more partners in the last 12 months; iii) condom use in the last 12 months; iv) having ever tested for HIV and receiving results; v) ever having been sexually or physically abused; and vi) having been circumcised. The bivariate analysis consisted of examining the influence of each independent variable on the dependant variable. All variables with a $p<0.20$ and those with critical importance were entered into a multivariable regression model (Hosmer and Lemeshow 1989).

\section{Variables and definitions}

Gender Equitable Men (GEM) Scale: Attitudes toward gender relations were measured using 15 items adapted from the Gender Equitable Men scale (Pulerwitz and Barker 2008). The items had a Cronbach's alpha or 0.73 for men and 0.71 for women. A typical item in the scale is "A man should have the final word about decisions in his home." Each of the items was scored on a 3-point scale, where 1=agree, $2=$ partially agree, and $3=$ do not agree. A high score represents high support for gender equitable norms. Responses to each item were summed and the total was divided into tertiles (Low, Medium, High equity).

Wealth index: The wealth index was developed according to the ZDHS and it measures a household's long-term standard of living (ZDHS 2007). The index is based on the household's ownership of consumer goods, dwelling characteristics, type of drinking water source, toilet 
facilities, and other characteristics related to a household's socio-economic status. A score was calculated for each household and individuals were ranked based on the total score of the household in which they reside. The score was divided into quintiles (Lowest, Second, Middle, Fourth, Highest). Approximately 12 percent of the analytic sample were missing information on items included in the index. We, therefore, imputed missing values using multiple imputation in STATA (Version 9.0). The missing values were imputed based on residency (urban/rural), the ward in which they lived, and age.

Physical and sexual abuse: Female respondents were asked if they experienced physical or sexual abuse by a current or former male partner; male respondents were asked if they perpetrated physical or sexual abuse (lifetime and in the last 12 months) to any current or former female partners. Physical abuse includes pushing, shoving, slapping, throwing an object, hitting, kicking, dragging, beating, choking, and burning, or threatening use or actually using a weapon. These questions were taken from the WHO violence against women instrument which was developed for international use (WHO 2000).

Alcohol problem: Alcohol abuse was assessed using the CAGE 4-item questionnaire (Ewing 1984). CAGE stands for Cut down, Annoyed, Guilty, and Eye-opener. The items include feeling the need to cut down on drinking (Cut down), being annoyed by people criticizing drinking (Annoyed), feeling guilty about drinking (Guilty), and needing an eye-opener first thing in the morning (Eye-opener). Item responses were scored 0 for 'No' and 1 for 'Yes', with a higher score indicating alcohol problem. A total score of two or greater was considered to be a clinically significant alcohol problem.

\section{Limitations}

A limitation of the study was the cross-sectional nature of the design, which limits the ability to make any causal inferences. Despite this, an understanding of associations is valuable for targeting programs. Secondly, the study faced some technological challenges with the use of the PDA which caused the loss of some data. We excluded 20 percent of males and 6 percent of females who only had data on sexual behaviors. Since this excluded group only had sexual behavior data, we were unable to compare the demographics of this group with the analytic sample to examine any biases. Additionally, 25 percent of males and 25 percent of females had missing data on sexual behaviors. However, since these respondents had all other data, they were included in the analytic sample for all other variables except the sexual behaviors. When comparing those who did not have sexual behavior data to those who had complete data, there were no differences with regard to education or urban/rural residency. However, those without sexual behavior data were more likely to be younger (49 percent vs. 38 percent; $p<0.001$ ) and in the lowest wealth tertile (44 percent vs. 40 percent; $p<0.001$ ). This should be kept in mind when interpreting levels of risk behaviors and related parameters. However, this should not impact examinations of associations for dependent outcomes such as HIV testing and risky behaviors. 


\section{Background Characteristics}

The analytic sample consisted of 845 males and 1,594 females. The median age of respondents was 28 for males and 26 for females (Appendix 2). Respondents in Luapula were older than those in other provinces, and Western province had a much younger age distribution.

Overall, only a small percentage of respondents (5.9 percent of males and 11.4 percent of females) had received no education; this was highest in Luapula province where 20.1 percent of females had no education. Copperbelt and Western provinces had a more educated population than other provinces, and education was more equitable between men and women.

Most respondents identified their religious affiliation as Protestant, while close to 20 percent identified themselves as Catholic. The proportion of men and women who identified as Protestant and Catholic did not vary greatly across provinces.

Wealth did not vary between genders, but varied greatly across provinces. Copperbelt province had the largest proportion of both males (39.0 percent) and females (38.3 percent) in the highest tier of the wealth index followed by respondents in Western province (16.5 percent of men and 17.1 percent of women).

Overall, over 60 percent of the sample was married or cohabiting as if married. In all provinces, women were more likely to be separated or divorced or widowed than men.

Approximately two-thirds of the sample was rural residents. However, in Copperbelt province, approximately half of the respondents were urban and half were rural, while in Eastern, Luapula, and Western provinces the majority of respondents resided in rural areas. Eastern province had the highest proportion of rural respondents (83.5 percent of males and 76.0 percent of females).

\section{Knowledge about HIV and AIDS}

The majority of respondents had heard about HIV and AIDS; the proportion among males and females who had heard of HIV was similar across provinces (Appendix 3). Western province had the highest proportion of respondents who had never heard of HIV compared to other provinces (12.9 percent of males and 11.5 percent of females).

A fairly high proportion of respondents (approximately four out of five) had correct knowledge of HIV prevention methods. The majority correctly agreed that HIV can be prevented by not having sex (84.4 percent of men and 81.4 percent of women), that having one uninfected partner can prevent HIV (85.5 percent of men and 80.6 percent of women), and that using condoms consistently can prevent HIV (80.9 percent of men and 76.7 percent of women). Respondents in Western province were less likely to correctly answer questions about prevention strategies compared to other provinces. 
Over three-quarters of respondents knew that a healthy looking person can have HIV (79.5 percent of men and 78.0 percent of women); however, knowledge of this was lowest in Western province where just 70.1 percent of men and 66.3 percent of women understood this fact.

Men were significantly less likely to subscribe to myths about whether HIV can be transmitted through mosquitoes and witchcraft compared to women. Overall 70.4 percent of men correctly responded that HIV cannot be acquired through mosquito bites, compared to 58.9 percent of women; 73.8 percent of men indicated that HIV could not be acquired through witchcraft compared to 68.8 percent of women. A large proportion of respondents had heard of antiretrovirals (ARVs): 87.3 percent of men and 87.5 percent of women.

A composite index was developed to measure comprehensive knowledge of HIV similar to the ZDHS (2007). Respondents were considered to have comprehensive knowledge about HIV and AIDS if they: i) know that both condom use and limiting sex partners to one uninfected partner are HIV prevention methods; ii) are aware that a healthy-looking person can have HIV; and iii) reject the two most common local misconceptions, that HIV and AIDS can be transmitted through supernatural means or through mosquito bites. Comprehensive knowledge was low and varied significantly across provinces for both males and females. Males and females in Copperbelt province had the highest comprehensive knowledge of HIV (53 percent and 49 percent), and those in Eastern province had the lowest comprehensive HIV knowledge (32 percent and 20 percent, respectively) (Figure 1). Significant differences were also found between males and females overall, where 47 percent of males had comprehensive knowledge of HIV compared to 35 percent of females (Figure 1).

Figure 1 also shows the comprehensive knowledge results of the 2007 ZDHS. The results for both males and females overall are comparable to those found in this study.

Figure 1. Comprehensive knowledge of HIV and AIDS by province

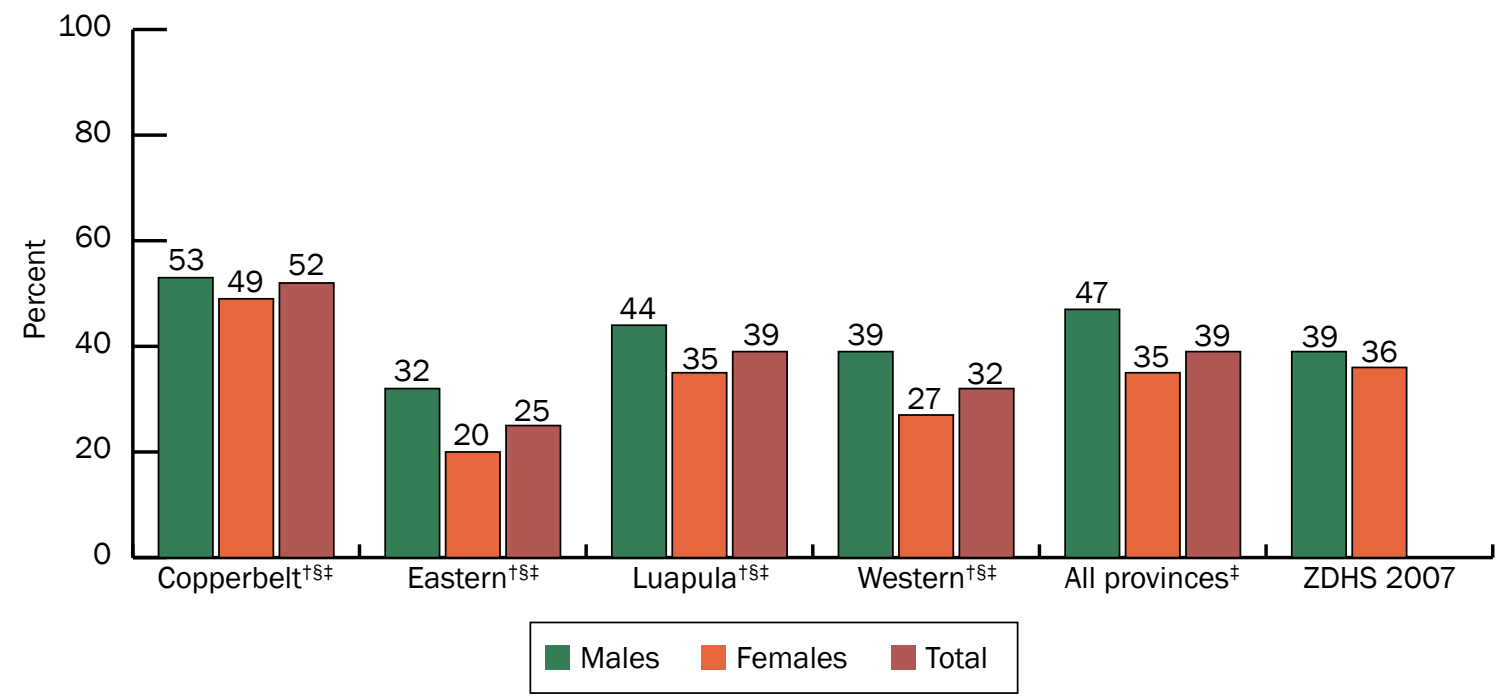

'Statistically different across provinces for males $(p<0.05)$.

sStatistically different across provinces for females $(p<0.05)$.

‡Statistically different between males and females $(p<0.05)$ 
We also assessed knowledge about HIV transmission from mother to child. Women had significantly higher knowledge that HIV could be transmitted through breastfeeding ( 80 percent of women versus 77 percent of men) (Figure 2). Knowledge about transmission through breastfeeding was lowest in Western province (59 percent in men and 72 percent in women).

Figure 2. Percent who knew that HIV can be transmitted through breastfeeding

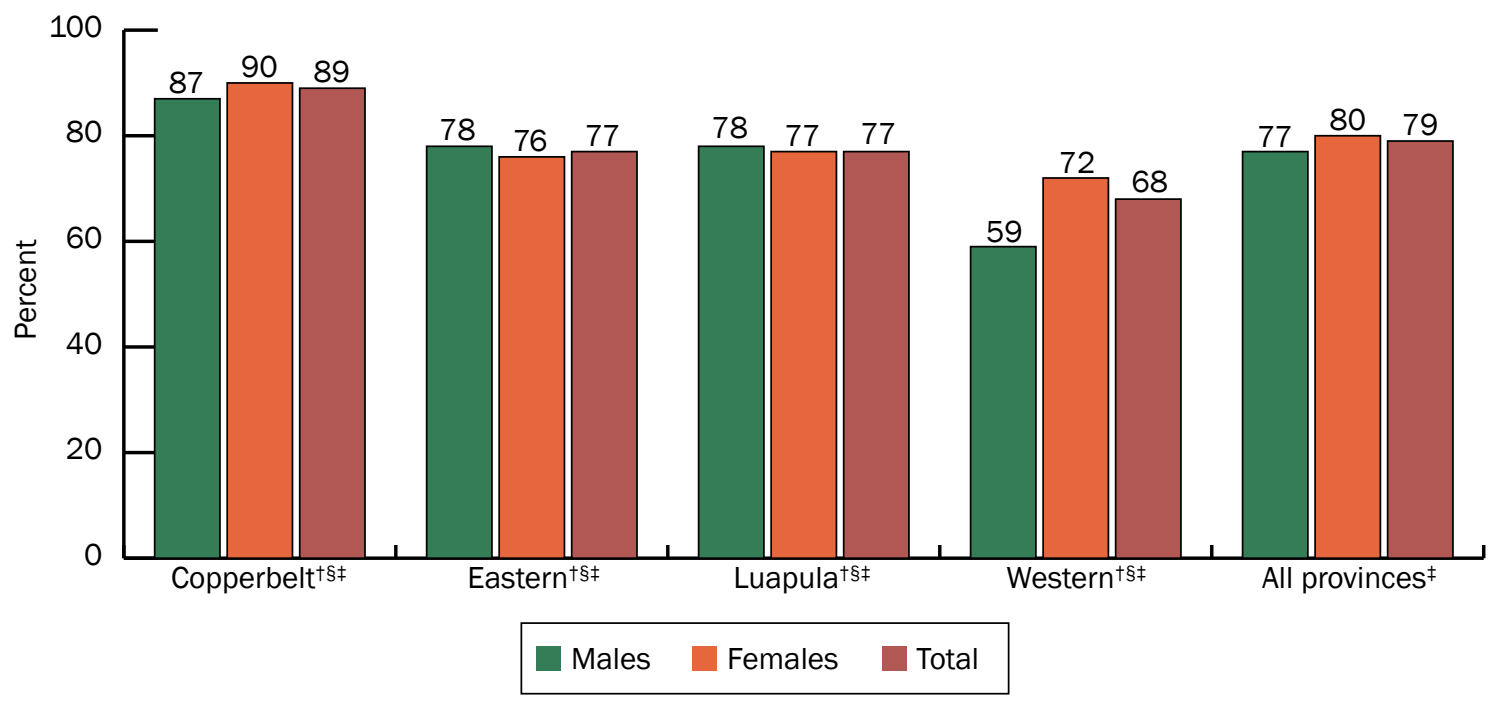

†Statistically different across provinces for males $(p<0.05)$.

sStatistically different across provinces for females $(p<0.05)$.

†Statistically different between males and females $(p<0.05)$

Knowledge about drugs to reduce mother to child transmission was extremely low in all provinces, ranging from 36 percent to only 71 percent (Figure 3). However, it was particularly low in Luapula where only 36 percent of men and 47 percent of women had heard of such drugs. Across provinces, women were significantly more likely to have heard of drugs that reduce transmission from a mother to their baby (65 percent of women versus 52 percent of men). However, in all provinces, the proportion of women who had heard of these drugs was still quite low, ranging from 47 percent in Luapula Province to 71 percent in Western Province. 
Figure 3. Percent who have heard of drugs to reduce HIV transmission from mother to baby*

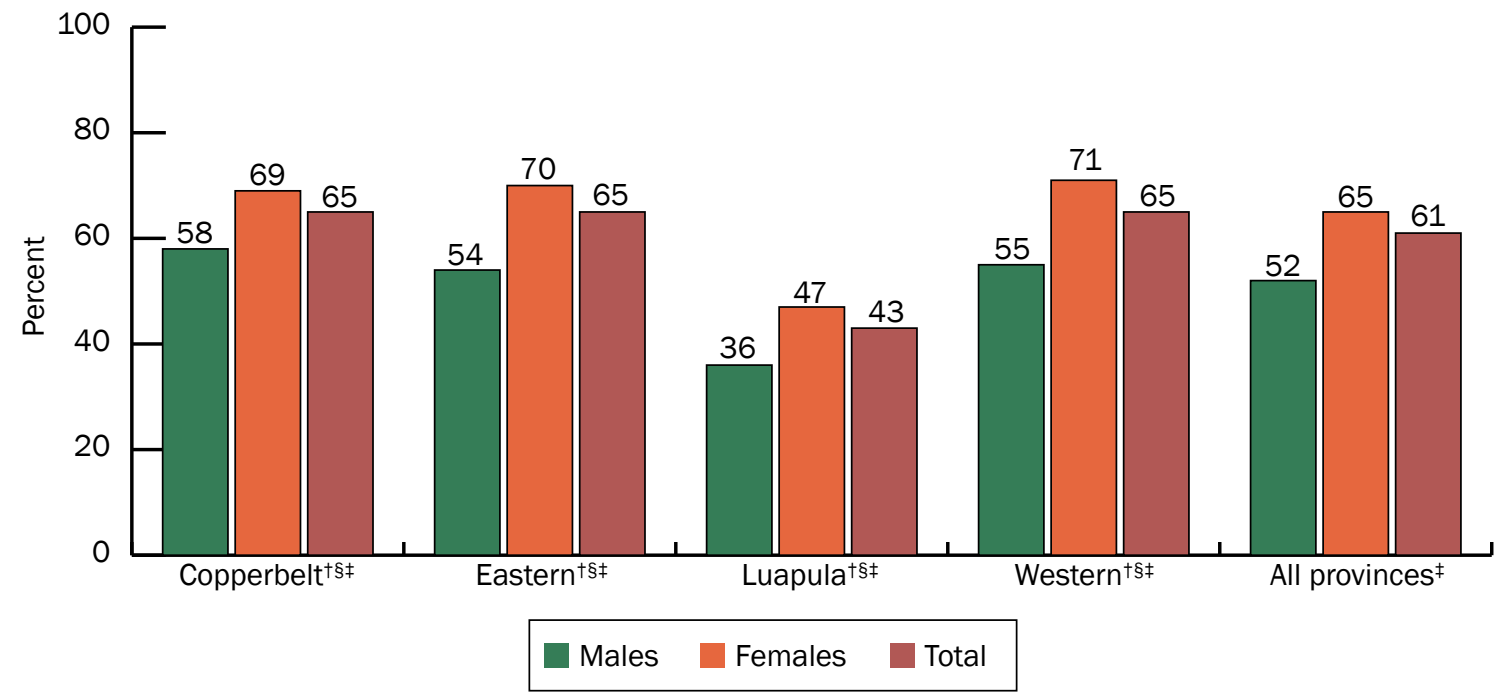

*Among those who know that HIV can be transmitted from mother to baby during pregnancy, during delivery, or through breastfeeding.

†Statistically different across provinces for males $(p<0.05)$.

§Statistically different across provinces for females $(p<0.05)$.

FStatistically different between males and females $(p<0.05)$

\section{HIV Testing}

\section{Knowledge of where to get tested for HIV}

Figure 4 shows that the majority of respondents knew where to test for HIV (79 percent), but this proportion varied greatly by sex and province. Across provinces, respondents in Western province were the least likely to know where they could test for HIV (71 percent) while those in Eastern were the most likely to know where to test for HIV (86 percent).

Additionally, a significantly lower proportion of male respondents knew where to test for HIV compared to female respondents (overall 63 percent versus 86 percent). This is likely due to HIV testing offered to women at ANC services. 
Figure 4. Percent who knows where to test for HIV

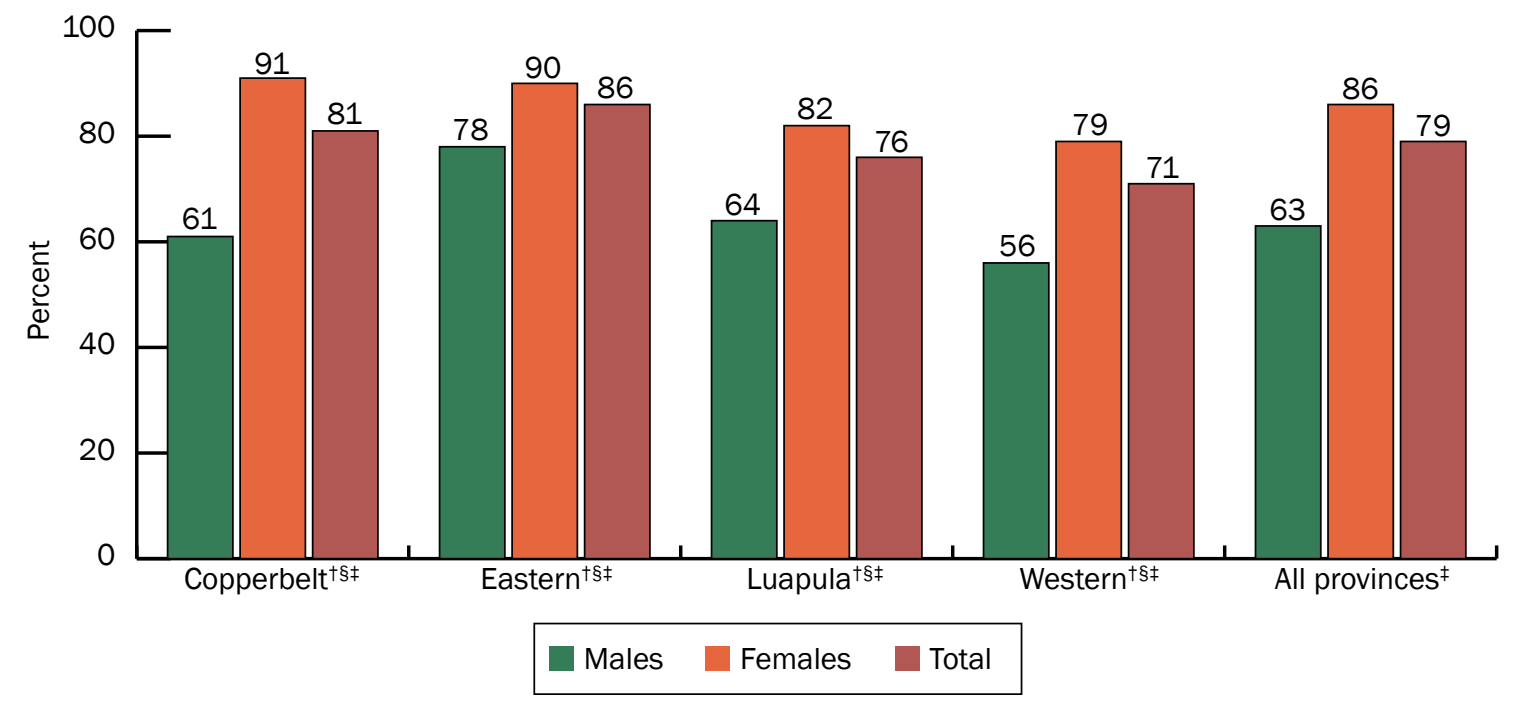

†Statistically different across provinces for males $(p<0.05)$.

\$Statistically different across provinces for females $(p<0.05)$.

₹Statistically different between males and females $(p<0.05)$.

\section{HIV testing history}

Figure 5 shows an overall significantly greater proportion of females having ever tested for HIV and received results compared to males (69 percent versus 53 percent). For women, this includes those who were tested at ANC centers. Proportions of male and female respondents who ever tested for HIV vary significantly across provinces and by gender within each province. Western province had the lowest proportion of men who had ever tested for HIV (40 percent), while Eastern province had the highest proportion (65 percent). Western and Luapula provinces had the lowest proportion of women who ever tested (approximately twothirds), and Eastern province had the highest (76 percent). While women were overall more likely to have ever tested for HIV, gender disparities in testing are most notable in Copperbelt and Western provinces.

These results are dramatically higher than the HIV testing rate found in the 2007 ZDHS results; the overall rates for male and female were 20 percent and 35 percent, respectively. 
Figure 5. Percent ever tested for HIV and received results

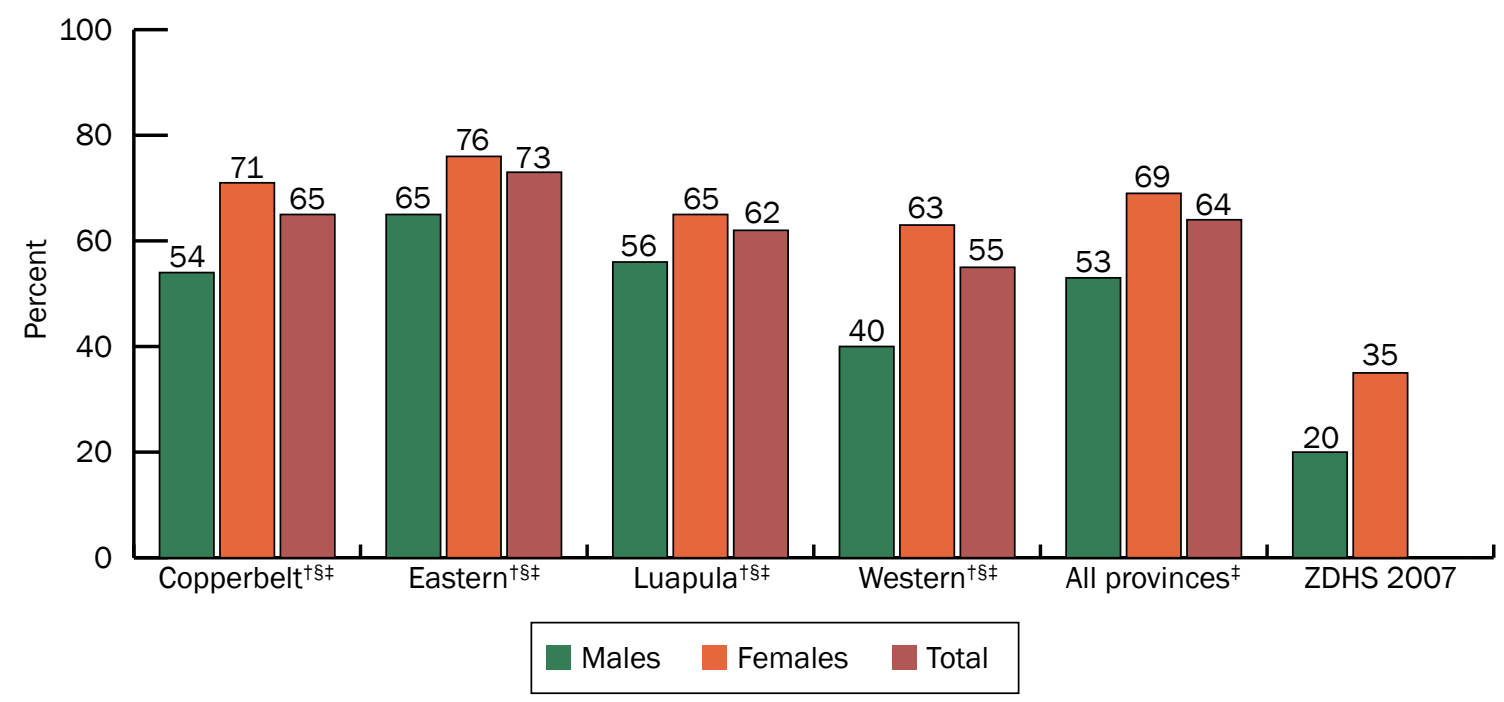

'Statistically different across provinces for males $(p<0.05)$.

sStatistically different across provinces for females $(p<0.05)$.

'Statistically different between males and females $(p<0.05)$.

\section{HIV testing outside of ANC settings}

Figure 6 shows the proportion of women who were tested for HIV and received results outside of the ANC setting. Only about one-half of the women who have ever tested for HIV were tested outside of the ANC setting; 36 percent were tested for HIV outside of ANC settings compared to 69 percent who were tested anywhere (including through ANC). This indicates that a large proportion of women were captured through the ANC system for HIV testing and explains the higher HIV testing rates among women compared to men.

Figure 6. Percent of women ever tested for HIV (excluding testing at ANC) and received results by province

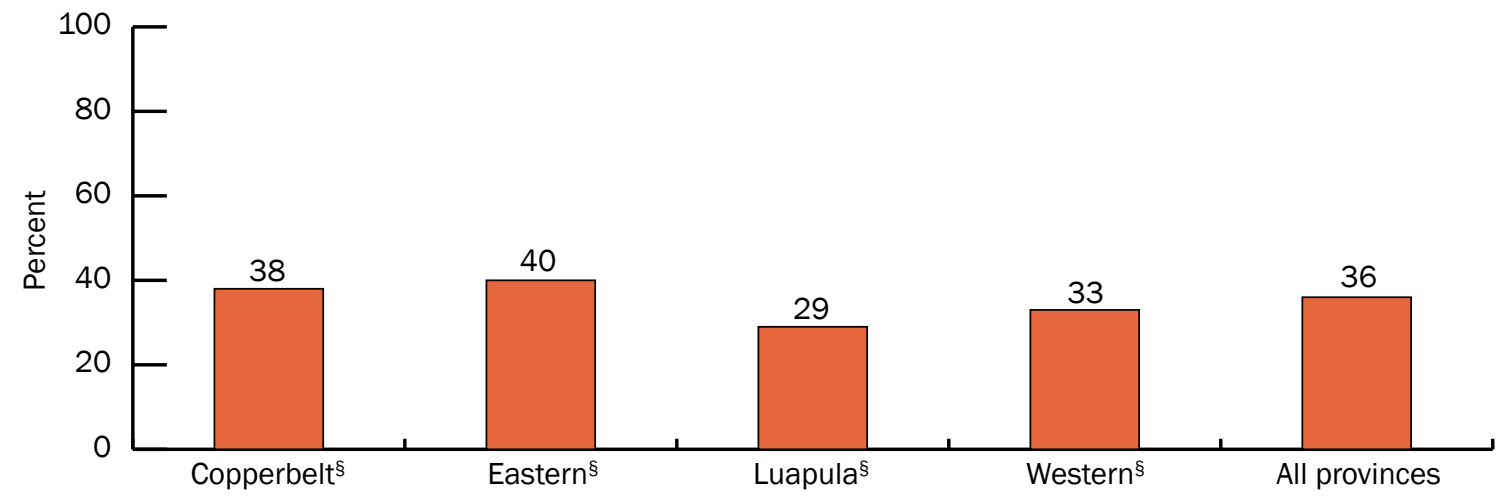

sStatistically different across provinces $(p<0.05)$. 


\section{HIV testing in antenatal clinics}

Overall, 76 percent of women who received antenatal services for their last pregnancy also received testing and their HIV test result (Figure 7). The highest proportion of women receiving testing and results during antenatal care were in Copperbelt (84 percent) and Eastern (79 percent) provinces. In Luapula and Western provinces, almost one in three women who accessed antenatal services did not receive HIV testing (28 percent and 29 percent, respectively).

Figure 7. HIV testing at antenatal care during last pregnancy among females who sought antenatal services

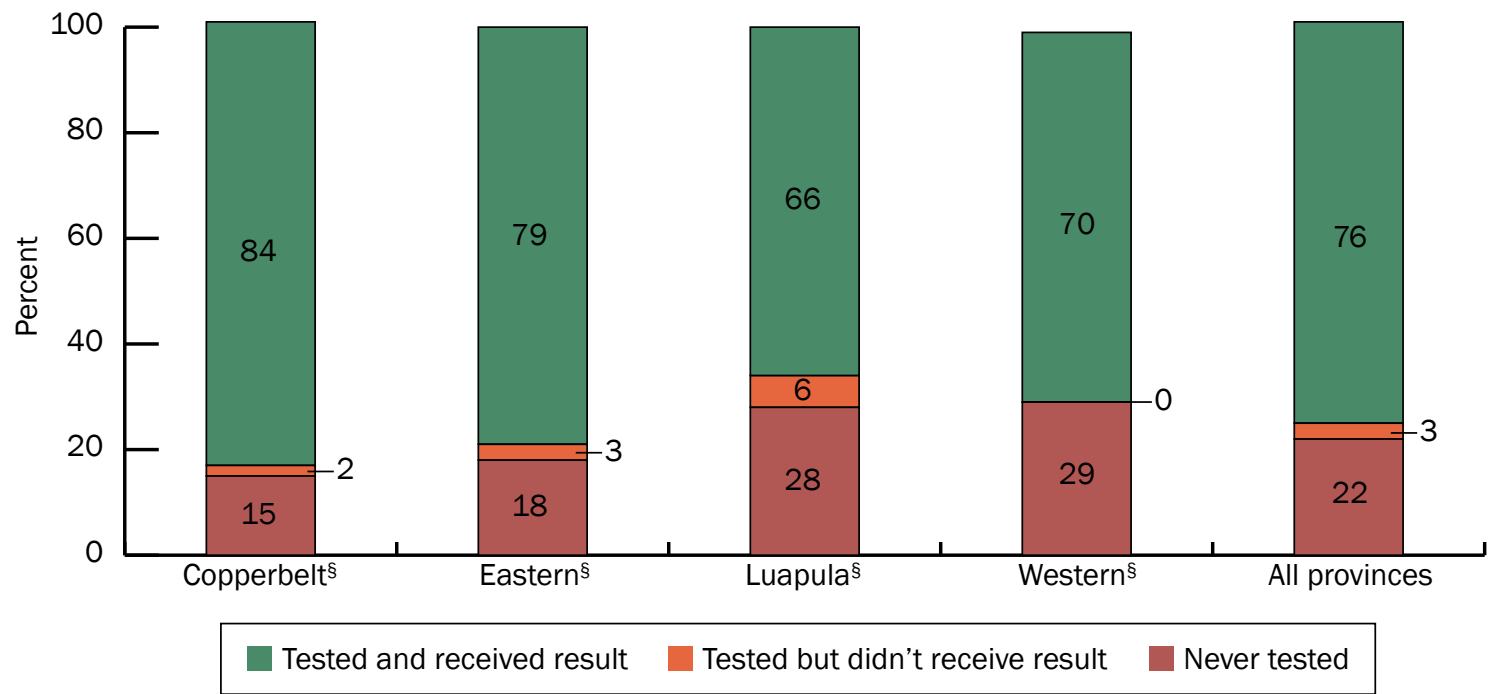

†Statistically different across provinces $(p<0.05)$.

\section{Recent HIV testing}

Almost all respondents who tested for HIV received the results of their test. Only 2 to 5 percent tested for HIV and did not receive results (Appendix 4). Across provinces, among those who tested for HIV, about one-half had tested within the past 12 months. Rates for the most part were similar across provinces and sex; however, males in Eastern province had the highest proportion that tested more than 12 months ago.

Overall, most respondents received their last HIV test at a government health facility (47.5 percent of males and 50.1 percent of females) or a government hospital (25.6 percent of males and 26.2 percent of females). However, in Luapula province, virtually all received their last test at a government health facility (96.2 percent of males and 88.1 percent of females). A much smaller proportion of respondents used stand alone VCT centers and mobile clinics (10.8 percent of males and 6.0 percent of females) or private testing services (5.2 percent of males and 7.1 percent of females) compared to government facilities. 
In Copperbelt province, males were significantly more likely to have last tested at a government hospital (21.2 percent of males) compared to females (7.8 percent of females); conversely, females in Eastern province were significantly more likely to have last tested at a government hospital (46.1 percent of females) compared to males (31.2 percent of males).

\section{Correlates of HIV testing}

Table 2 shows correlates of having been tested for HIV and receiving results. In multivariate analysis, those who tested and received results were significantly more likely to be female, living in Eastern province, living in a rural area, belonging to the middle economic tier, married or cohabiting or divorced, having comprehensive knowledge of HIV, and having at least one sex partner in the last 12 months. Additionally, those who tested and received their results are significantly more likely to have comprehensive HIV knowledge and more than one sex partner in the past year.

\section{Sexual Behaviors}

\section{Sexual activity}

Appendix 5 shows sexual encounters by province and sex. The majority of respondents engaged in sex at least once in their lifetime ( 84.8 percent of males and 87.0 percent of females). In all provinces, the rate of ever having had sex ranged from approximately 80 to 90 percent.

\section{Early sexual debut}

Among youth aged 15-24 years, 22.2 percent of males and 15.8 percent of females engaged in early sexual debut (before the age of 15). There was significant variation in early sexual debut across provinces, but no difference between males and females within each province or overall. Western province had the highest proportion of youth engaging in early sexual debut (39.3 percent for males and 25.4 percent for females), while Copperbelt province had the lowest rate of early sexual debut (around 7.0 percent).

\section{Recent sexual activity}

The majority of respondents were sexually active in the past 12 months (78.2 percent of males and 80.1 percent of females); this did not vary significantly across provinces. 
Table 2. Correlates of HIV testing and receiving results (including ANC testing) by key variables

\begin{tabular}{|c|c|c|c|c|c|}
\hline & HIV tested & $\begin{array}{l}\text { Odds } \\
\text { Ratio }\end{array}$ & p-value & $\begin{array}{c}\text { Adjusted } \\
\text { Odds Ratio }\end{array}$ & p-value \\
\hline \multicolumn{6}{|l|}{ Sex } \\
\hline Male & 52.8 & 1.0 & & 1.0 & \\
\hline Female & 68.9 & 2.0 & $<0.001$ & 2.4 & $<0.001$ \\
\hline \multicolumn{6}{|l|}{ Age } \\
\hline $15-24$ & 53.4 & 1.0 & & 1.0 & \\
\hline $25+$ & 70.2 & 2.1 & $<0.001$ & 1.2 & 0.238 \\
\hline \multicolumn{6}{|l|}{ Province } \\
\hline Copperbelt & 65.2 & 1.0 & & 1.0 & \\
\hline Eastern & 72.7 & 1.4 & $<0.01$ & 1.7 & $<0.01$ \\
\hline Luapula & 61.8 & 0.9 & 0.199 & 0.9 & 0.673 \\
\hline Western & 54.7 & 0.6 & $<0.001$ & 0.9 & 0.760 \\
\hline \multicolumn{6}{|l|}{ Residency } \\
\hline Urban & 58.7 & 1.0 & & 1.0 & \\
\hline Rural & 66.0 & 1.4 & $<0.001$ & 1.8 & $<0.001$ \\
\hline \multicolumn{6}{|l|}{ Education } \\
\hline No education/Primary & 65.1 & 1.0 & & - & - \\
\hline Secondary or higher & 61.5 & 0.9 & 0.077 & & \\
\hline \multicolumn{6}{|l|}{ Wealth index } \\
\hline Lower & 59.6 & 1.0 & & 1.0 & \\
\hline Middle & 70.9 & 1.7 & $<0.001$ & 1.5 & $<0.01$ \\
\hline Higher & 63.6 & 1.2 & 0.074 & 2.3 & $<0.001$ \\
\hline Marital status & $(n=1,745)$ & & & & \\
\hline Never married & 43.5 & 1.0 & & 1.0 & \\
\hline Married/Co-habiting & 74.9 & 3.9 & $<0.001$ & 2.2 & $<0.001$ \\
\hline Divorced/Widowed/Separated & 61.5 & 2.1 & $<0.001$ & 2.0 & $<0.01$ \\
\hline \multicolumn{6}{|l|}{ Had comprehensive HIV knowledge } \\
\hline Yes & 68.4 & 1.4 & $<0.001$ & 1.5 & $<0.01$ \\
\hline No & 60.3 & 1.0 & & 1.0 & \\
\hline Number of partners in last 12 months & $(n=1,685)$ & & & & \\
\hline None & 29.8 & 1.0 & & 1.0 & \\
\hline One & 73.6 & 5.3 & $<0.001$ & 3.2 & $<0.001$ \\
\hline Two or more & 68.6 & 3.6 & $<0.001$ & 3.0 & $<0.001$ \\
\hline Had non-regular partner last 12 months & $(n=1,686)$ & & & & \\
\hline Yes & 63.4 & 0.9 & 0.813 & - & - \\
\hline No & 65.6 & 1.0 & & & \\
\hline
\end{tabular}

\section{Multiple sex partners}

Among those who had sex in the last 12 months, 22.0 percent of men and 7.6 percent of females had more than one sex partner (Figure 8). Prevalence of multiple sex partners was 
significantly lower among females than males in all provinces. Males and females in Western province had the highest rate of multiple partners (35.4 percent of males and 17.8 percent of females) and Luapula had the lowest prevalence ( 7.8 percent of males and 0 percent of females). Overall, among those who had more than one sex partner in the past 12 months, condom use at last sex was extremely low. However, females were significantly more likely to use a condom at last sex than males (29.2 percent versus 6.3 percent) (Appendix 5).

Figure 8. Percentage who had 2 or more sex partners in the last 12 months (among those who had sex in the last 12 months)

'Statistically different across provinces for males $(p<0.05)$.

sStatistically different across provinces for females $(p<0.05)$

₹Statistically different between males and females $(p<0.05)$.

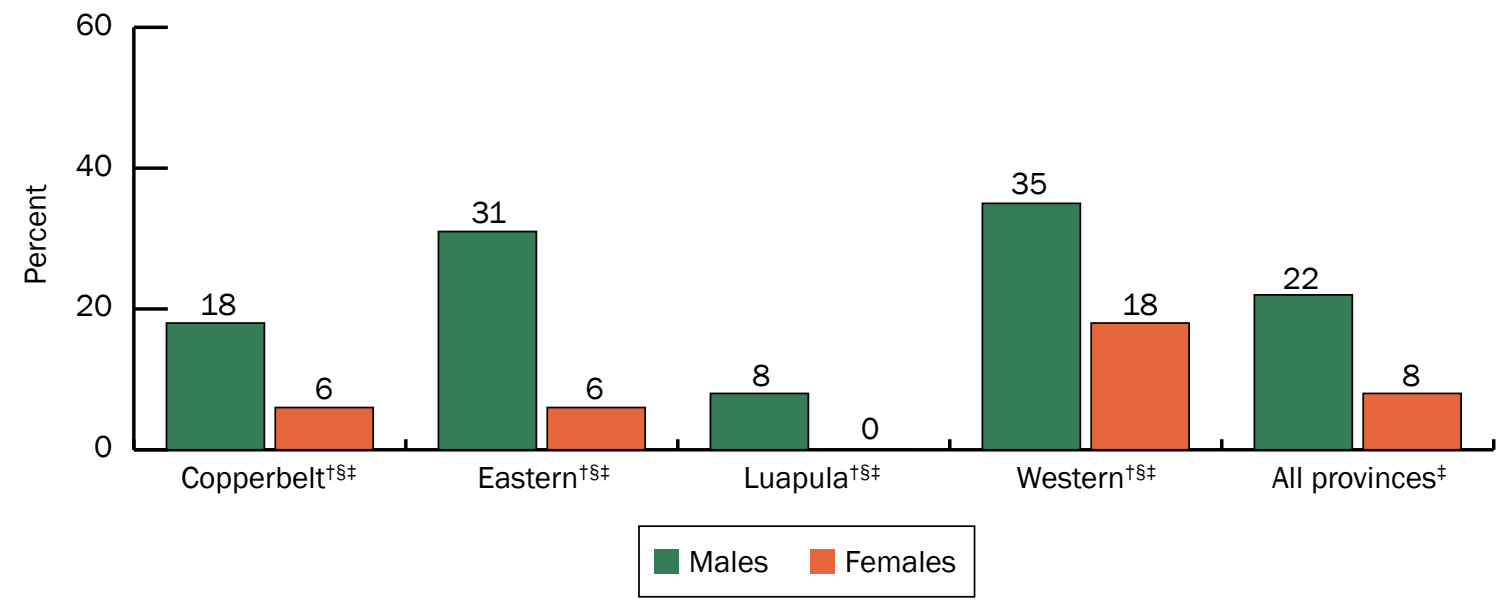

Table 3 shows the distribution of having multiple partners in the last 12 months among those who were sexually active during this same time frame. Having multiple partners was significantly more common among men, and among those from Eastern and Luapula province, living in a rural area, and in the lower and middle tiers of wealth. Having multiple partners was not significantly associated with age, education, marital status, HIV knowledge, or sexual debut. 
Table 3. Having sex with two or more partners in the last 12 months among those who had sex in the last 12 months $(n=1,272)$

\begin{tabular}{|c|c|c|c|c|c|}
\hline & $\begin{array}{c}\text { Had sex with } 2 \\
\text { or more partners } \\
\text { in the last } 12 \\
\text { months }\end{array}$ & $\begin{array}{l}\text { Odds } \\
\text { Ratio }\end{array}$ & $p$-value & $\begin{array}{c}\text { Adjusted } \\
\text { Odds } \\
\text { Ratio }\end{array}$ & p-value \\
\hline \multicolumn{6}{|l|}{ Sex } \\
\hline Male & 22.0 & 1.0 & & 1.0 & \\
\hline Female & 7.6 & 0.3 & $<0.001$ & 0.2 & $<0.001$ \\
\hline \multicolumn{6}{|l|}{ Age } \\
\hline $15-24$ & 13.6 & 1.0 & & 1.0 & \\
\hline $25+$ & 11.5 & 0.8 & 0.288 & 1.2 & 0.489 \\
\hline \multicolumn{6}{|l|}{ Province } \\
\hline Copperbelt & 10.1 & 1.0 & & 1.0 & \\
\hline Eastern & 12.6 & 1.3 & 0.313 & 1.2 & 0.506 \\
\hline Luapula & 2.6 & 0.2 & $<0.001$ & 0.2 & $<0.01$ \\
\hline Western & 23.3 & 2.7 & $<0.001$ & 2.5 & $<0.001$ \\
\hline \multicolumn{6}{|l|}{ Residency } \\
\hline Urban & 10.4 & 1.0 & & 1.0 & \\
\hline Rural & 12.9 & 1.3 & 0.213 & 1.7 & $<0.05$ \\
\hline \multicolumn{6}{|l|}{ Education } \\
\hline None or primary & 10.2 & 1.0 & & 1.0 & \\
\hline Secondary or higher & 14.5 & 1.4 & $<0.05$ & 1.1 & 0.749 \\
\hline \multicolumn{6}{|l|}{ Wealth index } \\
\hline Lower & 12.1 & 1.0 & & - & - \\
\hline Middle & 12.2 & 1.0 & 0.0957 & & \\
\hline Higher & 12.3 & 1.0 & 0.900 & & \\
\hline \multicolumn{6}{|l|}{ Marital status } \\
\hline Never married & 21.6 & 1.0 & & 1.0 & \\
\hline Married/Co-habiting & 9.7 & 0.4 & $<0.001$ & 0.5 & $<0.01$ \\
\hline Divorced/Wid'd/Separated & 13.6 & 0.6 & 0.158 & 0.9 & 0.824 \\
\hline \multicolumn{6}{|l|}{$\begin{array}{l}\text { Had comprehensive HIV } \\
\text { knowledge }\end{array}$} \\
\hline Yes & 11.7 & 1.1 & 0.476 & 1.2 & 0.289 \\
\hline No & 13.1 & 1.0 & & 1.0 & \\
\hline \multicolumn{6}{|l|}{ Had sex before age 15 year } \\
\hline Yes & 19.2 & 2.0 & $<0.01$ & 1.4 & 0.195 \\
\hline No & 10.9 & 1.0 & & 1.0 & \\
\hline \multicolumn{6}{|l|}{$\begin{array}{l}\text { Drunk at last sex (self or } \\
\text { partner) }\end{array}$} \\
\hline Yes & 17.4 & 1.6 & $<0.05$ & 2.1 & $<0.01$ \\
\hline No & 11.6 & 1.0 & & 1.0 & \\
\hline
\end{tabular}




\section{Non-regular partners}

Respondents were asked about the nature of the relationship with their last three sex partners in the last 12 months. Among those who had sex in the last 12 months, men were significantly more likely than women to have had sex with a non-regular partner (a non-marital, non-cohabiting partner) (31.4 percent versus 24.3 percent) (Figure 9). Similar to multiple partnerships, overall, Western province had the highest prevalence of non-regular partnerships in the past 12 months (approximately 50 percent for both men and women) compared to all other provinces. Western province also had the highest rate of extramarital sexual partnerships (17 percent) (Appendix 5). Luapula had the lowest rate of having non-regular partners among both men (13.3 percent) and women (6.1 percent). While men were significantly more likely than women to have a non-regular sex partner in Eastern (34.8 percent versus 10.1 percent) and Luapula (13.3 percent versus 6.1 percent) provinces, interestingly, men and women were equally likely to have non-regular partners in Copperbelt (approximately 20 percent) and Western (approximately 40 percent) provinces. Although condom use with their last non-regular sex partner was low for both men and women, it was significantly more common for women than for men (38.2 percent versus 22.9 percent) (Appendix 5).

Figure 9. Percentage who had non-regular sex partner(s) in the last 12 months (among those who had sex in the last 12 months)

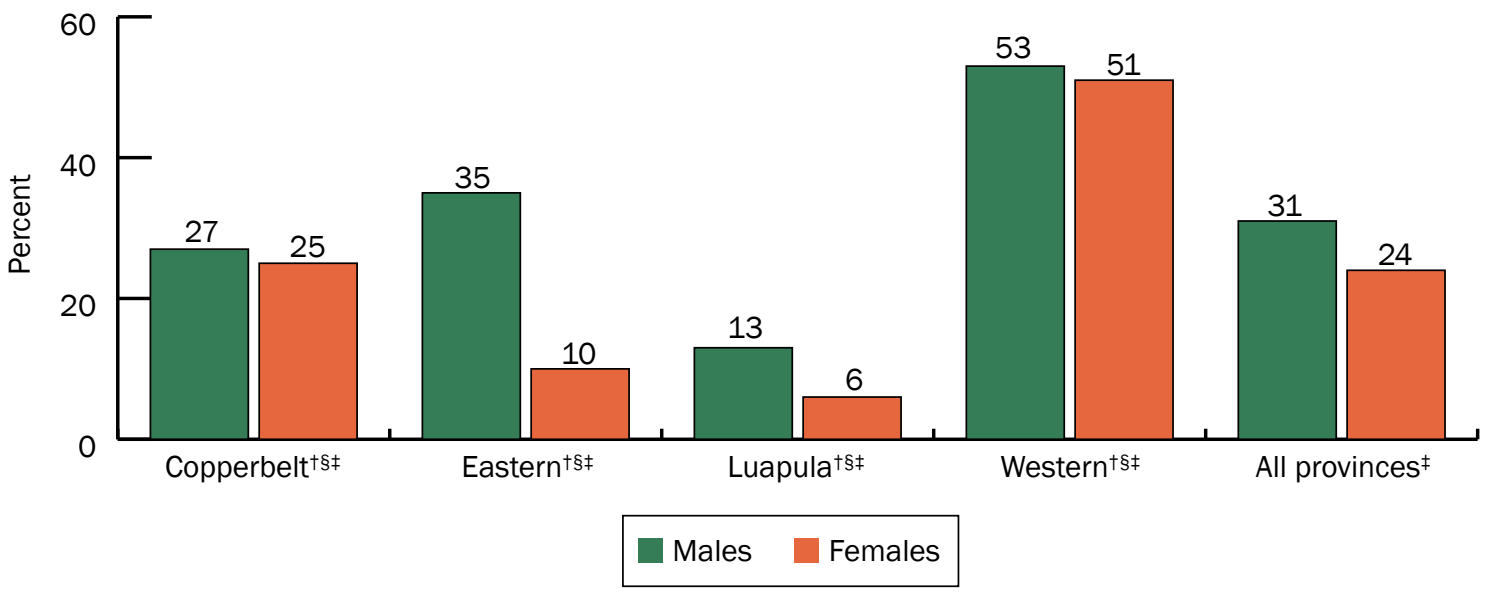

†Statistically different across provinces for males $(p<0.05)$.

sStatistically different across provinces for females $(p<0.05)$.

₹Statistically different between males and females $(p<0.05)$.

Table 4 shows the distribution of having a non-regular sex partner in the last 12 months among those who were sexually active during this time period. Having non-regular sex partners was significantly higher among men (31.4 percent), younger persons (48.4 percent), residents of Western province (51.3 percent), urban residents (31.5 percent), educated persons (37.5 percent), wealthier persons (31.4 percent), and never married persons (97.4 percent). Those who had early sexual debut (39.4 percent) and had multiple sex partners in the past 12 months (83.2 percent) were also significantly more likely to have non-regular sex partners. Comprehensive HIV knowledge was not associated with having a non-regular sex partner. 
Table 4. Had non-regular sex partner in the last 12 months among those who had sex in the last 12 months $(n=1,274)$

\begin{tabular}{|c|c|c|c|c|c|}
\hline & $\begin{array}{l}\text { Had non-regular sex } \\
\text { partner }\end{array}$ & $\begin{array}{l}\text { Odds } \\
\text { Ratio }\end{array}$ & p-value & $\begin{array}{c}\text { Adjusted } \\
\text { Odds } \\
\text { Ratio }\end{array}$ & p-value \\
\hline \multicolumn{6}{|l|}{ Sex } \\
\hline Male & 31.4 & 1.0 & & 1.0 & \\
\hline Female & 24.3 & 0.7 & $<0.01$ & 0.8 & 0.347 \\
\hline \multicolumn{6}{|l|}{ Age } \\
\hline $15-24$ & 48.4 & & & 1.0 & \\
\hline $25+$ & 16.7 & 0.2 & $<0.001$ & 0.1 & $<0.001$ \\
\hline \multicolumn{6}{|l|}{ Province } \\
\hline Copperbelt & 25.6 & 1.0 & & 1.0 & \\
\hline Eastern & 17.0 & 0.6 & $<0.05$ & 0.4 & $<0.01$ \\
\hline Luapula & 8.5 & 0.3 & $<0.001$ & 0.3 & $<0.001$ \\
\hline Western & 51.3 & 3.1 & $<0.001$ & 2.2 & $<0.001$ \\
\hline \multicolumn{6}{|l|}{ Residency } \\
\hline Urban & 31.5 & 1.0 & & 1.0 & \\
\hline Rural & 24.6 & 0.7 & $<0.05$ & 0.8 & 0.292 \\
\hline \multicolumn{6}{|l|}{ Education } \\
\hline None/Primary & 16.8 & 1.0 & & 1.0 & \\
\hline Secondary or higher & 37.5 & 3.0 & $<0.001$ & 2.8 & $<0.001$ \\
\hline \multicolumn{6}{|l|}{ Wealth index } \\
\hline Lower & 25.7 & 1.0 & & & \\
\hline Middle & 21.2 & 0.8 & 0.139 & - & - \\
\hline Higher & 31.4 & 1.3 & 0.050 & & \\
\hline \multicolumn{6}{|c|}{ Had comprehensive HIV knowledge } \\
\hline Yes & 27.4 & 1.1 & 0.559 & 1.0 & 0.957 \\
\hline No & 25.9 & 1.0 & & 1.0 & \\
\hline \multicolumn{6}{|c|}{ Had sex before age 15 years } \\
\hline Yes & 39.4 & 2.0 & $<0.001$ & 1.8 & $<0.01$ \\
\hline No & 24.3 & 1.0 & & 1.0 & \\
\hline \multicolumn{6}{|c|}{$\begin{array}{l}\text { Number of partners in last } 12 \\
\text { months }\end{array}$} \\
\hline 1 & 18.7 & 1.0 & & 1.0 & \\
\hline $2+$ & 83.2 & 21.6 & $<0.001$ & 34.5 & $<0.001$ \\
\hline \multicolumn{6}{|c|}{ Drunk at last sex (self or partner) } \\
\hline Yes & 31.0 & 1.2 & 0.371 & 1.1 & 0.805 \\
\hline No & 26.2 & 1.0 & & 1.0 & \\
\hline
\end{tabular}

\section{Correlates of condom use}

Table 5 shows correlates of condom use with the last partner among those sexually active in the past 12 months. Respondents significantly more likely to use condoms were female, younger (15-24 years old), residing in Eastern province, more educated, and had never been 
married. Those who had been physically or sexually abused were less likely to have used a condom at last sex. Comprehensive HIV knowledge, sexual debut, multiple partners, having a non-regular sex partner, and alcohol use with sex partner were not significantly associated with condom use at last sex. Simply knowing where to get condoms was not associated with actual condom use; however, affirmation that they could get condoms if they wanted to was strongly associated with condom use. 
Table 5. Condom use with last partner among those who had sex in the last 12 months $(n=1,211)$

\begin{tabular}{|c|c|c|c|c|c|}
\hline & $\begin{array}{l}\text { Used condom with } \\
\text { last sex partner }\end{array}$ & $\begin{array}{l}\text { Odds } \\
\text { Ratio }\end{array}$ & $p$-value & $\begin{array}{c}\text { Adjusted } \\
\text { Odds Ratio }\end{array}$ & $\overline{p \text {-value }}$ \\
\hline \multicolumn{6}{|l|}{ Sex } \\
\hline Male & 5.1 & 1.0 & $<0.001$ & 1.0 & \\
\hline Female & 16.6 & 3.7 & & 6.1 & $<0.001$ \\
\hline \multicolumn{6}{|l|}{ Age } \\
\hline $15-24$ & 23.1 & 1.0 & & 1.0 & \\
\hline $25+$ & 8.7 & 0.3 & $<0.001$ & 0.6 & $<0.05$ \\
\hline \multicolumn{6}{|l|}{ Province } \\
\hline Copperbelt & 10.1 & 1.0 & & 1.0 & \\
\hline Eastern & 16.9 & 1.8 & $<0.05$ & 2.8 & $<0.001$ \\
\hline Luapula & 6.3 & 0.6 & 0.093 & 0.8 & 0.593 \\
\hline Western & 20.7 & 2.3 & $<0.001$ & 1.6 & 0.052 \\
\hline \multicolumn{6}{|l|}{ Residency } \\
\hline Urban & 17.1 & 1.0 & & 1.0 & \\
\hline Rural & 11.9 & 0.7 & $<0.05$ & 0.8 & 0.187 \\
\hline \multicolumn{6}{|l|}{ Education } \\
\hline None/Primary & 9.6 & 1.0 & & 1.0 & \\
\hline Secondary or higher & 17.6 & 2.0 & $<0.001$ & 1.6 & $<0.05$ \\
\hline \multicolumn{6}{|l|}{ Wealth index } \\
\hline Lower & 11.8 & 1.0 & & & \\
\hline Middle & 11.2 & 0.9 & 0.779 & - & - \\
\hline Higher & 16.8 & 1.5 & $<0.05$ & & \\
\hline \multicolumn{6}{|l|}{ Marital status } \\
\hline Never married & 32.3 & 1.0 & & 1.0 & \\
\hline Married/Co-habiting & 8.2 & 0.2 & $<0.001$ & 0.4 & $<0.05$ \\
\hline Divorced/Wid'd/Separated & 20.0 & 0.5 & 0.059 & 0.8 & 0.499 \\
\hline \multicolumn{6}{|c|}{ Had comprehensive HIV knowledge } \\
\hline Yes & 12.9 & 1.1 & 0.651 & - & - \\
\hline No & 13.8 & 1.0 & & & \\
\hline \multicolumn{6}{|l|}{ Had sex before age 15 years } \\
\hline Yes & 13.0 & 1.3 & & & \\
\hline No & 15.8 & 1.0 & 0.286 & - & - \\
\hline \multicolumn{6}{|c|}{ Number of partners in last 12 months } \\
\hline 1 & 12.9 & 1.0 & & - & - \\
\hline $2+$ & 16.6 & 1.3 & 0.220 & & \\
\hline \multicolumn{6}{|c|}{$\begin{array}{l}\text { Had non-regular partner in the last } 12 \\
\text { months }\end{array}$} \\
\hline Yes & 27.2 & 4.1 & $<0.001$ & 1.8 & 0.103 \\
\hline No & 8.3 & 1.0 & & 1.0 & \\
\hline \multicolumn{6}{|l|}{ Drunk at last sex (self or partner) } \\
\hline Yes & 17.4 & 1.4 & 0.141 & - & - \\
\hline No & 12.8 & 1.0 & & & \\
\hline \multicolumn{6}{|l|}{ Know where to get male condom } \\
\hline Yes & 13.6 & 1.2 & & - & - \\
\hline No & 11.9 & 1.0 & 0.608 & & \\
\hline \multicolumn{6}{|c|}{ Can get a male condom if wanted to } \\
\hline Yes & 15.0 & 1.6 & $<0.05$ & 2.1 & $<0.01$ \\
\hline No & 9.8 & 1.0 & & 1.0 & \\
\hline \multicolumn{6}{|c|}{$\begin{array}{l}\text { Ever been physically or sexually abused } \\
\text { (females only) }\end{array}$} \\
\hline Yes & 15.1 & 0.5 & $<0.01$ & * & * \\
\hline No & 25.5 & 1.0 & & & \\
\hline
\end{tabular}

*Variable not included in final model as it is only for females. 


\section{Condom Accessibility}

Overall, over 85 percent of men and women in all provinces reported they knew where to get a condom (Figure 10). In general, there were no differences in knowing where to obtain condoms by sex.

Figure 10. Percent who knew where to get condoms by province and sex

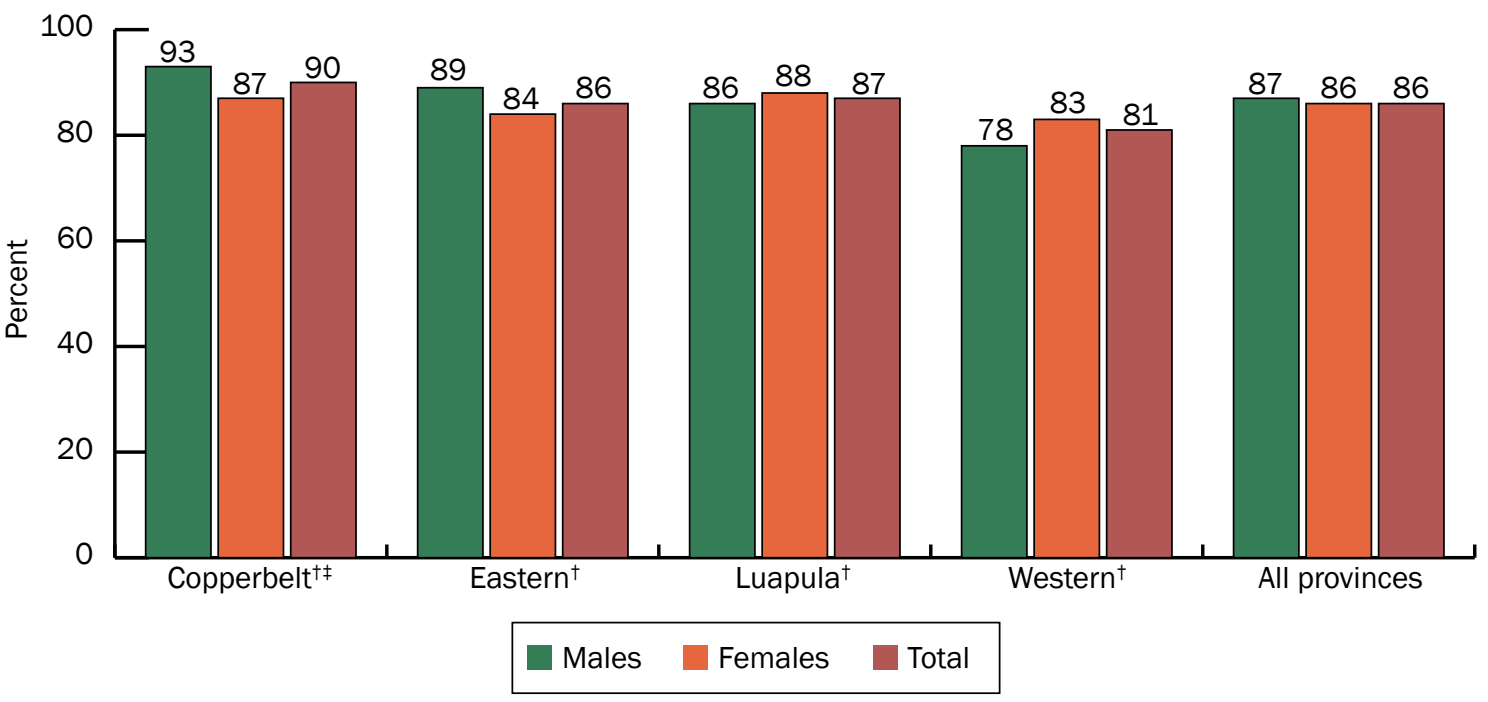

'Statistically different across provinces for males $(p<0.05)$.

sStatistically different across provinces for females $(p<0.05)$.

†Statistically different between males and females $(p<0.05)$.

Knowing where to obtain condoms does not necessarily equate to being able to obtain condoms if he/she wanted to. Approximately three-quarters of men and one-half of women reported they could obtain a condom if they wanted to (Figure 11); this decreased by approximately 15 percent in men and 29 percent in women from those who knew where to obtain a condom. In all provinces, while there was little difference in knowing where to obtain condoms between men and women, there was a significant difference between men and women in their reported ability to obtain a condom if they wanted to. Men were more likely to report being able to obtain a condom then women (72 percent versus 57 percent); the difference was seen in all provinces. 
Figure 11. Percent who could obtain a condom if wanted to by province and sex

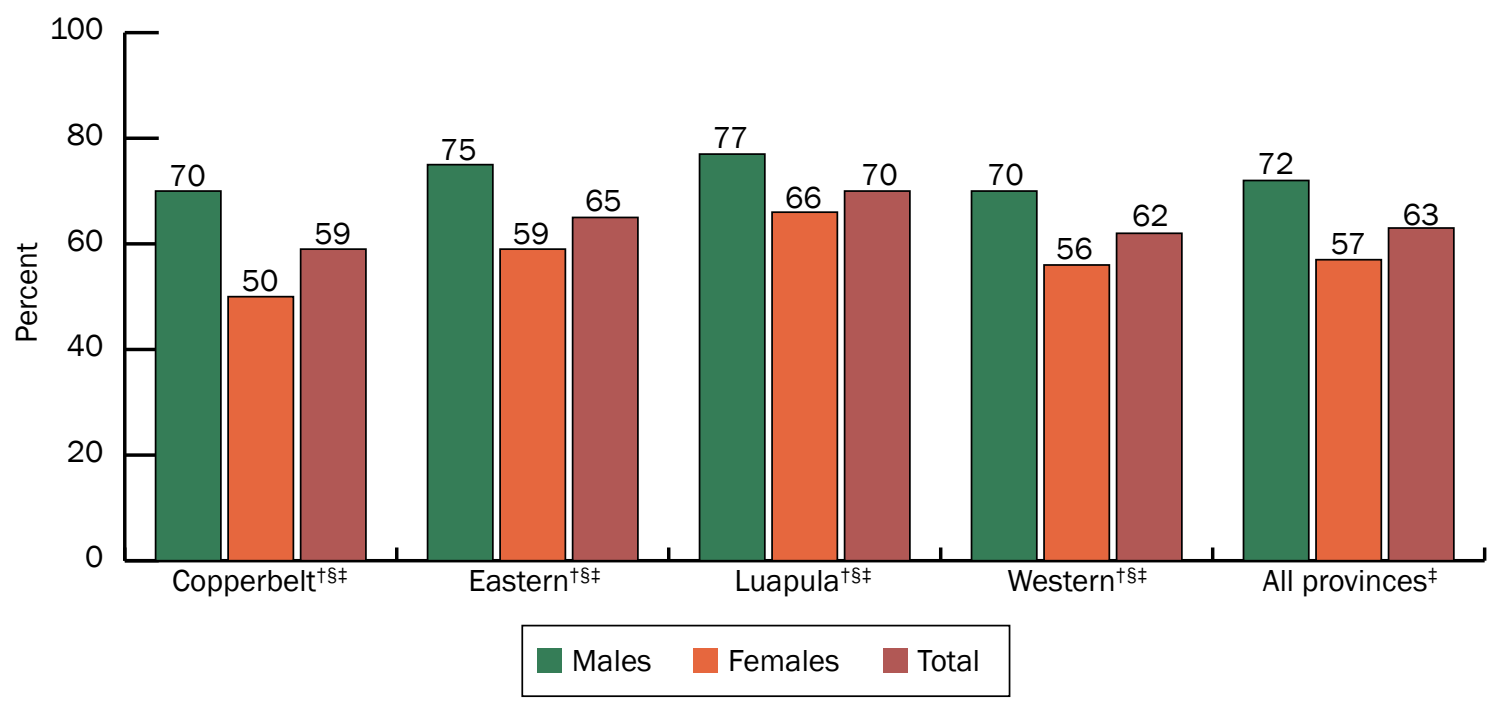

†Totals are statistically different between provinces $(p<0.05)$. §Statistically different across provinces for females $(p<0.05)$.

₹Statistically different between males and females $(p<0.05)$.

\section{Perceptions regarding abstinence and faithfulness}

Respondents were asked about their values regarding abstinence and faithfulness and how it compared to what they perceive truly happens in their community. The majority of men and women believed that both men and women should wait to have sex until they are married (over 80 percent) (Figure 12). However, only 10-15 percent thought that men or women actually do wait until they are married.

Figure 12. Percent agreement with abstinence statements by sex

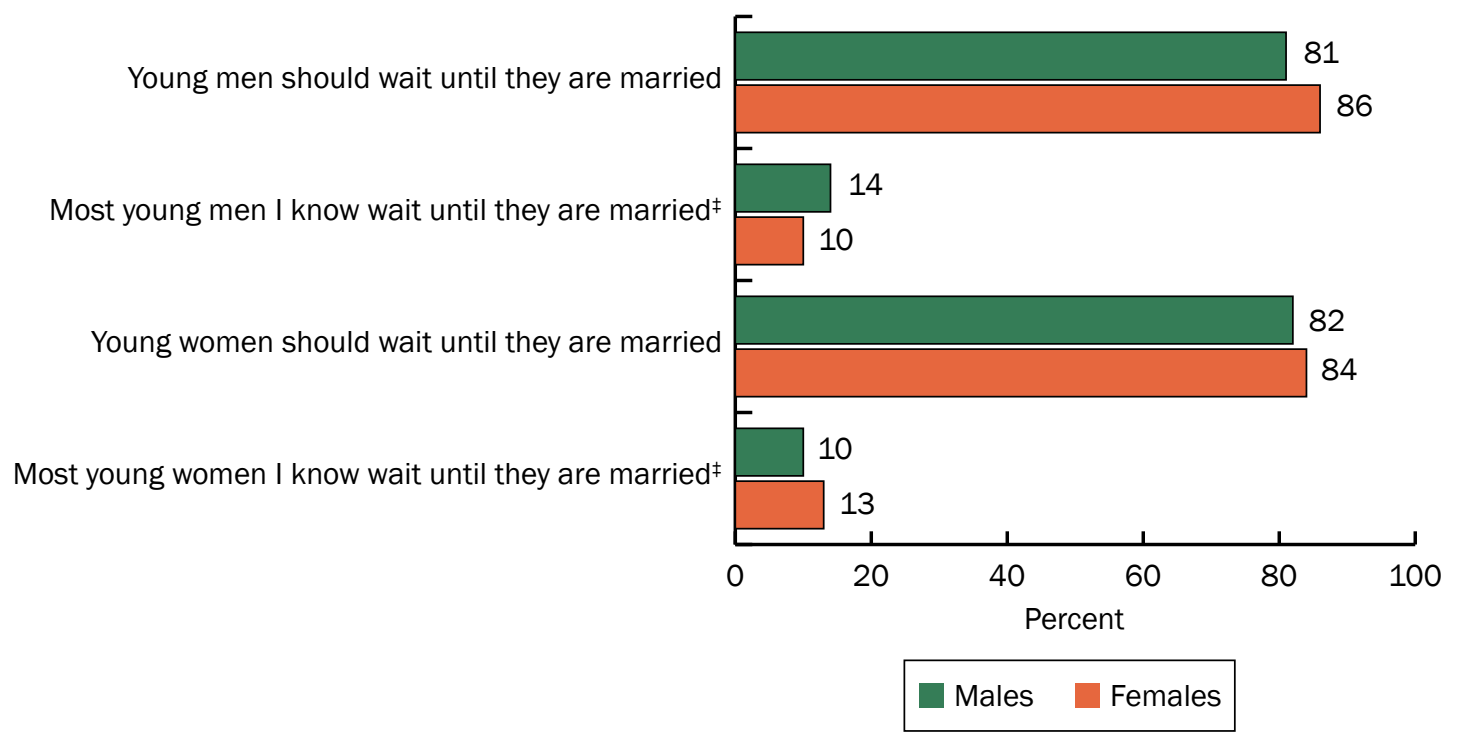

‡Statistically different between males and females $(p<0.05)$. 
Similar results were found regarding whether married men and women should have sex only with their wives or husbands, respectively (Figure 13). Again, while approximately 90 percent believed so, only 14-28 percent thought that most married men/women actually have sex only with their wives/husbands.

\section{Figure 13. Percent agreement with faithfulness statements by sex}

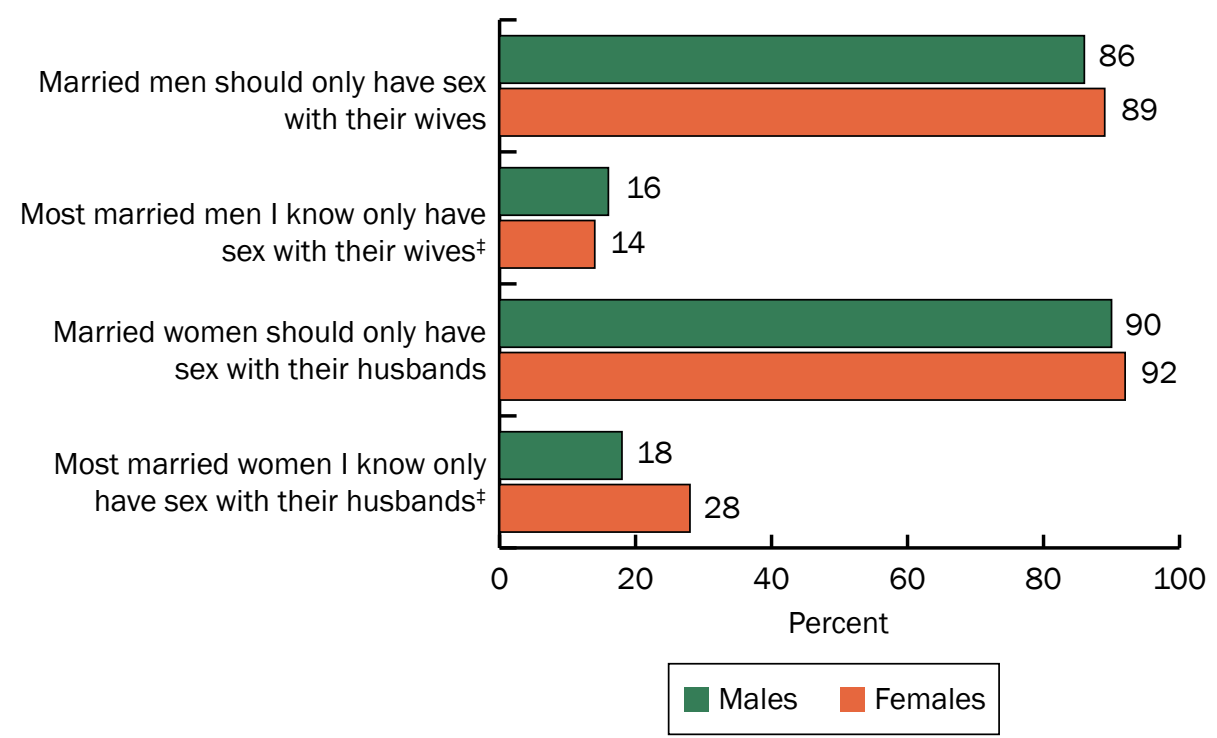

‡Statistically different between males and females $(p<0.05)$.

\section{Gender Relations}

\section{Gender equitable attitudes}

The GEM Scale was used to measure traditional attitudes toward gender norms related to HIV and AIDS and pregnancy prevention, violence, sexual relationships, domestic chores and caregiving, and homosexuality (Pulerwitz and Barker 2008). A typical item is "There are times when a woman deserves to be beaten" and "A man should have the final word about decisions in his home." A low equity score reflects having low gender equity (i.e., supporting inequitable gender norms). Figure 14 shows the proportion of respondents who had low gender equity attitudes by sex and province.

Slightly over one-third of all respondents (37 percent) scored in the lowest tertile of the GEM scale, indicating that 37 percent supported inequitable gender norms. Men were slightly more likely to support inequitable norms in all provinces except Luapula, where 60 percent of women support inequitable norms compared to 46 percent of men. Copperbelt had the lowest proportion of men and women supporting inequitable norms, while Luapula had the highest proportion supporting inequitable norms. 
Figure 14. Percent who supported inequitable gender norms by province and sex

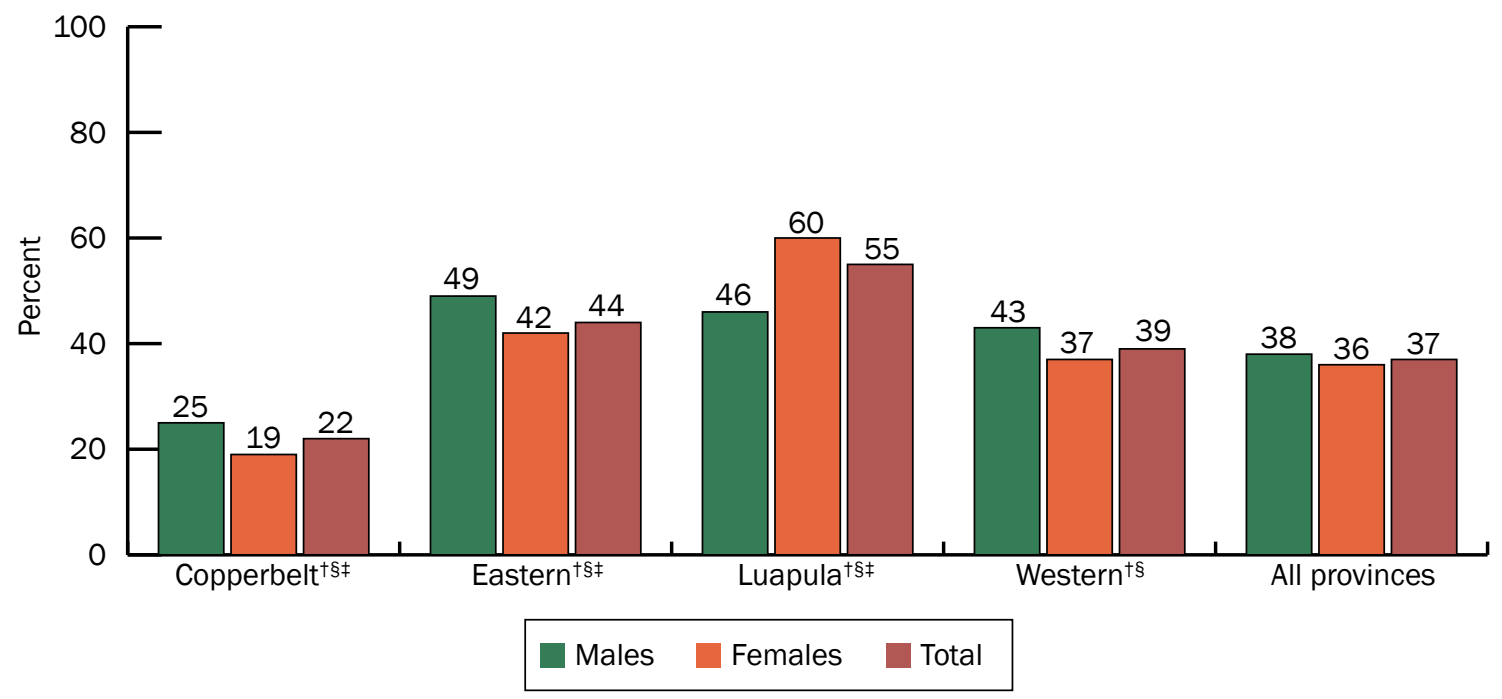

'Statistically different across provinces for males $(p<0.05)$.

sStatistically different across provinces for females $(p<0.05)$.

¥Statistically different between males and females $(p<0.05)$.

Figures 15 and 16 illustrate that higher risk sexual behaviors were associated with support for inequitable gender norms. Those who had two or more sex partners in the last 12 months and those who were intoxicated at last sex were significantly more likely to support inequitable gender norms.

Figure 15. Percent who supported inequitable gender norms by number of sex partners in the last 12 months $(n=1,687)$

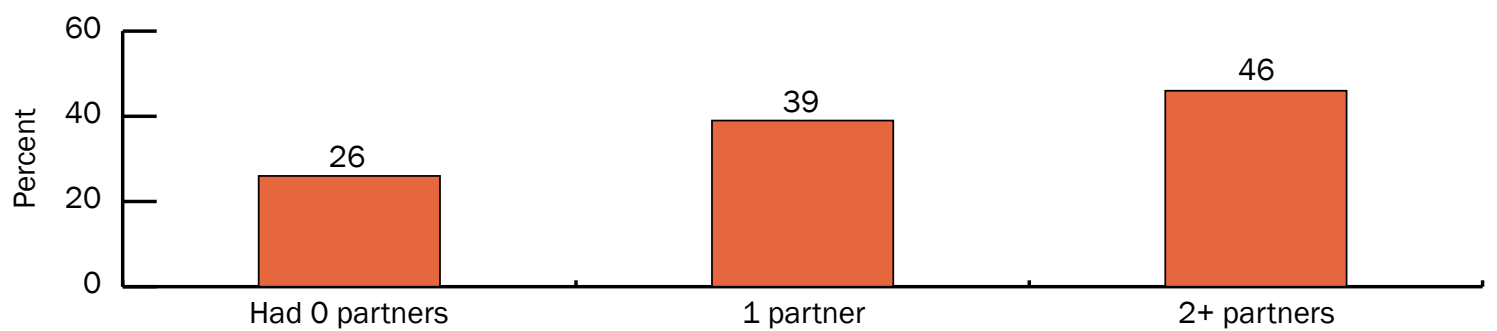

Statistically different $(p<0.001)$. 
Figure 16. Percent who supported inequitable gender norms by drunkenness at last sex in the last 12 months $(n=1,399)$

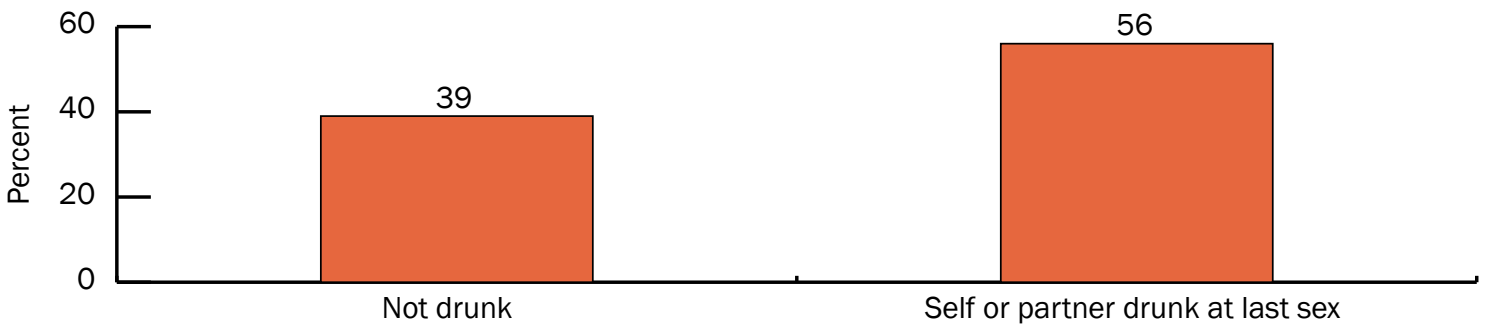

Statistically different $(p<0.01)$.

\section{Rape myths}

Figure 17 shows the proportion of respondents who strongly agreed, agreed, disagreed, and strongly disagreed with the four rape myth statements-statements that essentially blame women for the sexual violence they experience. Almost half of all respondents (48 percent) either strongly agreed or agreed with the statement, "If a woman doesn't fight back, you can't really say it was rape." And 38 percent of respondents strongly agreed or agreed with the statement "In any case, one would have to question whether the victim is promiscuous or has a bad reputation."

\section{Figure 17. Percent who agreed to the rape myths statements $(n=2,349)$}

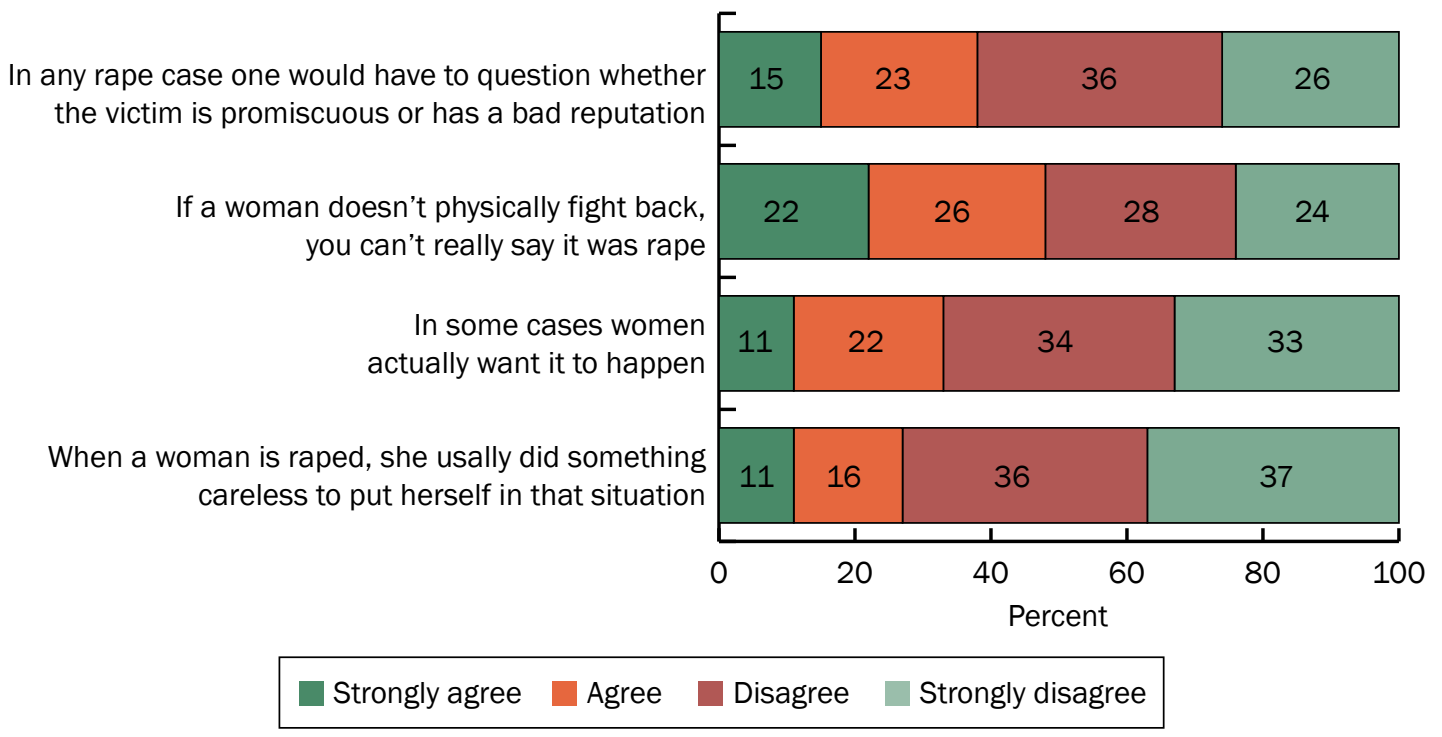

Figure 18 shows the proportion of respondents who agreed or strongly agreed with zero, one, two, three, or four of the rape myths listed above. Approximately 62 percent of respondents agreed with one or more rape myths and 14 percent agreed with all four. 
Figure 18. Number of rape myths supported by respondents, $\%(n=2,349)$

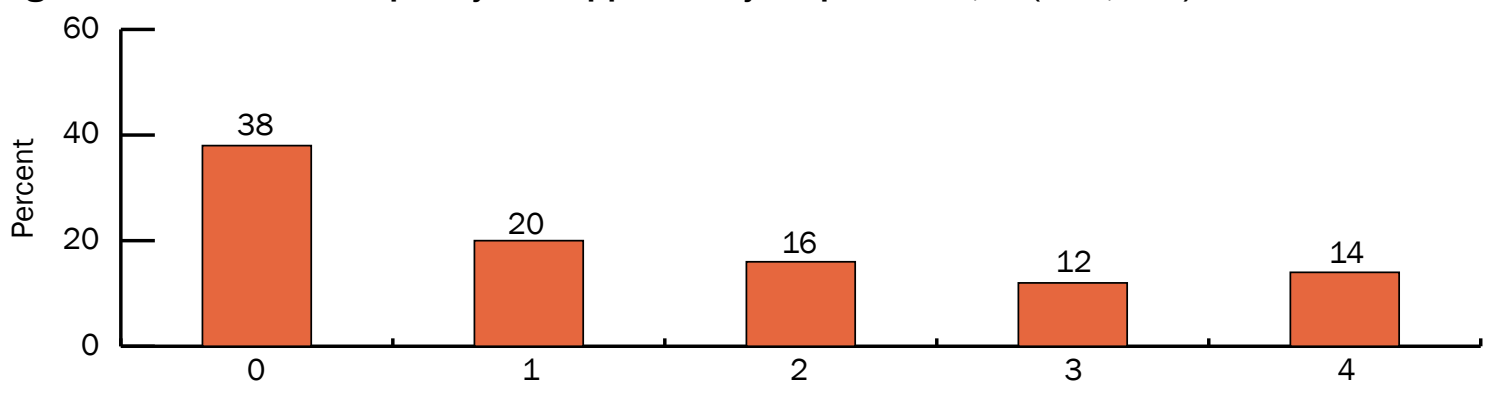

Figure 19 shows the proportion of respondents who supported rape myths by province and gender. Respondents who agreed to at least two of the rape myths were considered to generally support rape myths; in other words, they blame women for the rape that women experience. Overall, 42 percent of all respondents supported rape myths with a significantly higher proportion of males supporting these beliefs compared to females (46 percent of males versus 40 percent of females). However, in Eastern province women were significantly more likely than men to support rape myths (50 percent of women and 38 percent of men).

Males and females support of rape myths varied significantly across provinces. Western province had the largest proportion of males supporting rape myths compared to males in other provinces, while Eastern province had the highest proportion of females supporting rape myths compared to females in other provinces.

Figure 19. Percent who supported rape myths by province and sex

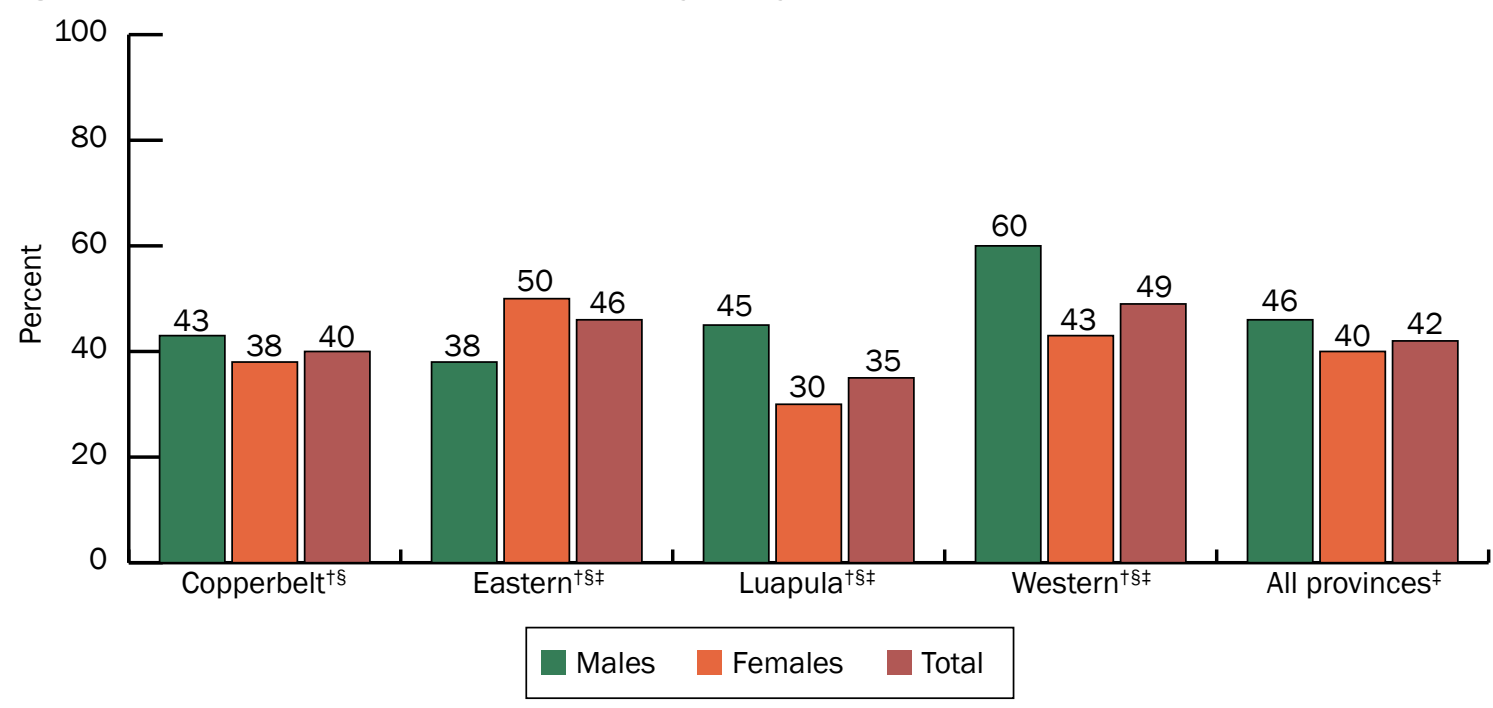

†Statistically different across provinces for males $(p<0.05)$.

\$Statistically different across provinces for females $(p<0.05)$.

₹Statistically different between males and females $(p<0.05)$. 


\section{Women experiencing physical and sexual violence}

Figure 20 shows the proportion of women who had experienced physical abuse (ever and in the past 12 months). Overall, a high proportion of women experienced physical abuse in their lifetime (35 percent) with 5 percent having experienced abuse in the past 12 months. The highest proportion of woman who experienced physical abuse was in Eastern province (42 percent ever and 11 percent in the past 12 months).

Figure 20. Percent of women who experienced physical abuse in their lifetime and in the last 12 months $(n=1,224)$

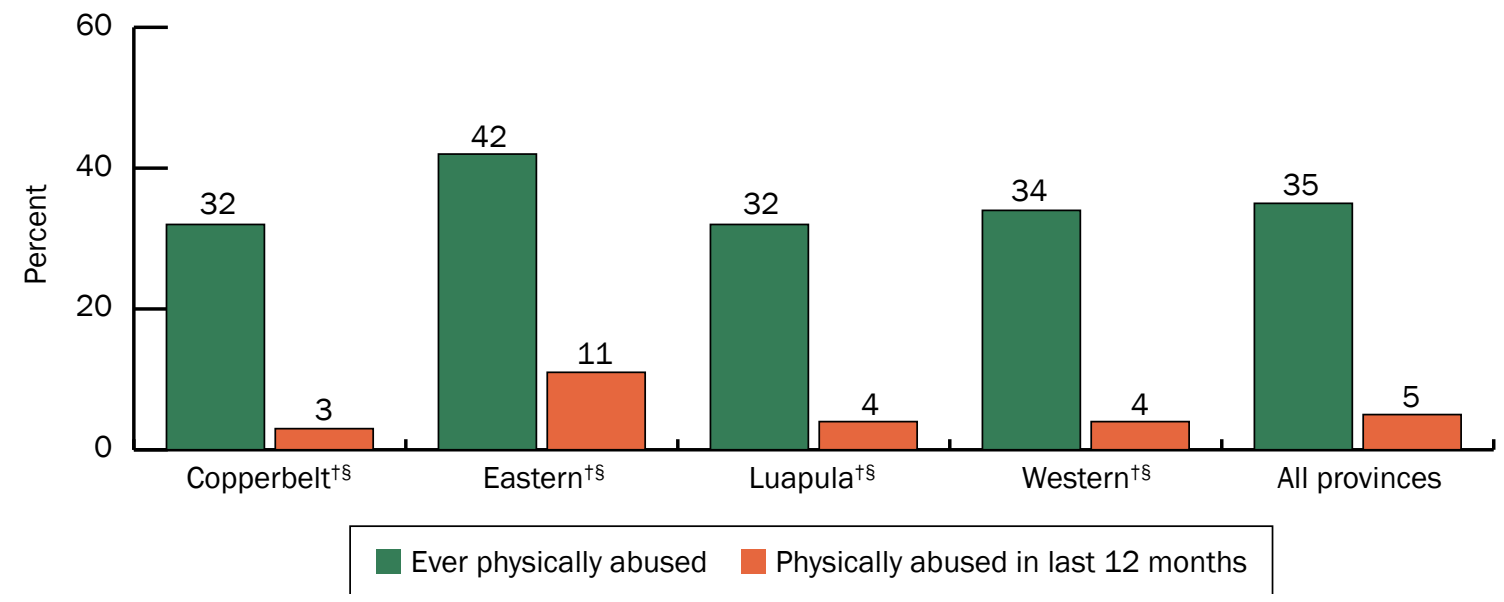

†Statistically different across provinces for ever physically abused $(p<0.05)$.

§Statistically different across provinces for physically abused in the last 12 months $(p<0.05)$.

Figure 21 shows the proportion of women who experienced sexual abuse in their lifetime and in the past 12 months. About one in five respondents (19 percent) experienced sexual abuse at least once in their lifetime and 1 percent experienced sexual abuse in the past 12 months.

Figure 21. Percent of women who experienced sexual abuse in their lifetime and in the last 12 months $(n=1,224)$

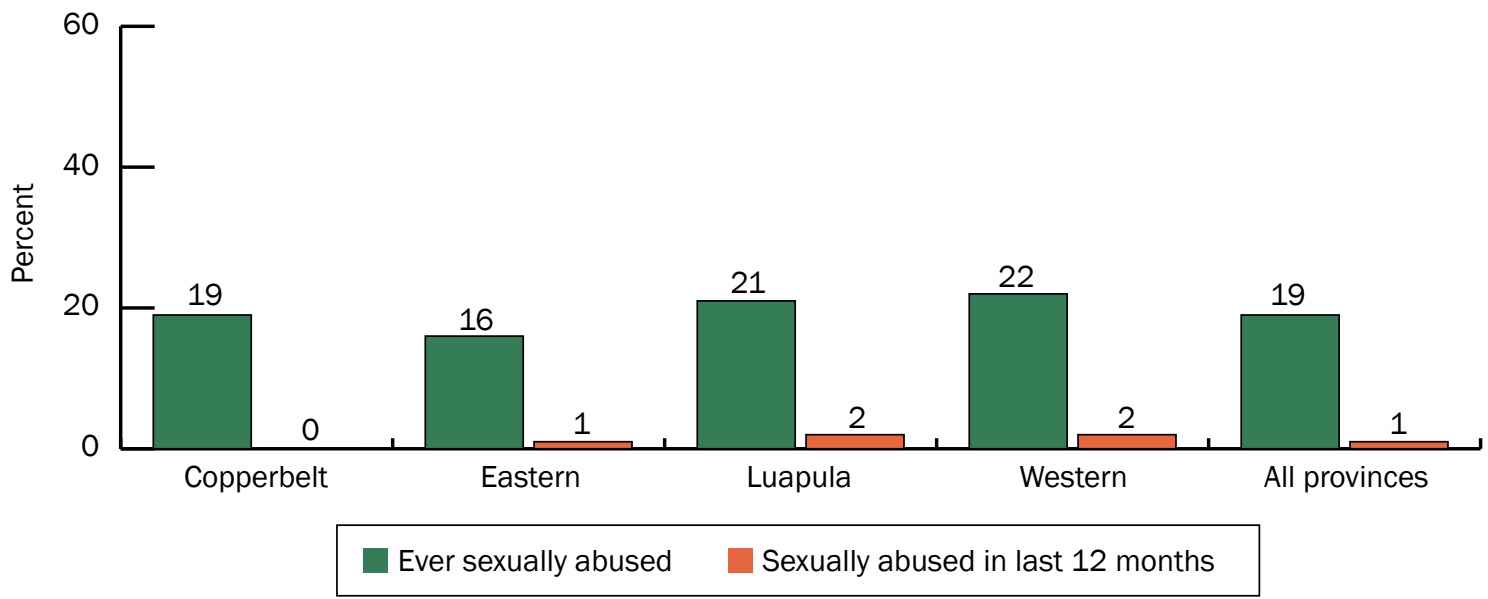

Note: Not statistically different across provinces for sexually abused ever or in last 12 months. 
Table 6 shows the proportion of women who were abused, either physically or sexually, and the proportion who sought services to stop the abuse. Approximately two out of three females experienced physical and/or sexual abuse in their lifetime (68.1 percent). A high proportion of females in all provinces (over 50 percent) have ever been physically or sexually abused; however, females in Copperbelt (78.0 percent) and Eastern (74.0 percent) experienced significantly more abuse than females in other provinces.

Despite these high levels of experience of abuse, very few women sought help or services to stop the perpetrators of abuse. Among those abused, only 14.9 percent sought help; females in Eastern (20.9 percent) and Western (18.4 percent) provinces demonstrated more help-seeking behavior while those in Luapula demonstrated the least amount of help-seeking behavior (7.9 percent). Of those who sought help, the vast majority sought help from their own family members ( 60 percent) or from their husband's family (24 percent). Only 6 percent sought help from police (Figure 22).

Table 6. Women's lifetime experience of physical or sexual abuse and help-seeking behavior by province

\begin{tabular}{|lccccc|}
\hline & $\begin{array}{c}\text { Copperbelt } \\
(\mathrm{n}=455) \\
\%\end{array}$ & $\begin{array}{c}\text { Eastern } \\
(\mathrm{n}=258) \\
\%\end{array}$ & $\begin{array}{c}\text { Luapula } \\
(\mathrm{n}=194) \\
\%\end{array}$ & $\begin{array}{c}\text { Western } \\
(\mathrm{n}=317) \\
\%\end{array}$ & $\begin{array}{c}\text { All provinces } \\
(\mathrm{n}=1,224) \\
\%\end{array}$ \\
$\begin{array}{l}\text { Ever physically or sexually abused } \\
78.0^{\dagger}\end{array}$ & $74.0^{\dagger}$ & $58.8^{\dagger}$ & $54.9^{\dagger}$ & 68.1 \\
$\begin{array}{l}\text { Sought help to stop perpetrator(s) } \\
\text { from abuse }\end{array}$ & $\begin{array}{c}(\mathrm{n}=355) \\
12.1^{\dagger}\end{array}$ & $\begin{array}{c}(\mathrm{n}=191) \\
20.9^{\dagger}\end{array}$ & $\begin{array}{c}(\mathrm{n}=114) \\
7.9\end{array}$ & $\begin{array}{c}(\mathrm{n}=174) \\
18.4\end{array}$ & $\begin{array}{c}(\mathrm{n}=834) \\
14.9\end{array}$ \\
\hline
\end{tabular}

†Statistically different across provinces $(p<0.05)$.

Figure 22. Percent of women who sought help from various sources among those who sought help after experiencing physical or sexual abuse $(n=126)$

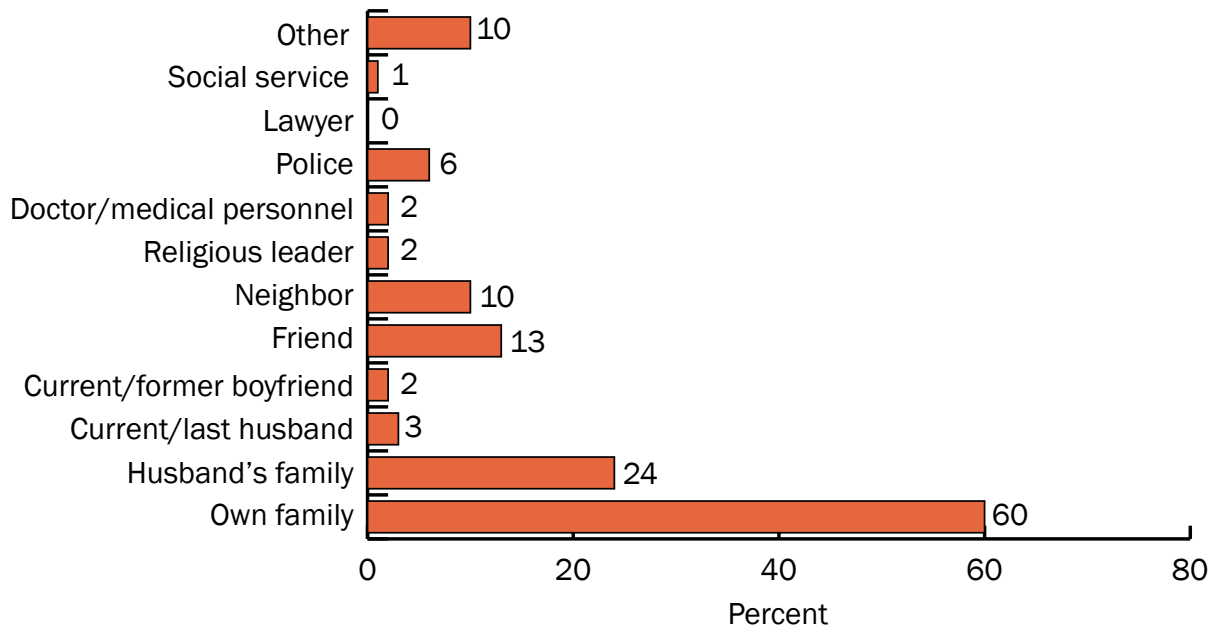


Table 7 shows factors associated with females having been physically and/or sexually abused. Females residing in a rural area and who were divorced, widowed, or separated or married/cohabiting were more likely to have experienced abuse. Age, education, and wealth were not associated with having been abused.

Table 7. Correlates of having been physically or sexually abused in their lifetime $(n=1,224)$

\begin{tabular}{|lcc|}
\hline Age & $\begin{array}{c}\text { Ever experienced physical } \\
\text { or sexual abuse }\end{array}$ & p-value \\
$15-24$ & 68.2 & 0.950 \\
$25+$ & 68.1 & \\
Residency & & $<0.05$ \\
$\quad$ Urban & 63.8 & \\
Rural & 70.8 & 0.532 \\
Education & & \\
$\quad$ None or primary & 69.2 & \\
Secondary or higher & 67.5 & 0.103 \\
Wealth index & & \\
Lower & 71.6 & \\
Middle & 65.0 & \\
Higher & 66.3 & $<0.01$ \\
Marital status & & \\
$\quad$ Never married & 54.0 & \\
Married/Co-habiting & 64.3 & \\
Divorced/Widowed/Separated & 70.6 & \\
\hline
\end{tabular}

Men were asked whether they agreed to specific statements justifying wife beating for various reasons such as wife going out without telling him, wife neglecting him, or wife refusing to have sex with him. Approximately one-third of male respondents agreed to at least one of the reasons that wife beating is justified (Figure 23). 
Figure 23. Percent of men who believe that wife beating is justified for various reasons $(n=819)$

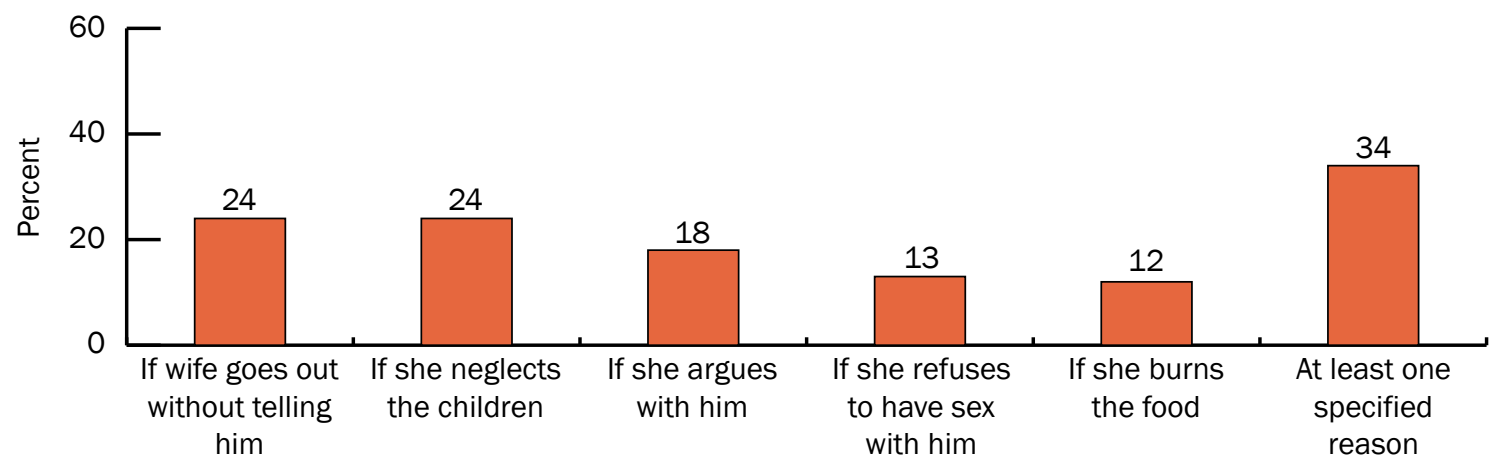

\section{Alcohol and Drugs}

Table 8 shows alcohol and drug use by province and sex. Overall, men were significantly more likely to use alcohol and be intoxicated in the past four weeks compared to women (28.3 percent of men and 4.9 percent of women). This difference between genders was significant in all provinces. Similarly, males were significantly more likely to have an alcohol problem (30.4 percent) compared to women (8.3 percent); the differences between males and females were found to be significant overall and at the province level. Copperbelt and Eastern provinces had the highest proportion of males with an alcohol problem (38.6 percent and 35.9 percent respectively).

While drug use was not common, 8.6 percent of males and 0.3 percent of females used drugs once in their lifetime, and men were overall significantly more likely to have ever used drugs compared to females. This was also true within each province. While a small proportion of those who ever used drugs reported getting high in the past four weeks ( 6 percent) virtu- 


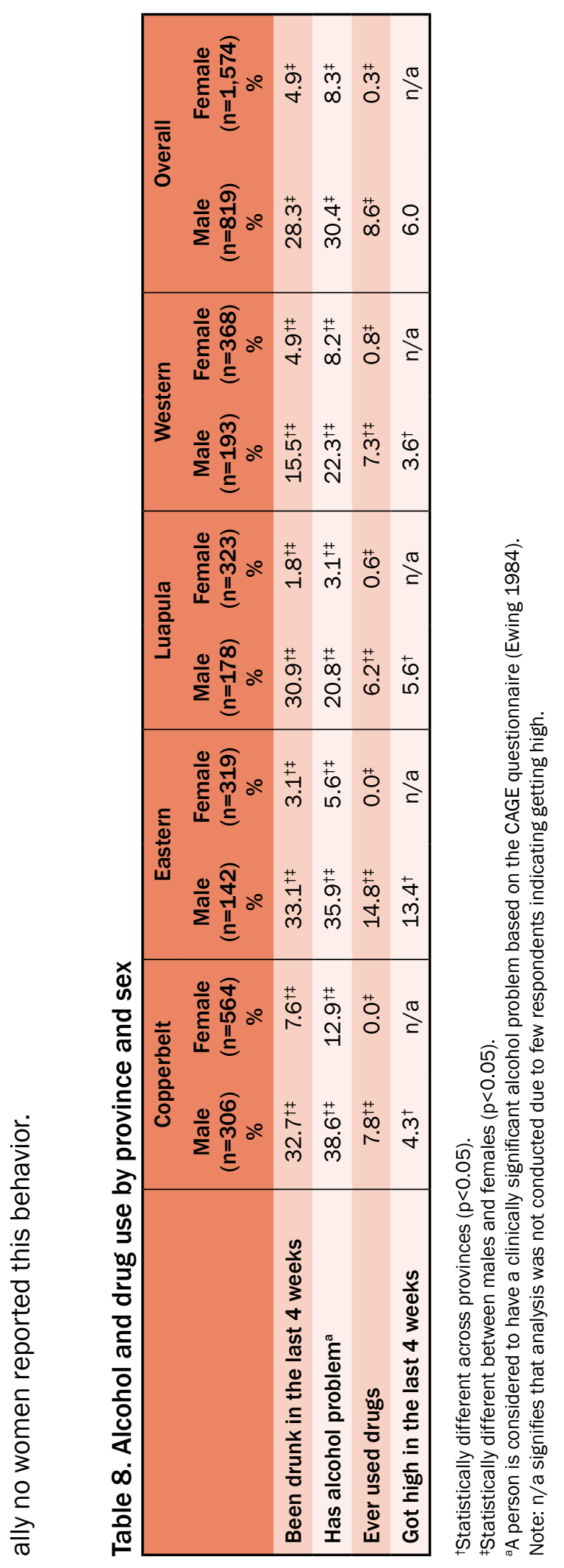




\section{Contraception and Pregnancy}

Overall, the majority of both males and females have heard of methods that men or women can use to avoid pregnancy (over three-quarters). Those in Western province were the least likely to have heard of such methods (Figure 24).

Figure 24. Percent of respondents who have heard of methods women or men can use to avoid pregnancy by province and sex

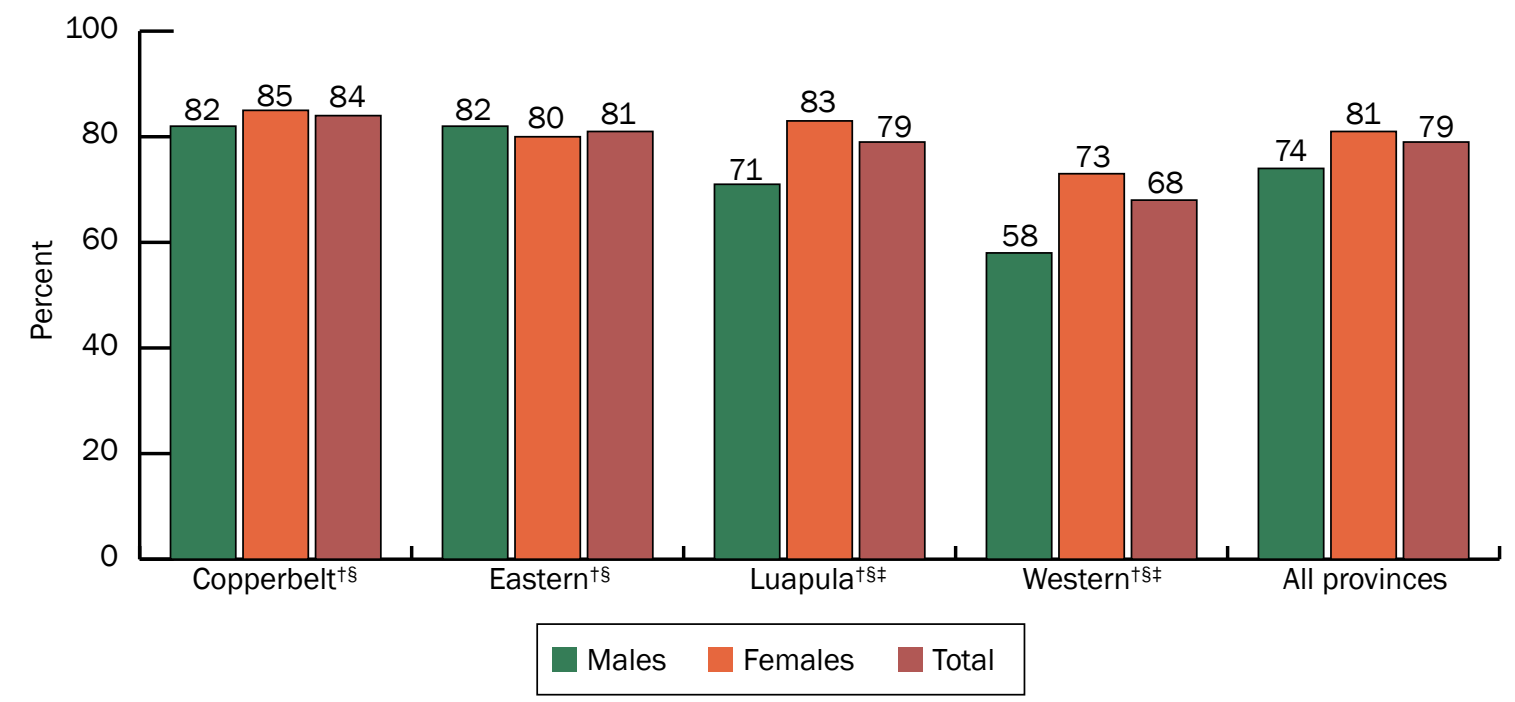

†Statistically different across provinces for males $(p<0.05)$.

§Statistically different across provinces for females $(p<0.05)$

†Statistically different between males and females $(p<0.05)$.

Among women who have heard of contraceptives, overall, nearly one-half have ever used some kind of contraceptive method and about one-quarter were currently using some method (Table 9). Women in Luapula were the least likely to have ever used or to be currently using any contraceptive method. However, women in Luapula, in fact, were also more likely to have wanted their last pregnancy (66.4 percent) compared to some of the other provinces like Copperbelt and Eastern where only 33-45 percent wanted their last pregnancy. In further exploring unintended pregnancies by age and marital status, we found that it was unmarried younger females who had the highest rate of unintended pregnancies (77-85 percent compared to approximately one-half of all other females) (Figure 25).

Challenges in obtaining contraceptives were most commonly reported by women in Copperbelt (23.0 percent). The most common challenges cited were long waiting times at facility (26.9 percent),periodic stock-outs at facility (23.8 percent), and high cost of service (10.4 percent) (data not shown). The majority of women (96.8 percent) had never heard of Postinor 2 , the emergency contraceptive pill.

The majority of women attended antenatal care for their last pregnancy (over 90 percent in all provinces) (Table 9); however, only 37.5 percent attended the four recommended ANC 
visits. Eastern province had the highest percentage of women with less than the four recommended ANC visits (54.6 percent). Eastern province also had the highest percentage of women who gave birth to a live child who later died (35.4 percent) compared to other provinces.

Table 9. Contraception use and antenatal care among women by province

\begin{tabular}{|c|c|c|c|c|c|}
\hline & $\begin{array}{c}\text { Copperbelt } \\
(n=569) \\
\%\end{array}$ & $\begin{array}{c}\text { Eastern } \\
(\mathrm{n}=325) \\
\%\end{array}$ & $\begin{array}{c}\text { Luapula } \\
(n=326) \\
\%\end{array}$ & $\begin{array}{c}\text { Western } \\
(n=374) \\
\%\end{array}$ & $\begin{array}{c}\text { All provinces } \\
(n=1,594) \\
\%\end{array}$ \\
\hline $\begin{array}{l}\text { Ever used any method to avoid/ } \\
\text { delay pregnancy }\end{array}$ & $52.0^{\dagger}$ & $54.5^{\dagger}$ & $27.3^{\dagger}$ & $43.5^{\dagger}$ & 45.4 \\
\hline $\begin{array}{l}\text { Currently using method to avoid/ } \\
\text { delay pregnancy }\end{array}$ & $29.7^{\dagger}$ & $26.8^{\dagger}$ & $15.0^{\dagger}$ & $23.1^{\dagger}$ & 24.5 \\
\hline $\begin{array}{l}\text { Who decided type of family } \\
\text { planning/spacing method }\end{array}$ & $(n=165)$ & $(n=86)$ & $(n=49)$ & $(n=85)$ & $(n=385)$ \\
\hline Mainly self & $29.7^{\dagger}$ & $16.3^{\dagger}$ & $32.7^{\dagger}$ & $37.7^{\dagger}$ & 28.8 \\
\hline Mainly partner & 17.0 & 11.6 & 6.1 & 8.2 & 12.5 \\
\hline Jointly & 52.7 & 64.0 & 61.2 & 52.9 & 56.4 \\
\hline Other & 0.6 & 8.1 & 0.0 & 1.2 & 2.3 \\
\hline $\begin{array}{l}\text { Faced any challenges in getting } \\
\text { contraceptive method }\end{array}$ & 23.0 & 15.1 & 12.2 & 10.6 & 17.1 \\
\hline Pregnancy intention (at last birth) & $(n=383)$ & $(n=285)$ & $(n=274)$ & $(n=265)$ & $(n=1,207)$ \\
\hline Wanted to be pregnant & $33.2^{\dagger}$ & $45.2^{\dagger}$ & $66.4^{\dagger}$ & $62.6^{\dagger}$ & $50.0^{\dagger}$ \\
\hline Wanted to wait until later & 35.4 & 35.8 & 23.5 & 24.8 & 30.5 \\
\hline $\begin{array}{l}\text { Did not want to get pregnant } \\
\text { at all }\end{array}$ & 31.4 & 19.0 & 10.1 & 12.6 & 19.5 \\
\hline $\begin{array}{l}\text { Attended antenatal care for last } \\
\text { pregnancy }\end{array}$ & $97.1^{\dagger}$ & $92.5^{\dagger}$ & $92.2^{\dagger}$ & $96.1^{\dagger}$ & 94.6 \\
\hline $\begin{array}{l}\text { Had }<4 \text { ANC visits (among } \\
\text { those who attended ANC for last } \\
\text { pregnancy) }\end{array}$ & $26.7^{\dagger}$ & $54.6^{\dagger}$ & $33.2^{\dagger}$ & $39.4^{\dagger}$ & 37.5 \\
\hline $\begin{array}{l}\text { Gave birth to a child (born alive) } \\
\text { but later died }\end{array}$ & $\begin{array}{c}(n=383) \\
18.5\end{array}$ & $\begin{array}{c}(n=285) \\
35.4\end{array}$ & $\begin{array}{c}(n=274) \\
28.8\end{array}$ & $\begin{array}{c}(n=265) \\
24.5\end{array}$ & $\begin{array}{c}(n=1,207) \\
26.2\end{array}$ \\
\hline \multicolumn{6}{|l|}{$\begin{array}{l}\text { Whom seen for antenatal care at } \\
\text { last pregnancy }\end{array}$} \\
\hline Doctor & $9.8^{\dagger}$ & $20.0^{\dagger}$ & $18.0^{\dagger}$ & $12.2^{\dagger}$ & 14.5 \\
\hline Clinical officer & 12.5 & 13.1 & 19.6 & 15.8 & 14.9 \\
\hline Nurse/Midwife & $87.0^{\dagger}$ & $73.9^{\dagger}$ & $58.0^{\dagger}$ & $82.6^{\dagger}$ & 76.5 \\
\hline Traditional birth attendant & $0.5^{\dagger}$ & $1.9^{\dagger}$ & $16.4^{\dagger}$ & $2.4^{\dagger}$ & 4.8 \\
\hline
\end{tabular}

†Statistically different across provinces $(p<0.05)$. 
Figure 25. Percent of unintended pregnancy by age and marital status

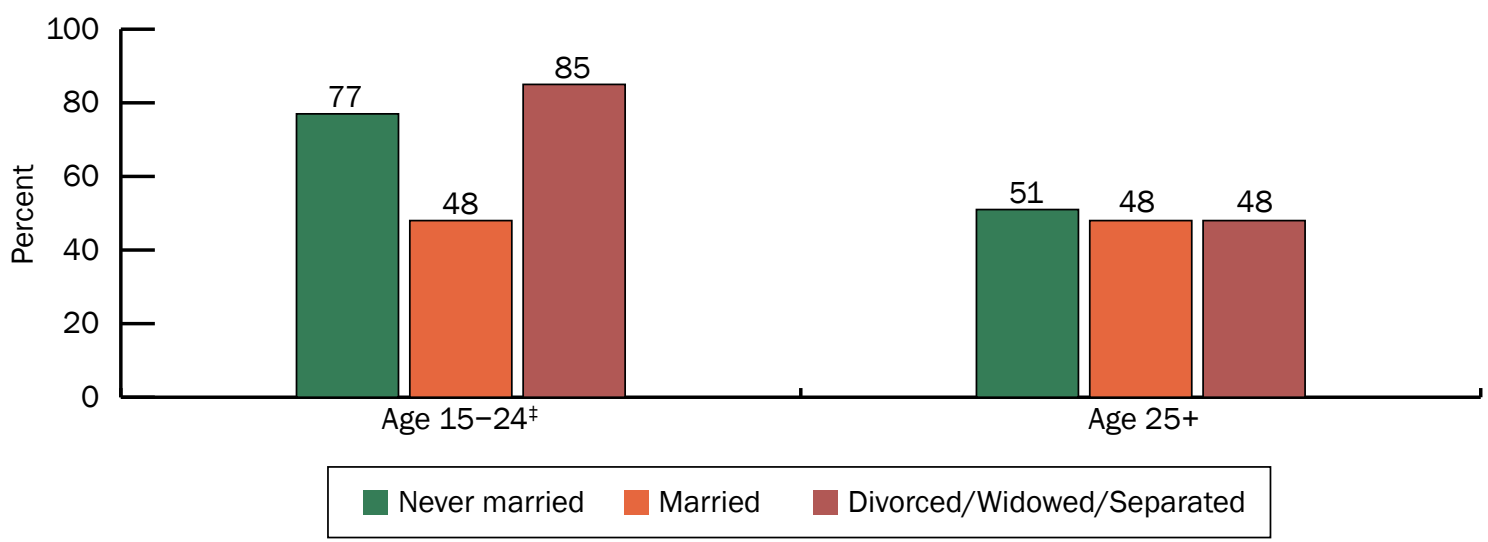

₹Statistically significant by marital status.

Women who reported some type of contraceptive use were most likely to report using the pill or injectables. Other types of contraception not included in Figure 26 were mentioned by less than 5 percent of women using any contraceptives; these include male and female sterilization, intrauterine devices, female condoms, diaphragm, foam/jelly, withdrawal, and emergency contraception.

Figure 26. Types of contraception currently used among women using some method to avoid or delay pregnancy by province

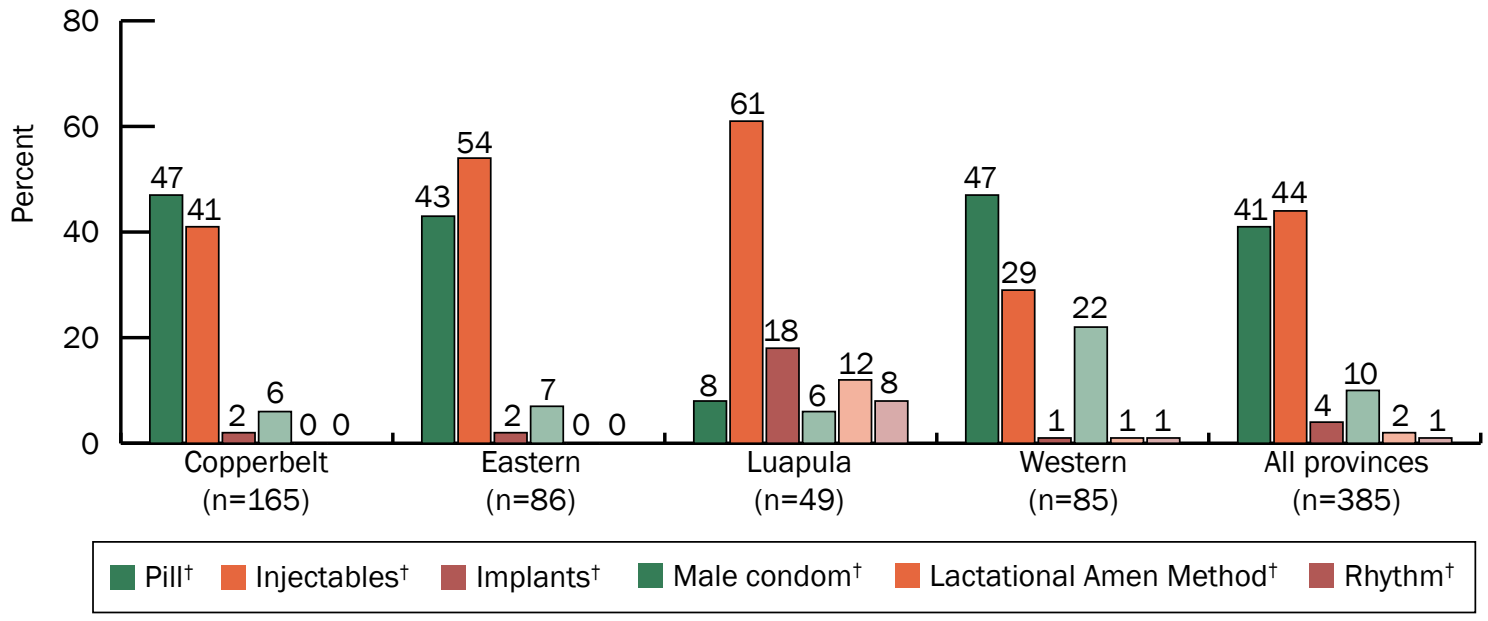

†Statistically different across provinces $(p<0.05)$.

\section{Men's perspective on contraception}

We examined men's attitudes toward contraception as a potential barrier to contraceptive use. Figure 27 shows that indeed a fairly high proportion of men (18 percent) think that contraception is women's business and 32 percent think that women who use contraception 
may become promiscuous. Men in Eastern were more likely to hold these views compared to men in other provinces. Fears about women becoming promiscuous due to contraceptive use was more common in all provinces than contraception being a woman's business.

\section{Figure 27. Men's views regarding contraception by province and sex ${ }^{*}$}

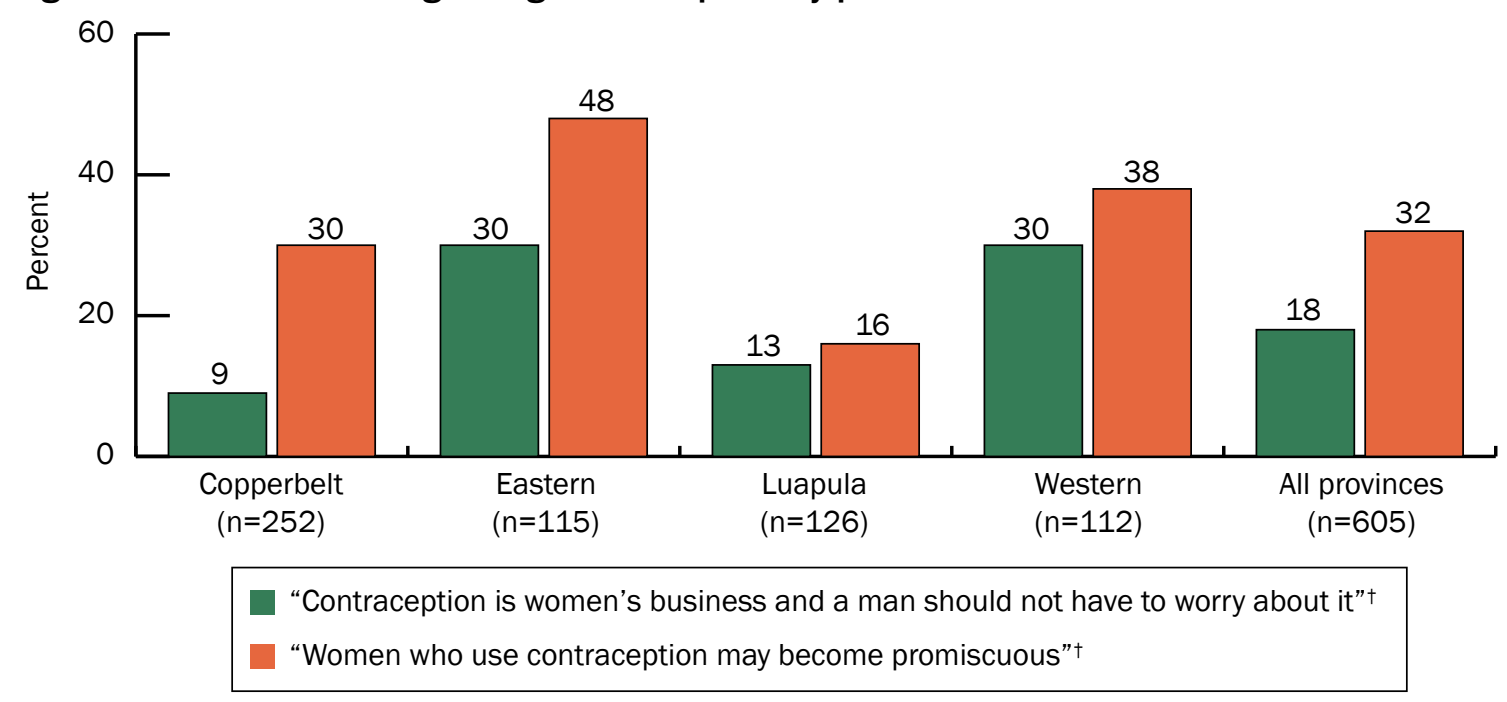

*Among those who have ever heard of contraception.

†'Statistically different across provinces $(p<0.05)$.

\section{Male Circumcision}

Figure 28 shows the percent of male respondents who are circumcised. While only 18 percent of respondent overall were circumcised, almost half of male respondents were circumcised in Western province (47 percent). This is a significantly higher proportion of circumcision compared to other provinces, where only 5-14 percent of males were circumcised.

Figure 28. Percent of male respondents who reported having been circumcised

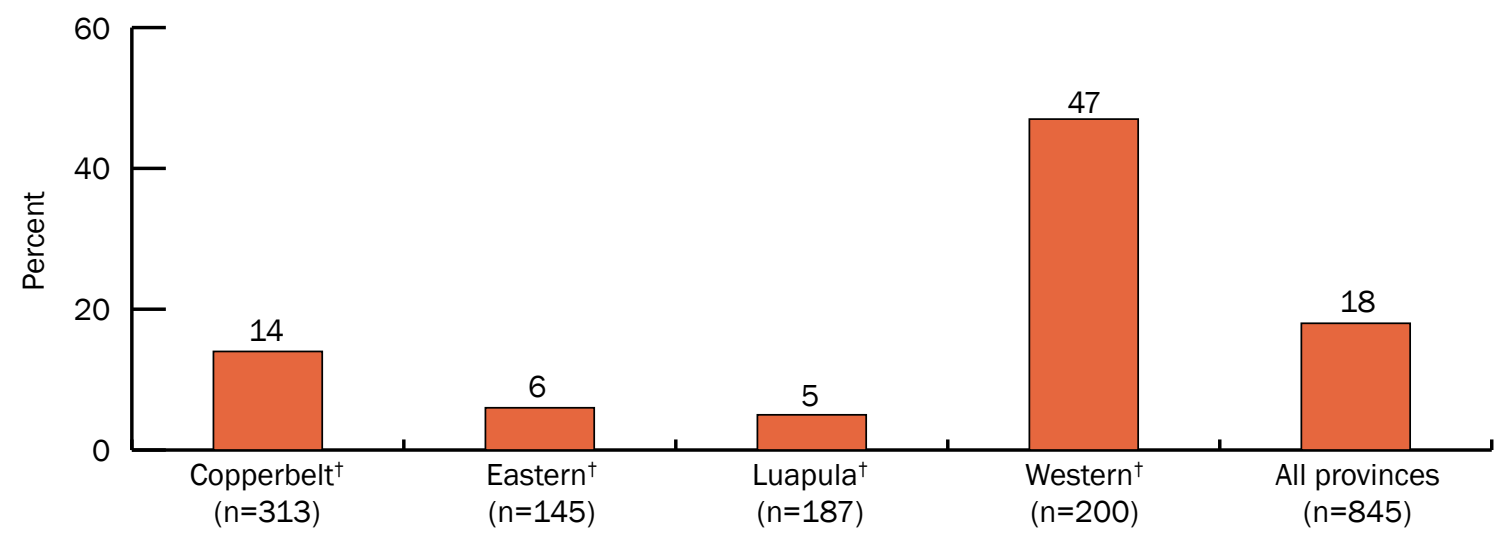

†Statistically different across provinces $(p<0.05)$. 
Figure 29 shows the age distribution of males who were circumcised. Most circumcised males were young boys and adolescents. Relatively few infant and adult circumcisions were reported.

Figure 29. Age of circumcision as reported by circumcised male respondents $(n=151)$

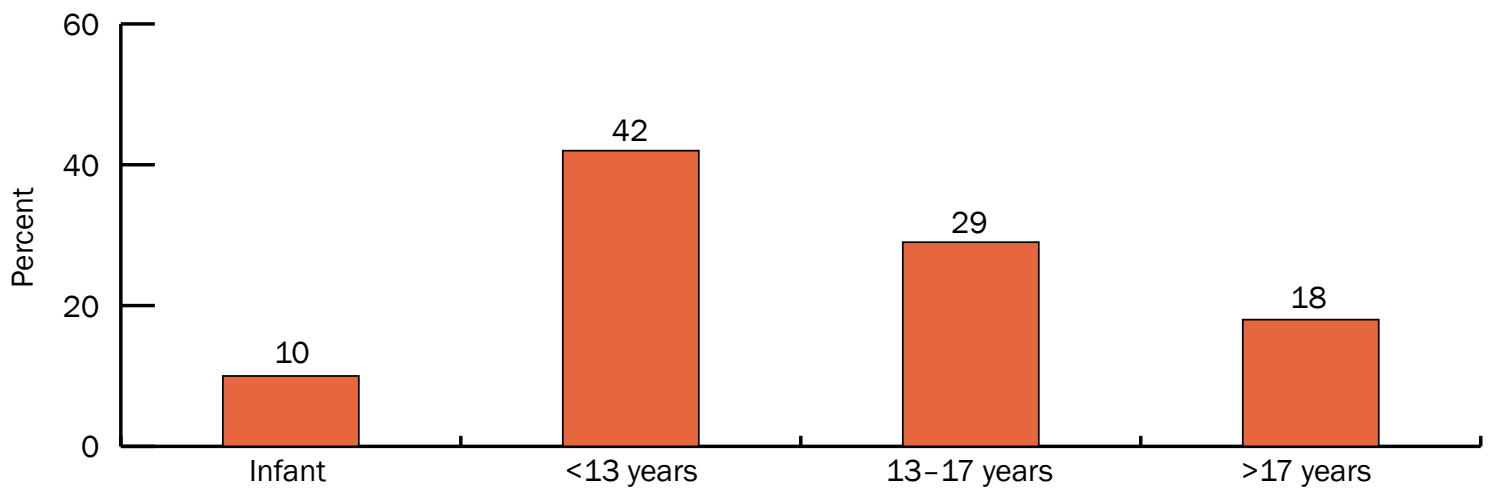

As seen in Figure 30, the majority of male circumcisions were performed by a traditional circumcisor (60 percent), while 35 percent were performed by a doctor. A small proportion of circumcisions were performed by trained nurses or midwives.

Figure 30. Persons who performed circumcision as reported by circumcised male respondents $(n=151)$

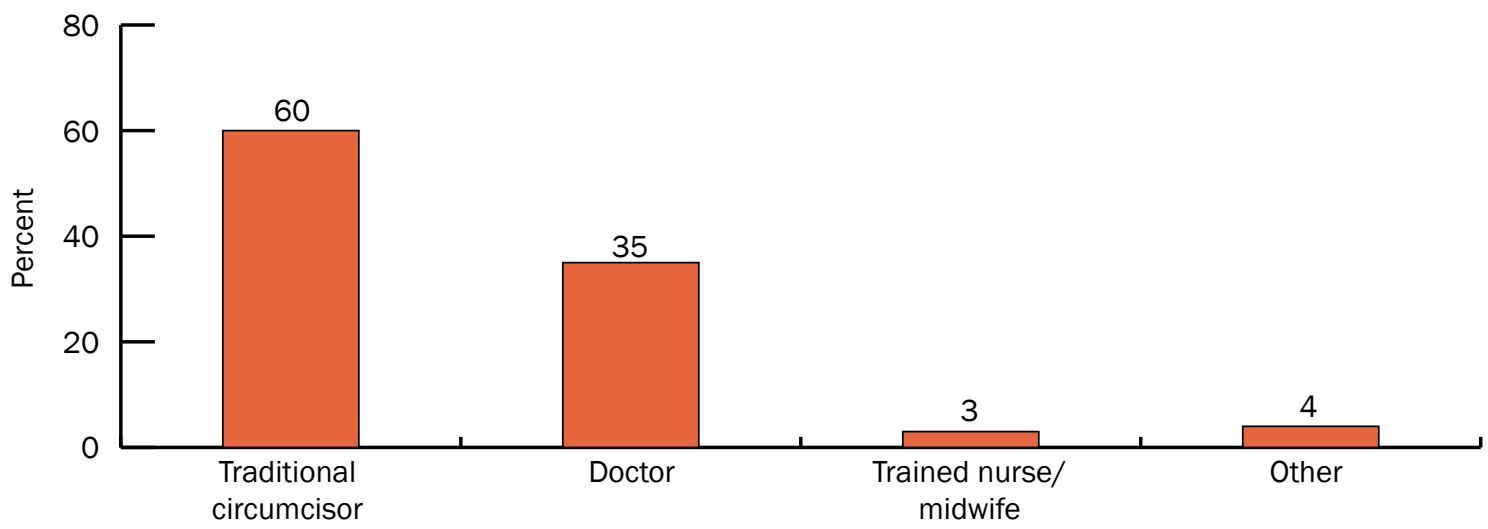

Table 10 shows the distribution of male circumcision by select socio-demographic and sexual risk characteristics. Men who reported having been circumcised were significantly more likely to have no comprehensive knowledge of HIV, and have two or more partners and have a non-regular sex partner in the last 12 months. Given these findings, it is important to know whether there is greater sexual risk taking due to a false sense of security in thinking that one is protected from HIV infection due to circumcision. Circumcision status did not vary by age, residency, education, wealth, or marital status. 
Table 10. Self-reported circumcision among male respondents $(n=821)$

\begin{tabular}{|c|c|c|c|c|c|}
\hline & $\begin{array}{c}\text { Self-reported } \\
\text { circumcised } \\
\%\end{array}$ & $\begin{array}{l}\text { Odds } \\
\text { Ratio }\end{array}$ & p-value & $\begin{array}{c}\text { Adjusted } \\
\text { Odds Ratio }\end{array}$ & p-value \\
\hline \multicolumn{6}{|l|}{ Age } \\
\hline $15-24$ & 21.6 & 1.0 & & 1.0 & \\
\hline $25+$ & 16.5 & 0.7 & 0.066 & 0.5 & 0.026 \\
\hline \multicolumn{6}{|l|}{ Province } \\
\hline Copperbelt & 14.0 & 1.0 & & 1.0 & \\
\hline Eastern & 5.6 & 0.4 & 0.011 & 0.1 & 0.002 \\
\hline Luapula & 5.1 & 0.3 & 0.003 & 0.5 & 0.074 \\
\hline Western & 47.2 & 5.5 & $<0.001$ & 7.3 & $<0.001$ \\
\hline \multicolumn{6}{|l|}{ Residency } \\
\hline Urban & 14.9 & 1.0 & & 1.0 & \\
\hline Rural & 20.4 & 1.5 & 0.05 & 1.7 & 0.081 \\
\hline \multicolumn{6}{|l|}{ Education } \\
\hline None or primary & 20.8 & 1.0 & & 1.0 & \\
\hline Secondary or higher & 17.0 & 0.8 & 0.181 & 0.6 & 0.115 \\
\hline \multicolumn{6}{|l|}{ Wealth index } \\
\hline Lower & 20.7 & 1.0 & & & \\
\hline Middle & 20.5 & 1.0 & 0.952 & - & 一 \\
\hline Higher & 15.1 & 0.7 & 0.058 & & \\
\hline \multicolumn{6}{|l|}{ Marital status } \\
\hline Never married & 25.5 & 1.0 & & & \\
\hline Married/Co-habiting & 17.1 & 0.6 & 0.018 & - & - \\
\hline Divorced/Wid'd/Separated & 13.3 & 0.4 & 0.303 & & \\
\hline \multicolumn{6}{|l|}{ Had comprehensive HIV knowledge } \\
\hline Yes & 12.5 & 0.5 & $<0.001$ & 0.6 & 0.040 \\
\hline No & 23.8 & 1.0 & & 1.0 & \\
\hline $\begin{array}{l}\text { Number of partners in last } 12 \\
\text { months }\end{array}$ & $(n=514)$ & & & & \\
\hline None & 16.8 & 1.0 & & 1.0 & \\
\hline One & 17.6 & 1.1 & 0.855 & 1.5 & 0.263 \\
\hline Two or more & 36.8 & 2.9 & 0.002 & 3.0 & 0.011 \\
\hline $\begin{array}{l}\text { Had non-regular partner last } 12 \\
\text { months }\end{array}$ & $(n=514)$ & & & & \\
\hline Yes & 34.4 & 2.7 & $<0.001$ & - & - \\
\hline No & 16.2 & 1.0 & & & \\
\hline Condom use at last sex & $(n=379)$ & & & & \\
\hline Yes & 15.0 & 0.7 & 0.511 & & \\
\hline No & 21.2 & 1.0 & & - & - \\
\hline
\end{tabular}




\section{Economic Empowerment}

Economic empowerment was examined in order to determine the level of economic disparity between male and female partners among those who are married or cohabiting. Appendix 6 contains details of the results of the economic empowerment section. Respondents were asked about whether they were earning any money (whether paid in cash or in kind). Among those who were married or cohabiting, there was a significantly higher proportion of males who were not earning any money compared to females in all provinces except Copperbelt (Figure 31). Overall, 28 percent of males reported they were not earning any money as opposed to 12 percent of females. The province with the highest proportion of males not earning anything was Luapula. This finding requires further investigation and may merit clarifying questions to be added to the follow-on surveys. Luapula also had the lowest proportion of females not earning any money. Earning with in-kind compensation such as housing or food is not unusual in a rural province like Luapula. The province that had the most similar proportion of those not earning any money was Copperbelt.

Figure 31. Percent not earning any money among male and female respondents who are married or cohabiting

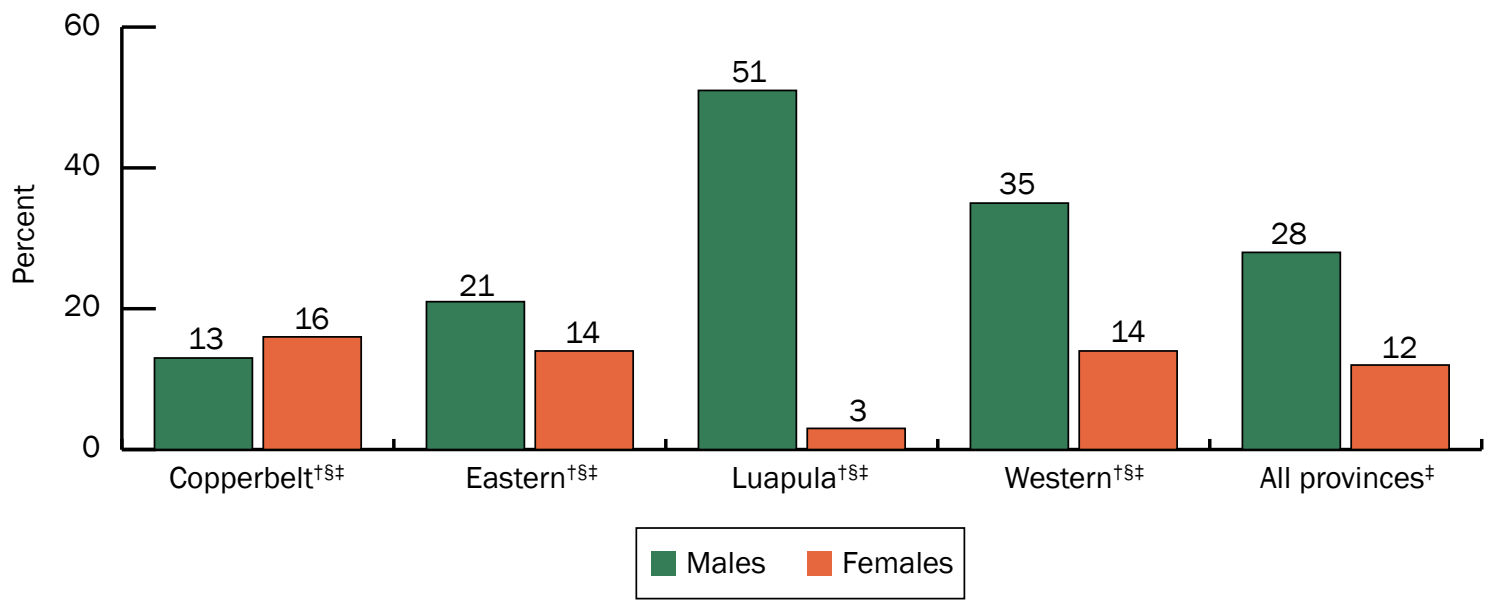

†Statistically different across provinces for males $(p<0.05)$.

\$Statistically different across provinces for females $(p<0.05)$.

₹Statistically different between males and females $(p<0.05)$.

Those who were married or cohabiting and earning money were asked about decision making related to how their earnings are spent. Overall, over one-half of males and females in all provinces indicated that the decision was made jointly with their spouses (Figure 32). Luapula had the highest proportion of males (65 percent) and females (69 percent) who indicated the decision was made jointly compared to the other provinces (approximately 45-60 percent). In Copperbelt, it appears that women are more likely to be decision makers regarding earnings compared to the men; 24 percent of men (compared to 11 percent of women) indicated that their spouse/partner made the decisions about their earnings and 32 percent of women (compared to 20 percent of men) indicated that they made their own decisions about their own earnings. However, in Eastern, it was the opposite: 35 percent of women 
(compared to 9 percent of men) indicated that their spouse/partner made the decisions about their own earnings and 32 percent of men (compared to 15 percent of women) indicated they made their own decision about their own earnings. Therefore, women appear to have more control over earnings (whether their own or their spouses) in Copperbelt, whereas women in Eastern appear to have less control over their or their partners' earnings. Those in Luapula, however, engage in more joint decision making about earnings. Western province appears to be different in that while a high proportion of women indicate they make their own decisions about their own earnings (33 percent), a high proportion (22 percent) also indicated that their spouses make the decision on their earnings.

Figure 32. Decision on how the money one earns will be used among married and co-habiting participants who were earning money

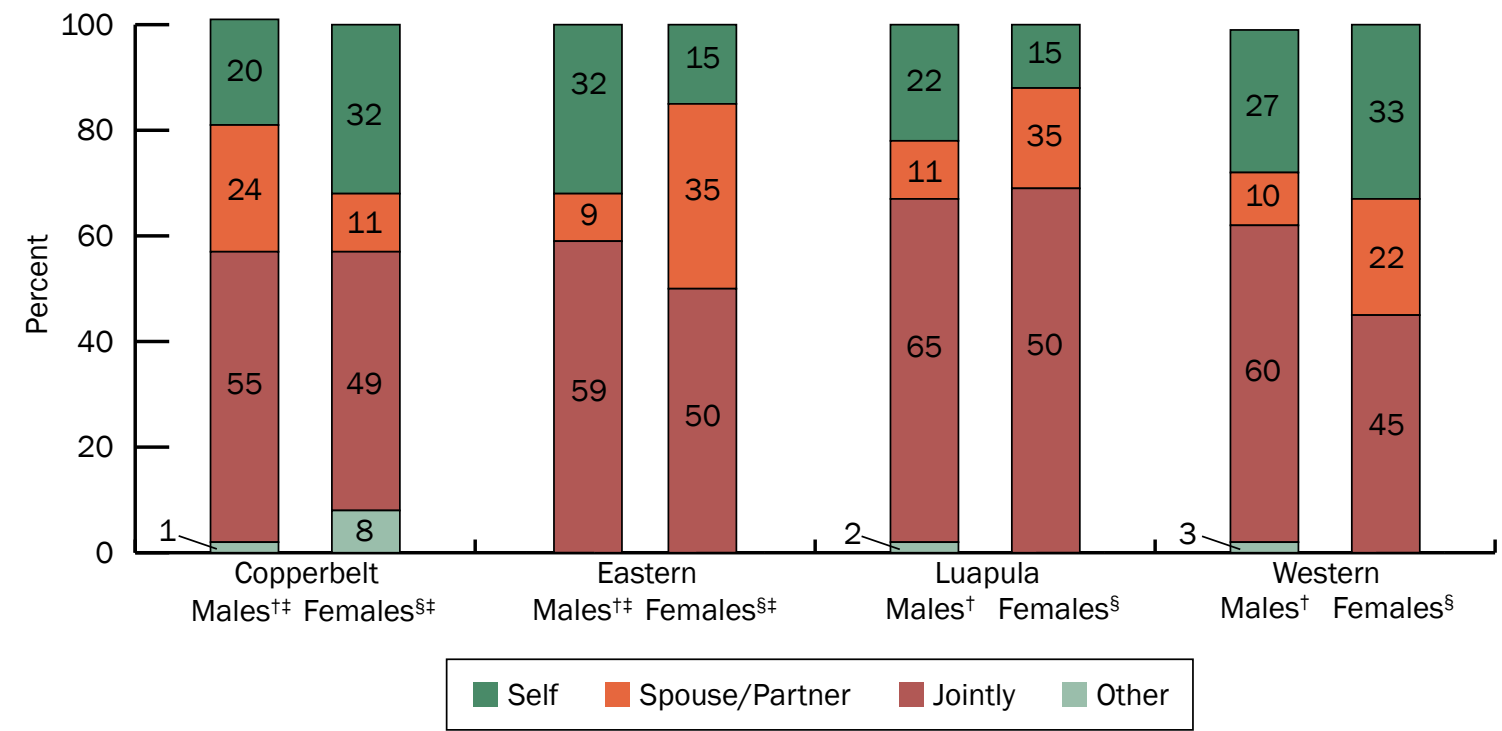

'Statistically different across provinces for males $(p<0.05)$.

sStatistically different across provinces for females $(p<0.05)$.

†Statistically different between males and females $(p<0.05)$.

Men and women who are married and living with their spouse or cohabiting were asked who makes the final decisions regarding food and clothing as well as on large investments such as a car or house. Overall, Luapula and Western provinces had higher proportions of men and women who indicated that these decisions were made jointly compared to other provinces (Figures 33 and 34). Interestingly, in all provinces, women were more likely than men to indicate that these decisions were made jointly. Overall, men were more likely than women to indicate that they made these decisions and in support of that, women were more likely than men to indicate that their spouses made these decisions. This was particularly true for decisions related to major household investments. 
Figure 33. Who has the final say on how you spend money on food and clothing among married and cohabiting participants

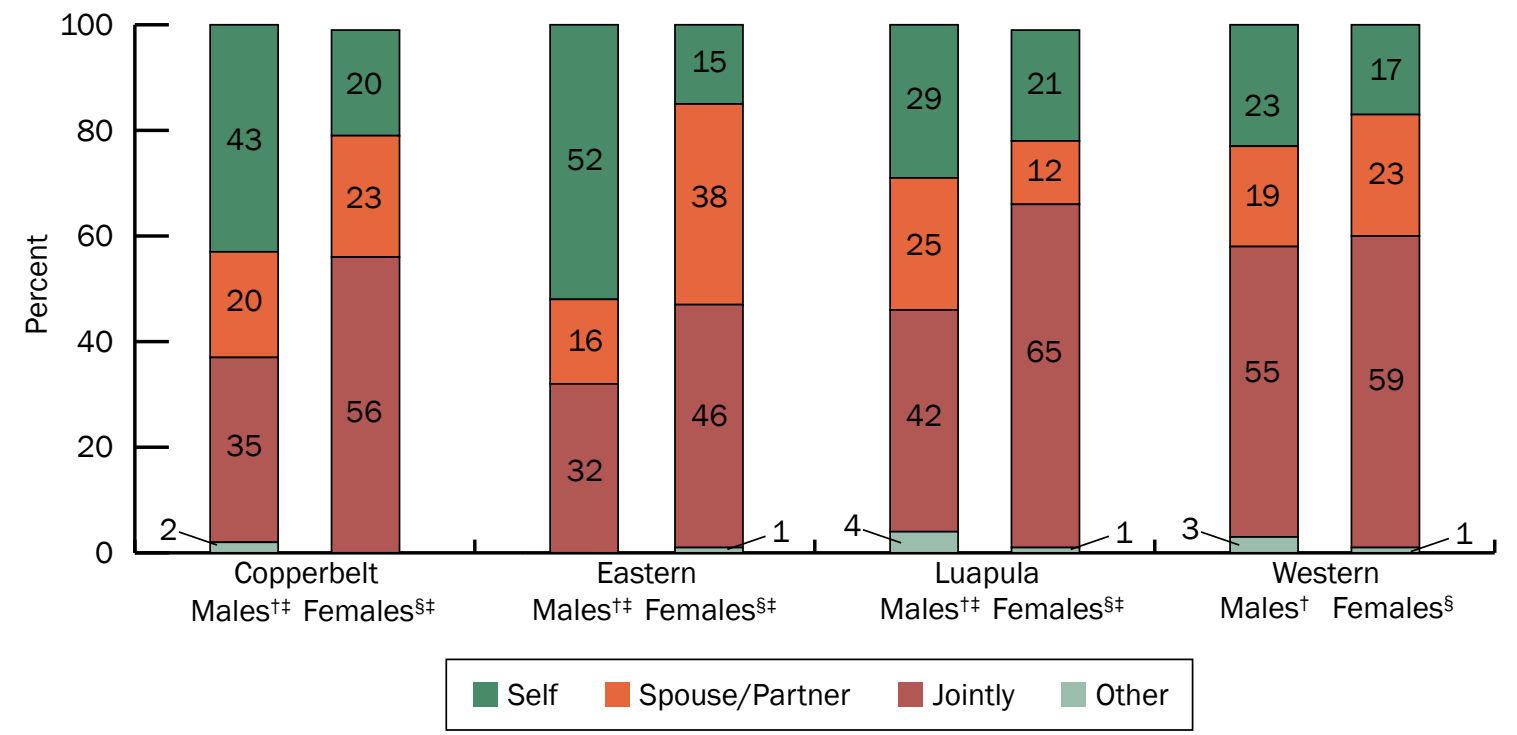

†Statistically different across provinces for males $(p<0.05)$.

$\$$ Statistically different across provinces for females $(p<0.05)$.

₹Statistically different between males and females $(p<0.05)$.

Figure 34. Who has the final say on how you spend money on large investments like car or house among married and co-habiting participants

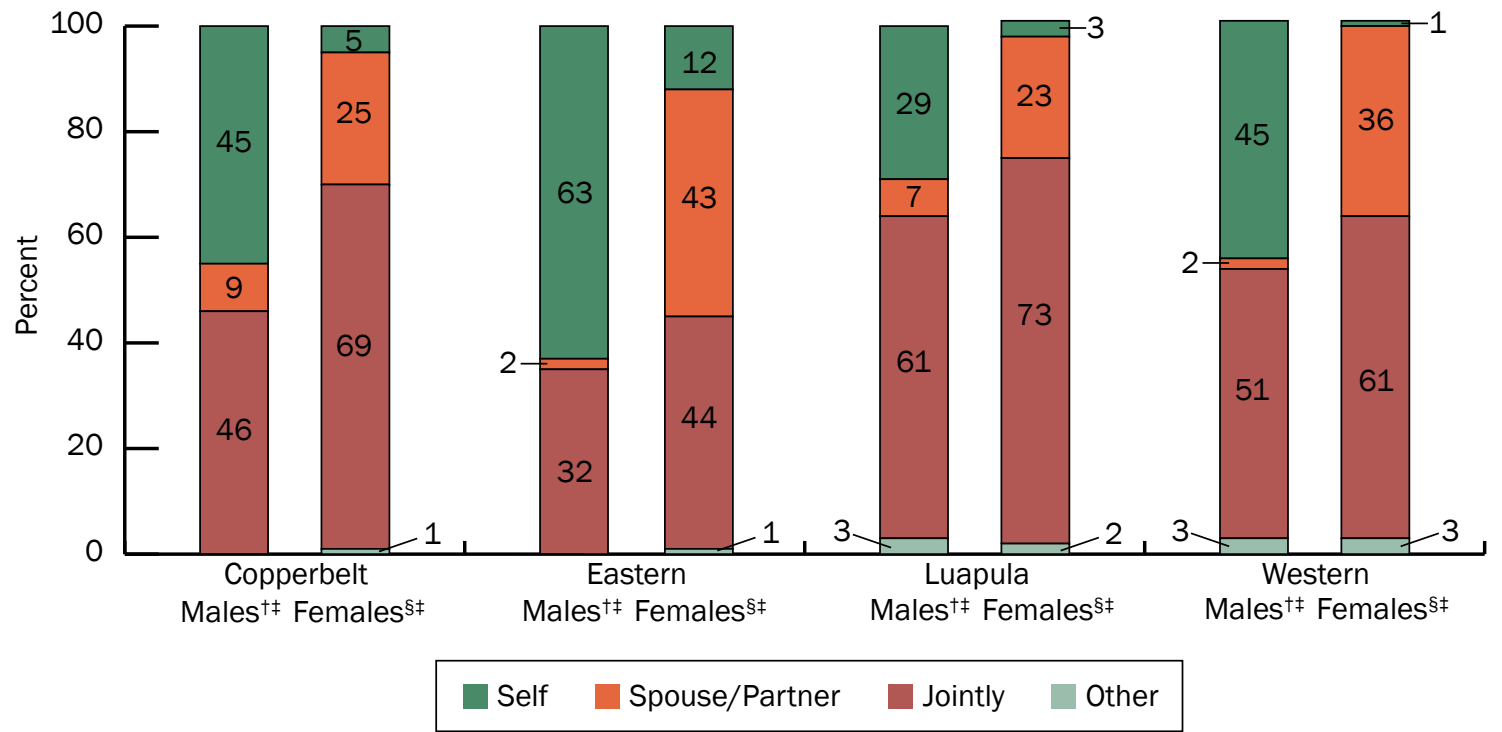

†Statistically different across provinces for males $(p<0.05)$.

sStatistically different across provinces for females $(p<0.05)$.

†Statistically different between males and females $(p<0.05)$. 
Women who were married or cohabiting were asked about who makes the final decisions related to health care and daily household purchases. It was again Luapula that showed the highest proportion of respondents who indicated that health care decisions ( 81 percent) and daily purchases decisions (70 percent) were made jointly with their spouses compared to other provinces (Figure 35). Additionally, Copperbelt had the highest proportion of females who indicated they made these decisions themselves, whereas Eastern had the highest proportion who indicated that their spouses/partners made these decisions compared to other provinces.

Figure 35. Who makes the decisions about health care among married and co-habiting female participants

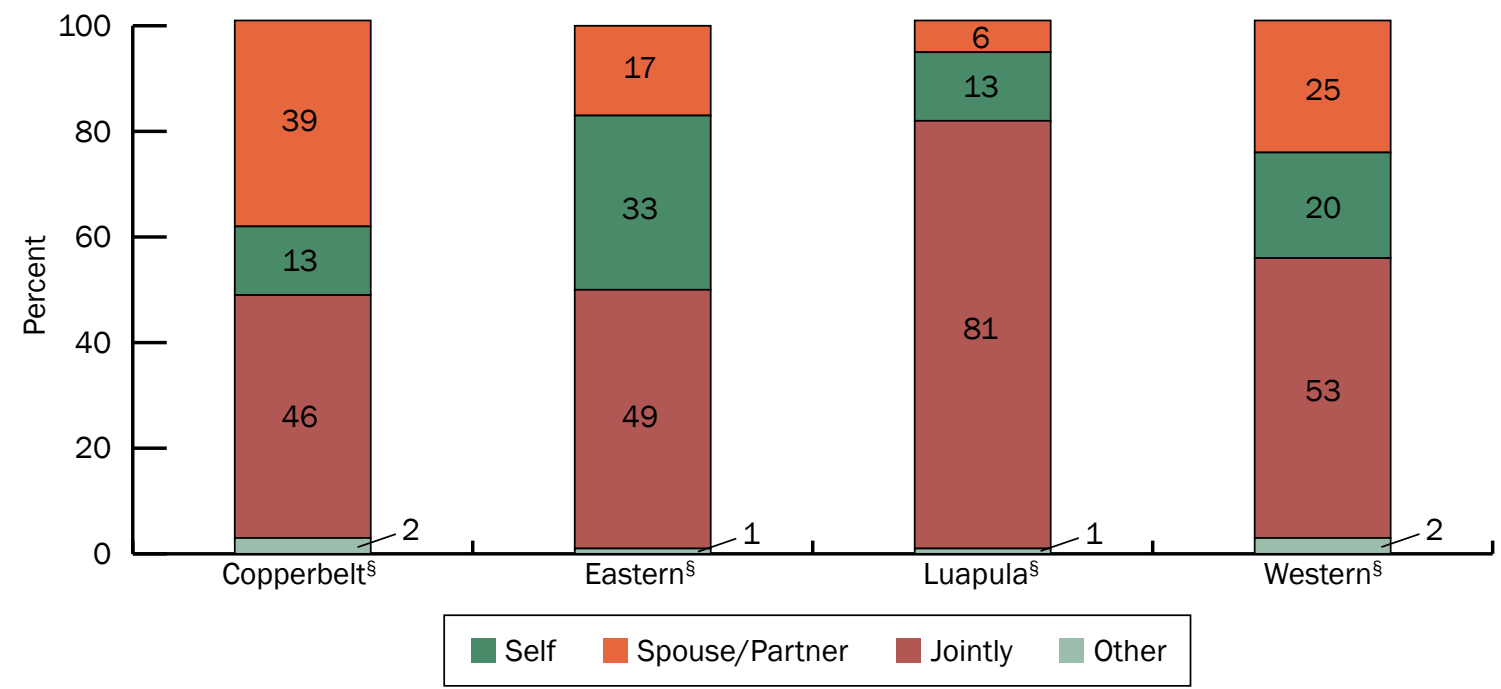

\$Statistically different across provinces $(p<0.05)$.

\section{CONCLUSIONS AND RECOMMENDATIONS}

\section{Gaps in HIV knowledge remain; however, knowledge is not sufficient for behavior change}

While the majority of respondents had heard of HIV and AIDS, knew HIV prevention strategies, and refuted common myths about HIV, comprehensive knowledge of HIV and AIDS was low in all provinces (approximately 50 percent or less). The data presented in this report also showed that approximately 15-25 percent of men and women answered questions on HIV prevention concepts incorrectly. A greater proportion correctly refuted the common myths about HIV. This demonstrates a need for improved HIV knowledge and education, particularly in Eastern province, which had the lowest overall comprehensive knowledge of HIV and AIDS. 
Use of evidence-based methods such as individual or small group level interventions and participatory learning and action approaches (PLA) are highly recommended as they can likely match knowledge levels with practice (YouthNet/Family Health International 2006).

It is worrisome that women had lower overall comprehensive knowledge of HIV. Women were less likely than men to correctly agree that using condoms and having one uninfected partner prevented HIV and more likely than men to believe misinformation about HIV transmission through mosquitoes and witchcraft. However, regardless of this lower knowledge of HIV prevention and transmission, women were less likely to have multiple sex partners in the last 12 months and more likely to use condoms, which is consistent with the UNGASS 2010 Zambia Country Report (National AIDS Council 2010). It should be further noted that while having correct knowledge of HIV prevention and transmission is important, it is not sufficient for practicing HIV preventive behaviors. Our results consistently indicated that comprehensive knowledge was not associated with having multiple partners, having a non-regular sex partner, or condom use. Therefore, while HIV programs aim to increase correct knowledge of HIV, behavior change communication must go beyond improving knowledge alone. Programs must address various other precursors to behavior change and address concepts based on behavior change theories such as motivation to change, improved perception of risk, intention to reduce risk, and building the skills needed to protect themselves and others. More importantly, studies have shown that behavior change is most effective when targeted at multiple levels. Programs must target not only the individuals but also the community (i.e., altering norms and behaviors of social groups, increasing access to services that reduce transmission such as STI treatment and male circumcision).

\section{Greater awareness of PMTCT is needed}

Knowledge that HIV can be transmitted through breast milk was fairly high. However, a large proportion of both men and women do not know of drugs that reduce mother to child transmission of HIV during pregnancy. This knowledge was low even among women; only 65 percent had heard of drugs to prevent transmission to a baby. Information and education about PMTCT, including education on transmission during pregnancy, and prevention must be accessible to women,especially during pregnancy through antenatal care.

\section{While HIV testing has increased, increasing testing is needed, particularly in men}

This study shows that overall one in five people still do not know where to be tested for HIV and a significant proportion of these are men. Not surprisingly, a significantly lower proportion of men also never tested for HIV, with Copperbelt and Western showing the greatest need for improved testing rates. This could be due to men utilizing health services less frequently than women and having no equivalent to routine opt-out testing within ANC. All provinces should consider conducting male-focused information and testing campaigns. Further, testing services should be evaluated to determine whether they are meeting the unique needs of men for HIV testing and sexual health. Male-centered/sensitive HIV counseling and testing promotional campaigns should be considered. In addition to communication strategies, collabo- 
rating with clinics and clinical technical assistance partners in HCT outreach events, special Male Testing Days, or the like should be considered. ZPI has engaged a Male Involvement Officer who will spearhead initiatives aimed at increasing male participation in various HIV prevention interventions including HCT in outreach and ANC settings (with spouses). Further, as in other African countries, in Zambia it is time to begin exploring other risk pathways, including through same-sex encounters.

Because about one in four women had also never tested for HIV, additional research should be conducted in areas of low testing uptake to determine barriers for both men and women. Results of this research show a strong preference for testing at government hospitals or health facilities, indicating stand alone VCT centers and mobile clinics may be underutilized or inaccessible. Further evaluation of these facilities may be needed to determine how they can increase testing among those not currently accessing testing services.

This study found higher testing rates compared to the 2007 ZDHS. This may indicate that HIV testing campaigns have improved testing since 2007. Although the increased testing trend compared to the 2007 ZDHS is encouraging, all provinces should aim to further increase testing. Findings related to testing behaviors are consistent with findings on knowledge of testing sites. While remaining aligned with national priorities and strategies, ZPI's communication strategies promoting testing should include specific information on where the local population can get tested in addition to the importance of knowing one's status. Adding to the knowledge base in Zambia on HIV testing behavior, results from this ZPI study provide useful insight and data that can inform existing and future NAC communication strategies.

Interestingly, Eastern province-which showed the lowest rates of comprehensive HIV knowledge-showed the highest overall and male testing rates. Understanding why this is the case may inform interventions and communication strategies in other provinces.

Our findings also suggest that testing promotion should be targeted at unmarried, urban populations of lower socio-economic status.

\section{HIV testing at ANC can be improved}

While the majority of women in all provinces (over 90 percent) attended ANC for their last pregnancy, approximately 15-30 percent were not tested for HIV. ZPI should continue to collaborate with clinics and clinical technical assistance partners to implement effective communication and support interventions to increase ANC-based testing.

Luapula and Western provinces in particular had the lowest HIV testing rates at ANC. Interestingly, it was also in Luapula where a larger proportion of women who sought ANC saw traditional birth attendants rather than doctors, nurse/midwives, or clinical officers, unlike women in other provinces. HIV programs should work with traditional birth attendants to encourage women to get tested for HIV. This may be through TBAs getting trained to provide HIV counseling and testing or through accompanying their patients for HIV testing. 


\section{Programs are needed to delay first sex}

With early sexual debut most prevalent in Western province (39.3 percent of male and 25.4 percent of female youths had had sex before age 15) and this province also having higher sexual risk behavior, a priority should be youth-centered behavioral risk reduction programming. Because early sexual debut is significantly associated with risky sex, pregnancy, and increased HIV and STI risk (Duncan et al. 1990; Greenberg et al. 1992; Laga et al. 2001; Pettifor et al. 2004; Kaestle et al. 2005), interventions should include life skills and HIV prevention programs in schools and out of school. Programs should also promote positive communication with children on sexuality and HIV, and improve/provide youth-friendly sexual health services. Because early sexual encounters are often risky (i.e., non-condom use, sexual coercion), research is needed to understand social, cultural, and structural factors to help make the first experience safer for young people.

\section{Men are more likely to engage in risky sex; however, women are also risky}

Risky sex (having multiple partners, having a non-regular sex partner, and not using condoms) was more common among males than females, indicating an imminent need for male-centered programs that reduce sexual risk behaviors. About one in five males had multiple partners in the past 12 months, compared to less than one in 10 females. Additionally, men overall were less likely to use a condoms during their last sex; this was among men who had sex with multiple partners and/or non-regular partners. Programs must be designed to meet the sexual health needs of men, with messaging specifically tailored to high-risk men. For example, programs should use existing structures to integrate HIV prevention programming. These may include 'insakas' (among the Bemba people) or 'gobelo' (for the Tonga people), which are safe spaces traditionally used by boys (though not exclusively) in traditional communities.

It should be noted, however, that while having two or more partners in the last 12 months was uncommon in women, it was not uncommon for women to have sex with non-regular partners (approximately one-quarter of sexually active women). Therefore, programs must not assume that it is only men who need counseling on sex with non-regular partners. Although women do have non-regular partners, women were significantly more likely to use a condom with non-regular partners compared to men. However, condom use even in women remains low: only about one-third of those with multiple partners and those with non-regular partners used a condom at last sex. Western province also had significantly higher risk behaviors compared to other provinces.

\section{It is not enough to know where to get condoms; condom promotion must be central to HIV prevention strategy}

Multivariate analysis of condom use suggests that the most important predictor of condom use is being able to get a condom themselves if they wanted to. Knowing where to obtain condoms did not equate to being able to obtain condoms. Logistical barriers may be partly to blame for not being able to access condoms; however, socio-cultural barriers are the more 
likely culprit. Condom promotion campaigns must be intensified. Convenient and confidential condom distribution points should be accessible to men and women; distribution venues should be tailored differently for men and women.

Interestingly, data also showed that men were more likely than women to report being able to obtain a condom if they wanted one. Despite barriers deterring women from obtaining condoms, women were six times more likely to use condoms compared to men. This may be due to women's concerns about unwanted pregnancies which can affect them more than their male partners. Additionally, a married woman is unlikely to risk getting an STI and potentially passing it on to her husband. Lastly, the stigma of having extramarital relations is much higher for a woman than a man. Therefore, a woman will go to greater lengths (including using condoms) to hide the extramarital relations.

\section{Promotion of condom use in married couples is needed}

Condom use was significantly less common among married couples. While it seems reasonable not to expect condom use within marriages, our findings showed that 14 percent of men and 5 percent of women had sex outside the marriage. However, even if there was no extramarital sex, many Zambian married couples are in HIV discordant relationships. According to the Modes of Transmission study, there is evidence that most new HIV infections in Zambia are among married couples (National AIDS Council 2009). This suggests that ZPI condom promotion programs should aim to increase awareness of and condom use among couplesas both an HIV prevention strategy as well as a family planning method.

\section{Sexual risk reduction programs must be tailored to the local context}

Our findings consistently indicated that Western province had the highest sexual risk-greater likelihood of early sexual debut, having multiple partners, having non-regular partners, and having extra-marital partners. Understanding the reasons for this will help to inform strategic programming.

\section{Behavior change communication messages must address contradictions in what should be and how things are with regard to abstinence and being faithful}

Findings that were presented on perceptions around abstinence and faithfulness show a disconnect between a moral code and the social norm. Strict values held by both males and females around sex before marriage and faithfulness and what respondents believed actually happened in the community differed immensely. Some of this may have been due to social desirability bias, in which respondents may have tried to express their strict moral code to interviewers. While risky behavior does not appear to be acceptable among the majority of respondents, the behaviors themselves appear to be the social norm.

While this is not a surprising finding, these contradictions have specific implications for our approaches to BCC. BCC messages need to be re-evaluated and must be made more persua- 
sive. Social psychologists describe to this kind of contradiction in beliefs, values, and behaviors as a cognitive dissonance-a sort of fundamental disconnect (Festinger 1957; Festinger and Carlsmith 1959). The theory explains that people's experience of such dissonance is uncomfortable, so much so that individuals need to resolve the dissonance to create consonance. Resolving the dissonance can occur in different ways. Public health professionals want people to stop the behaviors that put people at risk. However, more often, people find other means of resolving dissonance, such as refusing the health promotion message-to block it out or avoid it altogether. Another common way is finding justifications for the risky behaviors (i.e., "I'm going to die someday anyway, so I might as well enjoy myself now," or "We're too far along in this heated moment. We can't stop now to talk about condoms," or "She/He is an educated professional. Surely she/he doesn't have HIV or STIs"). The key question here is whether existing BCC approaches are adequate in addressing these psychosocial processes. BCC messages must be based on a sound understanding of how people relate to our key messages. More specifically, BCC approaches must speak to people in such a way that they do not just tune out. Lastly, strategies must tackle the process of justifying sexual risk-taking, including addressing some of the common justifications in Zambian populations.

\section{Improving gender norms must be part of any HIV prevention program}

This study pointed out the high prevalence of inequitable gender norms and the need for programs to promote gender-equitable norms to both men and women. There is evidence that inequitable gender norms are associated with risky behaviors such as more partner violence and less condom use (Pulerwitz et al. 2010). This study in particular found that inequitable gender norms were associated with having multiple sex partners and being drunk during sex. Indeed, it is difficult to tease out whether individuals with poor gender attitudes were more prone to risky behaviors or whether poor gender attitudes are a result of the risky behaviors. However, it is clear that gender inequitable attitudes and risky behaviors are intertwined and must be addressed together in any HIV prevention program. Behavior change programs improving gender norms have been shown to improve HIV and STI risk outcomes (Pulerwitz et al. 2006; Pulerwitz et al. 2010).

All ZPI interventions and activities have been designed to be gender-sensitive, taking into account the impact of gender on becoming infected with HIV, as well as having access to treatment, care, and support. More specifically, ZPI will: i) engage female and male community leaders and key custodians of cultural knowledge to challenge harmful cultural and traditional gender norms, and to encourage positive cultural norms; ii) engage men as partners, fathers, and beneficiaries in HIV prevention, in addressing male norms and behaviors that put men and women at risk of HIV infection, and in encouraging behaviors that promote healthy relationships between men and women; iii) provide HIV prevention education for young girls and boys to address the links between gender, sexuality, and HIV; iv) address gender-based violence and violence against children by raising awareness of the links between violence and HIV, and plan actions to reduce violence; and v) increase women's and girls' access to economic empowerment through livelihoods and financial skills training. 


\section{High level of abuse and misconceptions about rape exist; programs are needed to support survivors of gender-based violence}

Our findings show that it was common for women in all provinces to have experienced physical or sexual abuse. Further, myths abound around rape, and these are used by many to enable them to justify rape. Although the correction of these myths alone is not sufficient to prevent rape, it is a necessary component of any rape prevention intervention.

Despite the high levels of abuse experienced by women, very few seek help after the abuse. Women who do seek help were more likely to do so from family members. This might suggest that ZPI will need to focus on improving family response to abuse.

However, it will also be important to help women know where else they can turn to for help. There is a need to strengthen health and psychosocial services for survivors of GBV. Providers at health facilities must be sensitized and doctors and nurses need to be trained to provide services for survivors of GBV (Elson and Keesbury 2010).

Additionally, interventions must promote cooperation between the police victim support unit (VSU) and health services to improve physical and psychosocial support and care for survivors of gender-based violence. Interventions have been successfully implemented at police stations to provide appropriate, timely and sensitive services and care for victims, including in Zambia (Keesbury et al. 2009; Raifman et al. 2011). Linkages must be developed between local hospitals/health centers and the police and other NGOs or CBOs dealing with GBV in order to facilitate referrals for victims. Services for survivors of GBV should include emergency contraception, psychosocial counseling, STI testing and treatment, and post-exposure prophylaxis to prevent HIV. Working with the police and health services may serve to improve the supply side of services for rape victims; however, the survivors must also be willing to report incidents and seek help from police and hospitals. Community sensitization strategies must be conducted through various channels in order to facilitate help-seeking behaviors so that survivors obtain medical attention in a timely manner.

\section{Alcohol risk reduction is needed}

The data in this report show that alcohol use and abuse was moderately common with males, but infrequent with females. Alcohol inhibits judgment and is a risk factor for sexual transmission of HIV (Cook and Clark 2005; Kalichman et al. 2007). People under the influence are less likely to use a condom during sex and are more likely to engage in sex with a casual partner, whose status is unknown to them. As part of a comprehensive risk reduction strategy during HIV counseling and testing, counselors should be given the appropriate tools to evaluate alcohol use such as the CAGE tool (Ewing 1984), and to recommend strategies for reducing risk related to alcohol abuse. Additionally, alcohol risk reduction should be implemented along with improving gender equitable norms for the same target group, as the study found that those who were drunk during last sex were more likely to subscribe to inequitable gender norms. 


\section{High levels of unintended pregnancies and low levels of contraception}

use

There were high levels of unintended pregnancies, particularly in Copperbelt (67 percent) and Eastern (55 percent). The results show that unintended pregnancies were most common among younger unmarried females. Despite high levels of unintended pregnancies, only a small percentage of women were currently using any contraceptive method (15-30 percent). It is clear that access to family planning must be a priority for ZPI, with a particular focus on targeting younger unmarried women. It will be important to know whether younger unmarried women are self-denying access to family planning services or whether health providers are denying them access or both. Additionally, awareness of and access to emergency contraceptive need to be improved. The majority of respondents had never heard of emergency contraception, which is a key component of the Zambia national family planning method mix. Emergency contraceptive use could lower the rates of unintended pregnancies.

\section{Need for improvement in ANC coverage}

While attendance of at least one ANC visit for a pregnancy was high (over 90 percent), a high proportion of women (one-third) actually did not complete the four recommended ANC visits. The proportion was as high as one-half in Eastern province. It was also Eastern province that had the highest percentage of women who gave birth to a live child who later died (35.4 percent) compared to other provinces. Unfortunately we do not have information on the age and causes of death. This low rate of ANC coverage and the high proportion of deaths urgently need further investigation in Eastern province.

\section{Low uptake of medical circumcision}

Male circumcision in Zambia has strong ties to ethnic identity; certain ethnic communities consider it the process for male admission into adulthood. Overall, about one in five males were circumcised; however, the male circumcision rate varied greatly across provinces and this is in line with what was reported in the 2007 ZDHS. Western province had the highest rate of male circumcision (nearly 50 percent of men). This is likely due to the practice of circumcision as a tradition.

The majority of circumcisions were conducted by traditional circumcisors. Medical male circumcision is still one of the best known method to reduce the risk for acquiring HIV in men. As medical male circumcision is being scaled-up throughout Zambia, tailored strategies to increase uptake may be needed for different provinces as barriers to circumcision may vary across provinces.

This study found that those who were circumcised had lower comprehensive knowledge of HIV and were significantly more likely to have had sex with multiple partners in the past year. Given these findings, it is important to know whether there is greater sexual risk taking due to a false sense of security in thinking that one is protected from HIV infection due to circumcision. Future research should explore local level understanding of the protective effects of circumcision and barriers to circumcision, as well as any behavioral disinhibition. 


\section{Luapula appears to have the greatest women's economic empowerment while Eastern has the lowest}

Based on questions related to family financial decisions, Luapula appears to have the greatest equity in that the province had the highest proportion of participants who indicated that decisions about earnings, health care, daily purchases, food and clothing, and large investments were made jointly. Interestingly, however, it was also the only province in which approximately one-half of the men indicated that they had no earnings (in money) compared to only $3.4 \%$ of the women in Luapula. It is very likely that the men are earning their wage in other forms of compensations such as fishing. This is common in a rural province such as Luapula. It will be worth further exploration into how household decisions are made in order to achieve this kind of decision making equity in other provinces. What are the unique socio-cultural and economic factors in Luapula whereby family financial decisions are able to be made jointly?

Additionally, of note was that Eastern province had the lowest women's economic empowerment based on family financial decision making. It had the highest proportion of respondents who indicated that the male partner had the final say with regard to earnings and other household decisions.

ZPI is implementing economic empowerment programs. The intervention includes, but not limited to, training and capacity building in entrepreneurship skills; social support and linkages to cash transfer and food support programs; support for asset growth and protection; support for job skills and job placement; linkages for small businesses and entrepreneurs.

\section{Concluding Remarks}

This study determined baseline levels of key indicators related HIV, GBV, and reproductive health. These baseline levels will be used as part of the evaluation in measuring the effect of the ZPI program. These baseline measures will be compared with midline and endline levels to assess ZPI's programmatic success. Additionally, the baseline findings provided critical insights into key areas for interventions in Zambia and highlighted variability in the populations across provinces and between males and females that provide valuable guidance for programming. 
Auvert, B. et al. 2005. "Randomized, controlled intervention trial of male circumcision for reduction of HIV infection risk: the ANRS 1265 Trial," PLoS Med 2(11): e298.

Bailey, R. C. et al. 2007. "Male circumcision for HIV prevention in young men in Kisumu, Kenya: a randomised controlled trial," Lancet 369(9562): 643-56.

Cook, R. L. and D. B. Clark. 2005. "Is there an association between alcohol consumption and sexually transmitted diseases? A systematic review," Sex Transm Dis 32(3): 156-64.

Duncan, M. E. et al. 1990. "First coitus before menarche and risk of sexually transmitted disease," Lancet 335(8685): 338-40.

Dunkle, K. L. et al. 2004. "Gender-based violence, relationship power, and risk of HIV infection in women attending antenatal clinics in South Africa," Lancet 363(9419): 1415-1421.

Elson, L. and J. Keesbury. 2010. "PEPFAR special initiative on sexual and gender-based violence," Baseline Report. Lusaka: Population Council.

Ewing, J. A. 1984. “Detecting alcoholism. The CAGE questionnaire,” JAMA 252(14): 1905-1907.

Festinger, L. 1957. A Theory of Cognitive Dissonance. Stanford, CA: Stanford University Press.

Festinger, L. and J. M. Carlsmith. 1959. “Cognitive consequences of forced compliance," J Abnorm Psychol 58(2): 203-210.

Gabrysch, S. et al. 2008. "The role of context: neighbourhood characteristics strongly influence HIV risk in young women in Ndola, Zambia," Trop Med Int Health 13(2): 162-170.

Gillespie, S. et al. 2007. “Is poverty or wealth driving HIV transmission?” AIDS 21(Suppl 7): S5-S16.

Gouws, E. et al. 2008. "The epidemiology of HIV infection among young people aged 15-24 years in southern Africa," AIDS 22(Suppl 4): S5-S16.

Gray, R. H. et al. 2007. "Male circumcision for HIV prevention in men in Rakai, Uganda: a randomised trial," Lancet 369(9562): 657-666.

Greenberg, J. et al. 1992. "Age at first coitus. A marker for risky sexual behavior in women," Sex Transm Dis 19(6): 331-334.

Halperin, D. T. and H. Epstein. 2004. “Concurrent sexual partnerships help to explain Africa's high HIV prevalence: implications for prevention," Lancet 364(9428): 4-6.

Hosmer, D. W., Jr and S. Lemeshow. 1989. Applied Logistic Regression. New York: Wiley.

International Group on Analysis of Trends in HIV Prevalence and Behaviours in Young People in Countries most Affected by HIV. 2010. "Trends in HIV prevalence and sexual behaviour among young people aged 15-24 years in countries most affected by HIV," Sex Transm Infect 86(Suppl 2): ii72-ii83.

Kaestle, C. E. et al. 2005. "Young age at first sexual intercourse and sexually transmitted infections in adolescents and young adults," Am J Epidemiol 161(8): 774-780.

Kalichman, S. C. et al. 2007. "Alcohol use and sexual risks for HIV/AIDS in sub-Saharan Africa: systematic review of empirical findings," Prev Sci 8(2): 141-151.

Keesbury, J. et al. 2009. "The Copperbelt Model of Integrated Care for Survivors of Rape and Defilement: Testing the feasibility of police provision of emergency contraceptive pills." Lusaka: Population Council.

Laga, M. et al. 2001. “To stem HIV in Africa, prevent transmission to young women,” AIDS 15(7): 931-934.

Mah, T. L. and D. T. Halperin. 2008. "Concurrent sexual partnerships and the HIV epidemics in Africa: Evidence to move forward." AIDS Behav 14(1): 11-16.

Malhotra, N. and J. Yang (2011). “Risky behaviour and HIV prevalence among Zambian men," J Biosoc Sci 43(2): 155-165.

Maman, S. et al. 2002. "HIV-positive women report more lifetime partner violence: findings from a voluntary counseling and testing clinic in Dar es Salaam, Tanzania," Am J Public Health 92(8): 1331-1337. 
Mishra, V. et al. 2007. "A study of the association of HIV infection with wealth in sub-Saharan Africa," Working Paper. Measure DHS. Retrieved February 16, 2012, http://www.measuredhs.com/pubs/pdf/WP31/WP31.pdf.

Morris, M. et al. 2010. "Timing is everything: international variations in historical sexual partnership concurrency and HIV prevalence," PLoS One 5(11): e14092.

Morris, M. and M. Kretzschmar. 1997. "Concurrent partnerships and the spread of HIV," Aids 11(5): 641-648.

National AIDS Council, Ministry of Health, Government of Zambia. 2010. "Zambia Country Progress Report UNGASS 2010 Reporting." Lusaka: Government of Zambia.

National AIDS Council, Ministry of Health, Zambia. 2009. "Zambia: HIV Prevention Response and Modes of Transmission Analysis.” Geneva: UNAIDS and World Bank Global HIV/AIDS Program.

Pettifor, A. E. et al. 2004. "Early age of first sex: a risk factor for HIV infection among women in Zimbabwe," AIDS 18(10): 1435-1442.

Pulerwitz, J. and G. Barker. 2008. "Measuring attitudes toward gender norms among young men in Brazil: Development and psychometric evaluation of the GEM scale," Men \& Maculinities 10: 322-338.

Pulerwitz, J. et al. 2006. "Promoting more gender-equitable norms and behaviors among young men as an HIV/ AIDS prevention strategy," Horizons Final Report. Washington, DC: Population Council.

Pulerwitz, J. et al. 2010. "Addressing gender dynamics and engaging men in HIV programs: lessons learned from Horizons research," Public Health Rep 125(2): 282-292.

Raifman, S. et al. 2011. "The prevention and management of HIV and sexual and gender-based violence: responding to the needs of survivors and those-at-risk." Washington, DC: Population Council.

Singh, K. et al. 2011. "Age, poverty and alcohol use as HIV risk factors for women in Mongu, Zambia," Afr Health Sci 11(2): 204-210.

Steen, R. et al. 2009. "Control of sexually transmitted infections and prevention of HIV transmission: mending a fractured paradigm," Bull World Health Organ 87(11): 858-865.

Stephenson, R. 2010. "Community-level gender equity and extramarital sexual risk-taking among married men in eight African countries," Int Perspect Sex Reprod Health 36(4): 178-188.

Stringer, J. S. et al. 2005. "Effectiveness of a city-wide program to prevent mother-to-child HIV transmission in Lusaka, Zambia," AIDS 19(12): 1309-1315.

Torpey, K. et al. 2010. "Reducing pediatric HIV infection: estimating mother-to-child transmission rates in a program setting in Zambia," J Acquir Immune Defic Syndr 54(4): 415-422.

WHO. 2000. "Violence against women instrument from the WHO multi-country study on women's health and domestic violence against women." Geneva: World Health Organization.

YouthNet/Family Health International. 2006. "Engaging communities in youth reproductive health and HIV projects: a guide to participatory assessments." Arlington, VA: FHI.

Zablotska, I. B. et al. 2006. "Alcohol use before sex and HIV acquisition: a longitudinal study in Rakai, Uganda," AIDS 20(8): 1191-1196.

ZDHS. 2007. Zambia Demographic and Health Survey 2007. Calverton, MD: Central Statistical Office, Ministry of Health, Tropical Diseases Research Centre, University of Zambia, and Macro International Inc. 


\section{APPENDIX 1: ZPI INDICATORS}

\begin{tabular}{|c|c|c|c|c|c|c|c|c|c|c|c|c|c|c|}
\hline 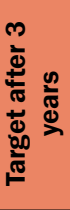 & & 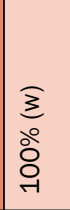 & $\begin{array}{l}\hat{\xi} \\
\circ \\
\stackrel{े}{\sigma} \\
\end{array}$ & $\begin{array}{l}3 \\
3 \\
\circ \\
o \\
-1\end{array}$ & $\begin{array}{c}\hat{g} \\
\text { ڤे } \\
\grave{\emptyset}\end{array}$ & 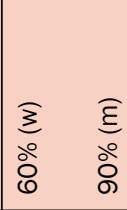 & 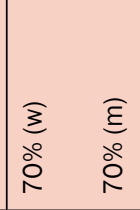 & 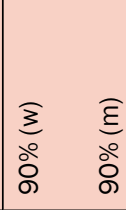 & 욱 & 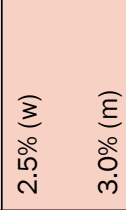 & ठิำ & ঃे & 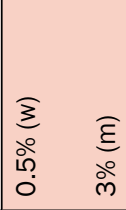 & 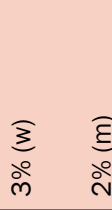 \\
\hline 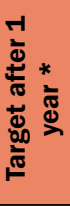 & & & $\begin{array}{l}\bar{\xi} \\
\stackrel{\circ}{\circ} \\
\text { ठ }\end{array}$ & 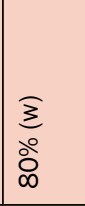 & 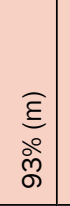 & 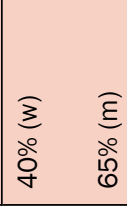 & 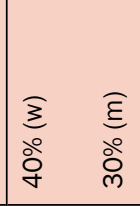 & 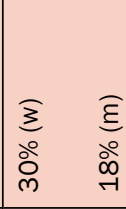 & 웜 & 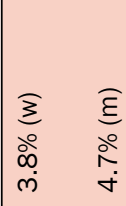 & ठें & ১̊ & * & * \\
\hline 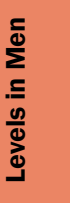 & 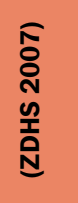 & \begin{tabular}{|}
$\stackrel{\leftrightarrow}{\leftarrow}$ \\
$\stackrel{\infty}{\circ}$
\end{tabular} & & $\begin{array}{l}\text { مे } \\
\text { ஸे }\end{array}$ & & & 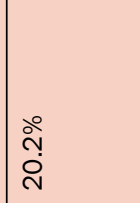 & 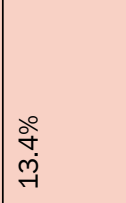 & $\begin{array}{l}\stackrel{\circ}{0} \\
\text { ஸे } \\
\text { जे }\end{array}$ & $\begin{array}{l}\stackrel{2}{\hat{~}} \\
\text { م่ }\end{array}$ & $\stackrel{\pi}{\simeq}$ & $\stackrel{\pi}{\Omega}$ & 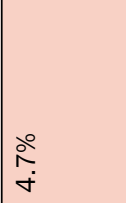 & 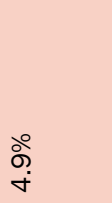 \\
\hline 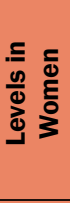 & 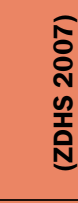 & $\begin{array}{l}\ddot{0} \\
\dot{0} \\
\infty\end{array}$ & & $\begin{array}{l}\text { iे } \\
\text { مْ } \\
\text { مْ }\end{array}$ & & & 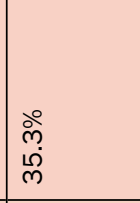 & 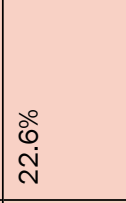 & $\stackrel{\pi}{己}$ & 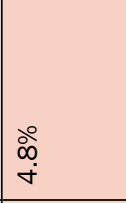 & 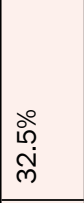 & & 今े & 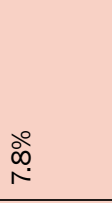 \\
\hline 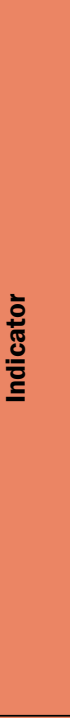 & & 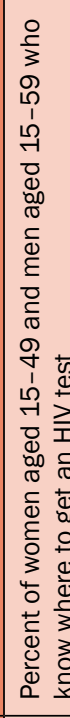 & & 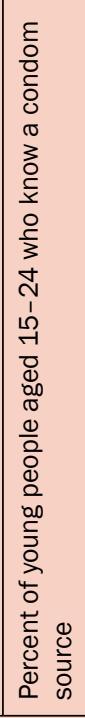 & & 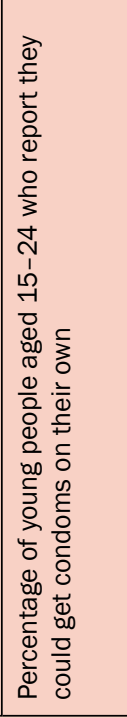 & 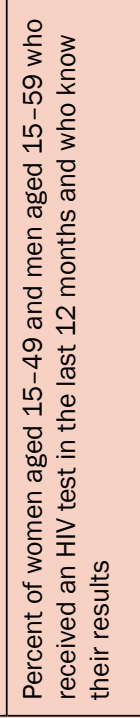 & 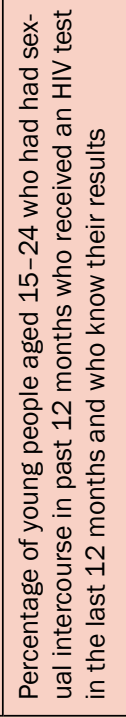 & 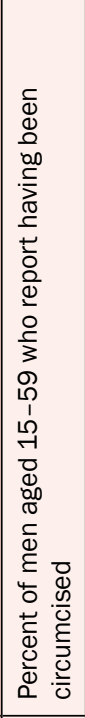 & 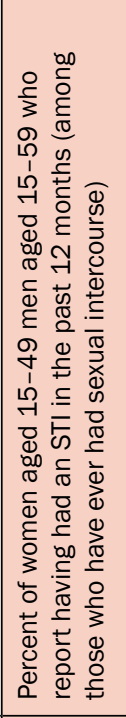 & 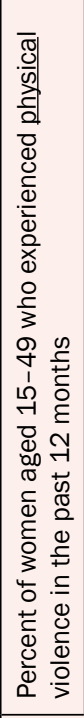 & 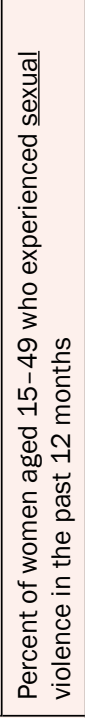 & 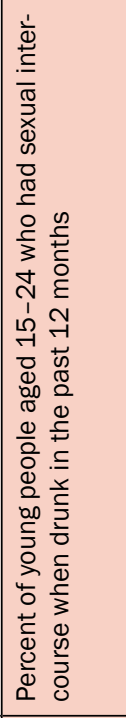 & 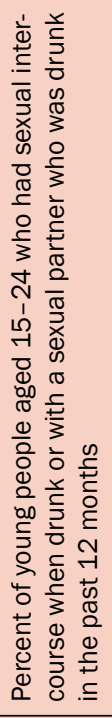 \\
\hline & & 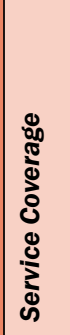 & & & & & & & 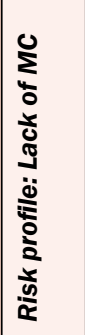 & 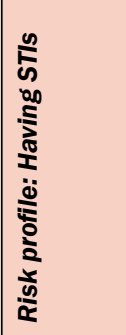 & 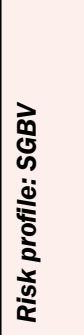 & & 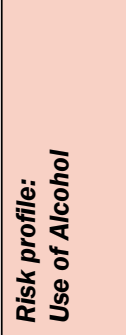 & \\
\hline
\end{tabular}




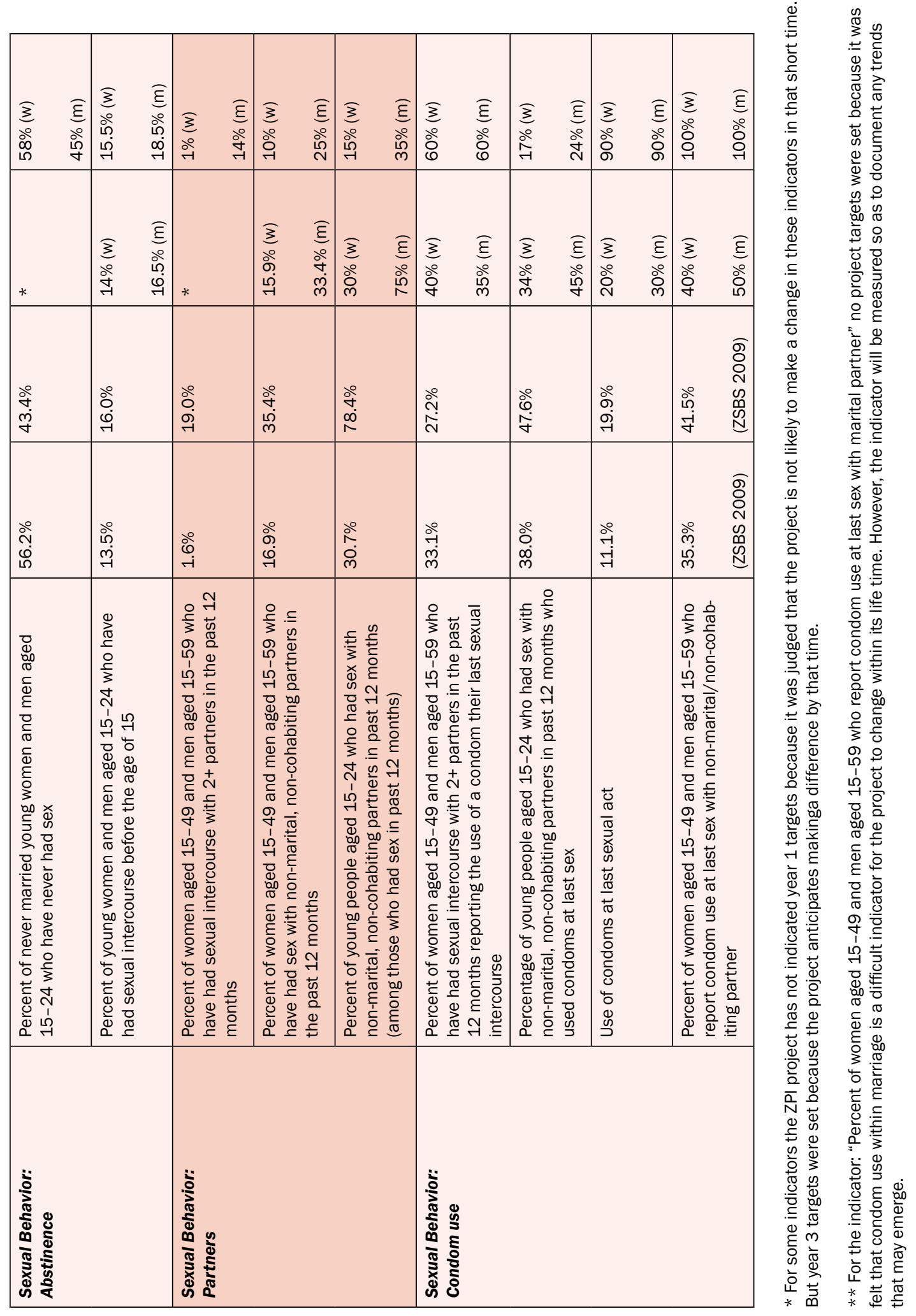




\section{APPENDIX 2: SOCIO-DEMOGRAPHIC CHARACTERISTICS BY PROVINCE AND SEX}

\begin{tabular}{|c|c|c|c|c|c|}
\hline 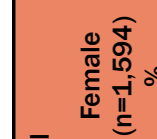 & $\stackrel{\infty}{\sim}$ & $\begin{array}{l}\text { f } \\
\text { d } \\
\text { d } \\
0 \\
0\end{array}$ & 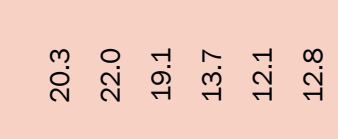 & 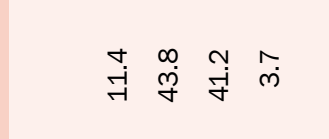 & 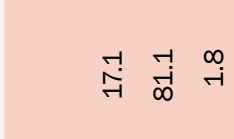 \\
\hline$\frac{\frac{0}{\pi}}{2}$ & i & 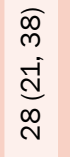 & 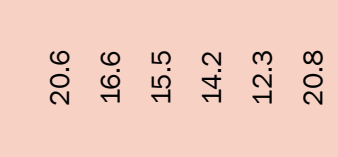 & 勇 & $\begin{array}{ll}\circ \\
\stackrel{్}{\rightarrow}\end{array}$ \\
\hline$=\frac{\underline{\underline{w}}}{\bar{w}}$ & $\widehat{\Lambda}$ & 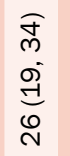 & & 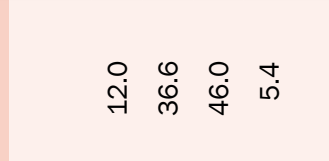 & 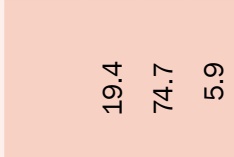 \\
\hline$\stackrel{n}{\Sigma}$ & $\stackrel{\infty}{\sim}$ & 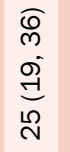 & 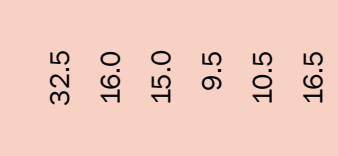 & 褡 & $\widehat{\hat{N}}$ \\
\hline 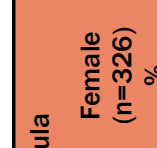 & ลे & $\begin{array}{l}\widehat{o} \\
\text { d } \\
\text { di } \\
\text { d }\end{array}$ & 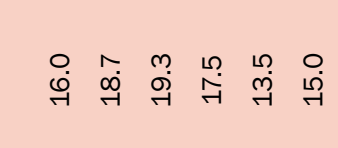 & 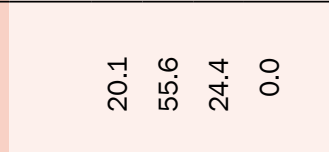 & 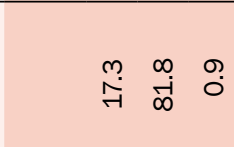 \\
\hline$\frac{\frac{0}{\pi}}{2}$ & $\stackrel{m}{m}$ & 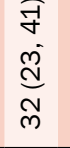 & 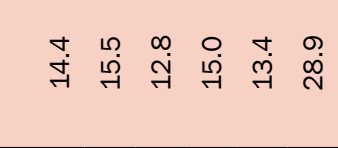 & 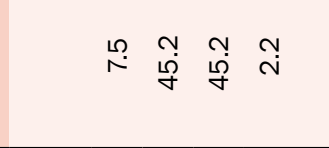 & 呙 \\
\hline 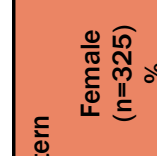 & $\stackrel{\infty}{\sim}$ & 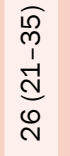 & 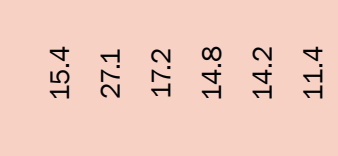 & 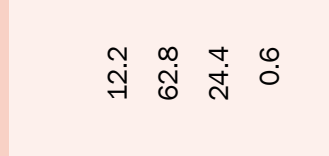 & 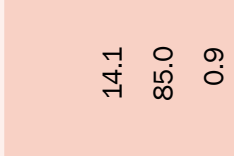 \\
\hline$\frac{\frac{0}{\pi}}{2}$ & $\vec{m}$ & 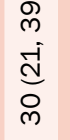 & 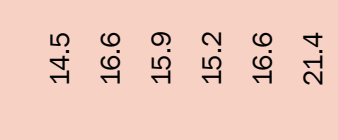 & 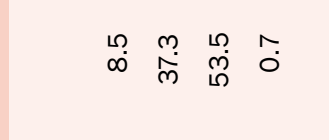 & 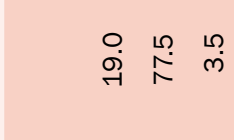 \\
\hline 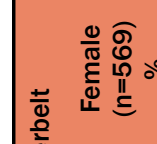 & ล & 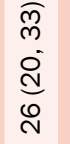 & 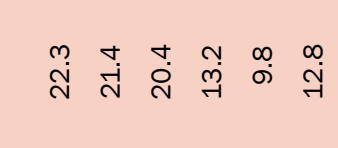 & 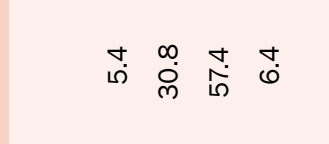 & 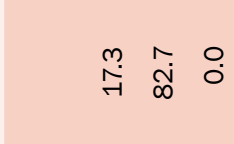 \\
\hline 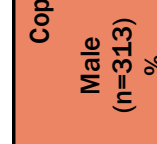 & 品 & $\begin{array}{l}\widehat{\tilde{m}} \\
\text { dij } \\
\infty \\
\stackrel{n}{\infty}\end{array}$ & 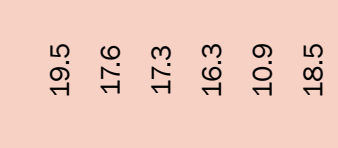 & 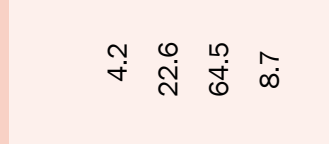 & 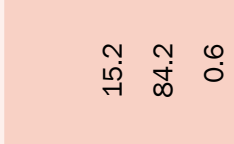 \\
\hline 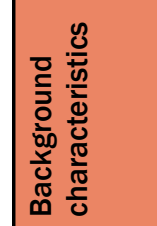 & 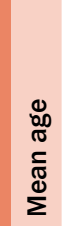 & 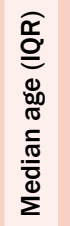 & 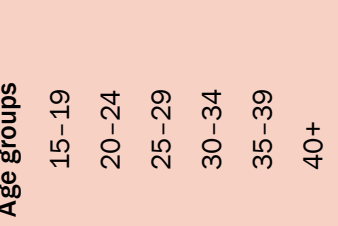 & 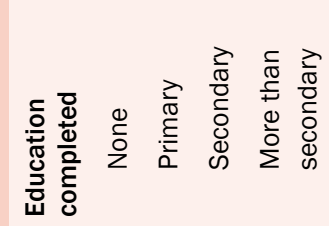 & 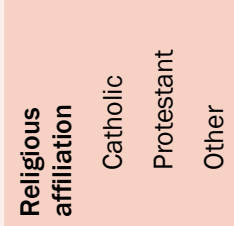 \\
\hline
\end{tabular}




\begin{tabular}{|c|c|c|c|c|c|}
\hline 西 & ت્ત & $\underset{\infty}{\infty}$ & కี & $\stackrel{+}{+}$ & 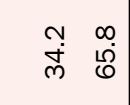 \\
\hline 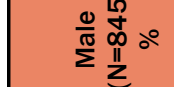 & 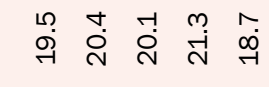 & $\stackrel{\vec{n}}{i}$ & $\stackrel{m}{\substack{0 \\
\dot{\theta}}}$ & $\stackrel{\circ}{i}$ & 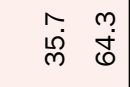 \\
\hline & 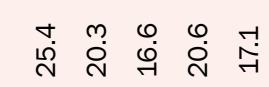 & 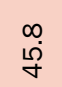 & $\stackrel{m}{\dot{g}}$ & $\stackrel{\circ}{\dot{n}}$ & \begin{tabular}{ll|l}
$N$ & $\infty$ \\
& 0 \\
0 & 0
\end{tabular} \\
\hline$\frac{0}{\sigma}$ & 吕 & 官 & ํํำ & $\stackrel{4}{A}$ & 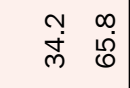 \\
\hline & 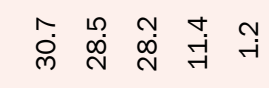 & $\stackrel{\vec{H}}{\vec{H}}$ & 앗 & ने & 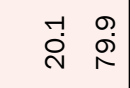 \\
\hline & 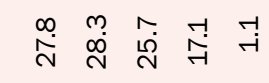 & $\stackrel{0}{\text { ì }}$ & $\stackrel{\infty}{i}$ & $\stackrel{\circ}{\circ}$ & 苞 \\
\hline & 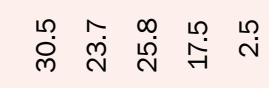 & $\stackrel{\text { ন }}{-7}$ & $\stackrel{\text { L̊ }}{\stackrel{2}{R}}$ & 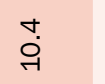 & $\begin{array}{ll}\dot{d} & 0 \\
\dot{i} & \dot{0}\end{array}$ \\
\hline & 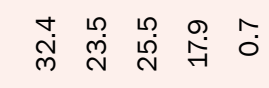 & $\stackrel{\sim}{\sim}$ & 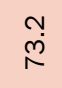 & $\stackrel{\bullet}{m}$ & 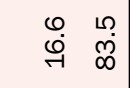 \\
\hline 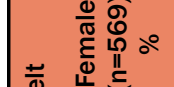 & 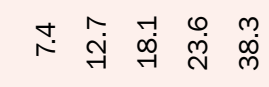 & $\stackrel{\mathscr{L}}{\stackrel{\sim}{\sim}}$ & $\stackrel{\infty}{\infty}$ & 5 & 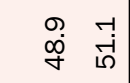 \\
\hline 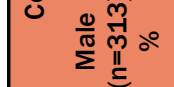 & 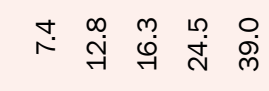 & ঙे & $\underset{\dot{S}}{0}$ & $\stackrel{\circ}{\rightarrow}$ & 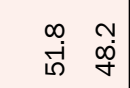 \\
\hline 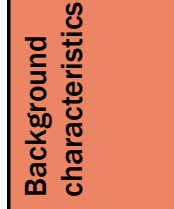 & 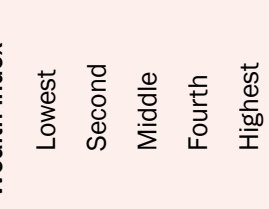 & \multicolumn{3}{|c|}{ 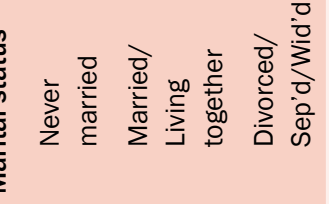 } & 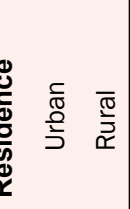 \\
\hline
\end{tabular}




\section{APPENDIX 3. KNOWLEDGE ABOUT HIV AND AIDS}

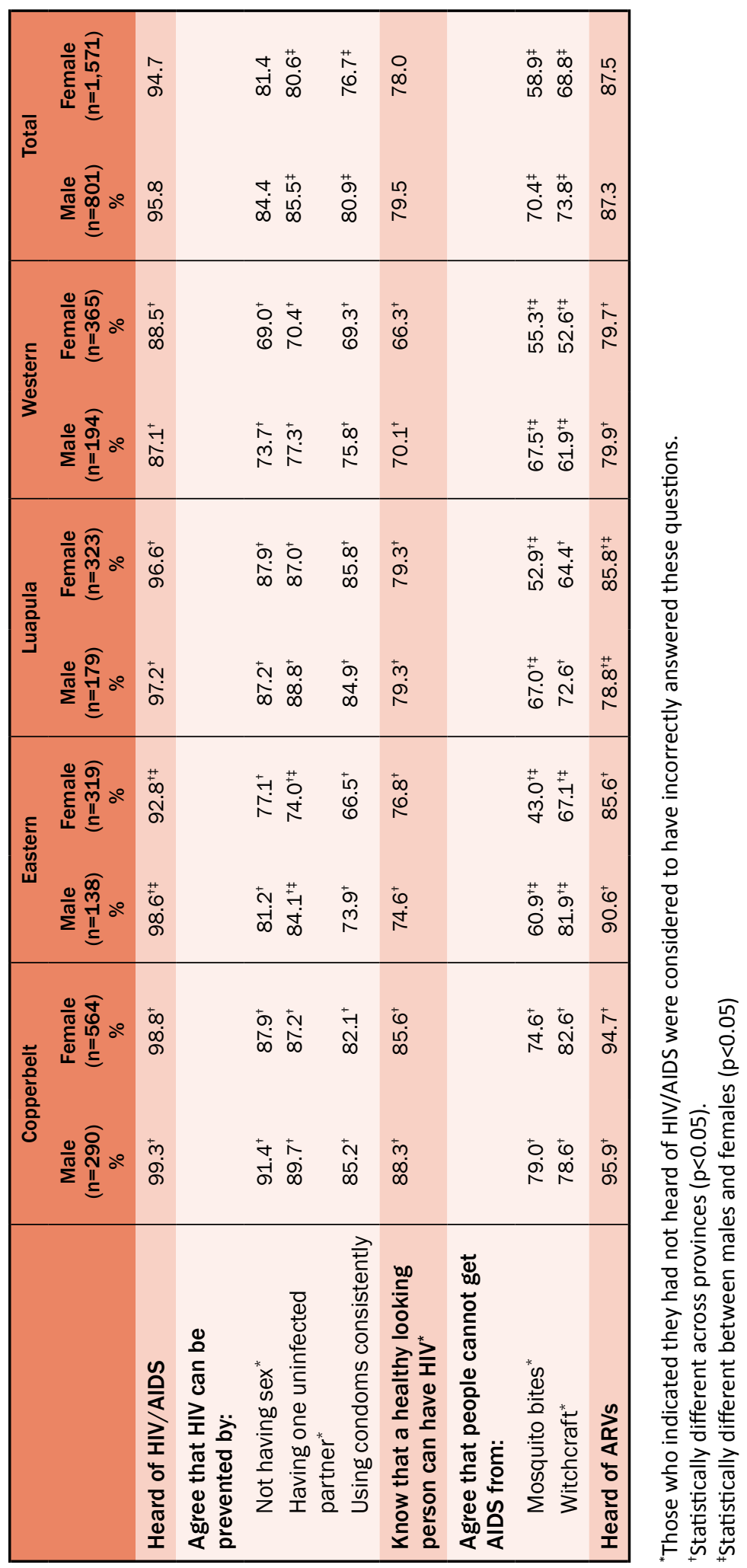




\section{APPENDIX 4. HIV TESTING}

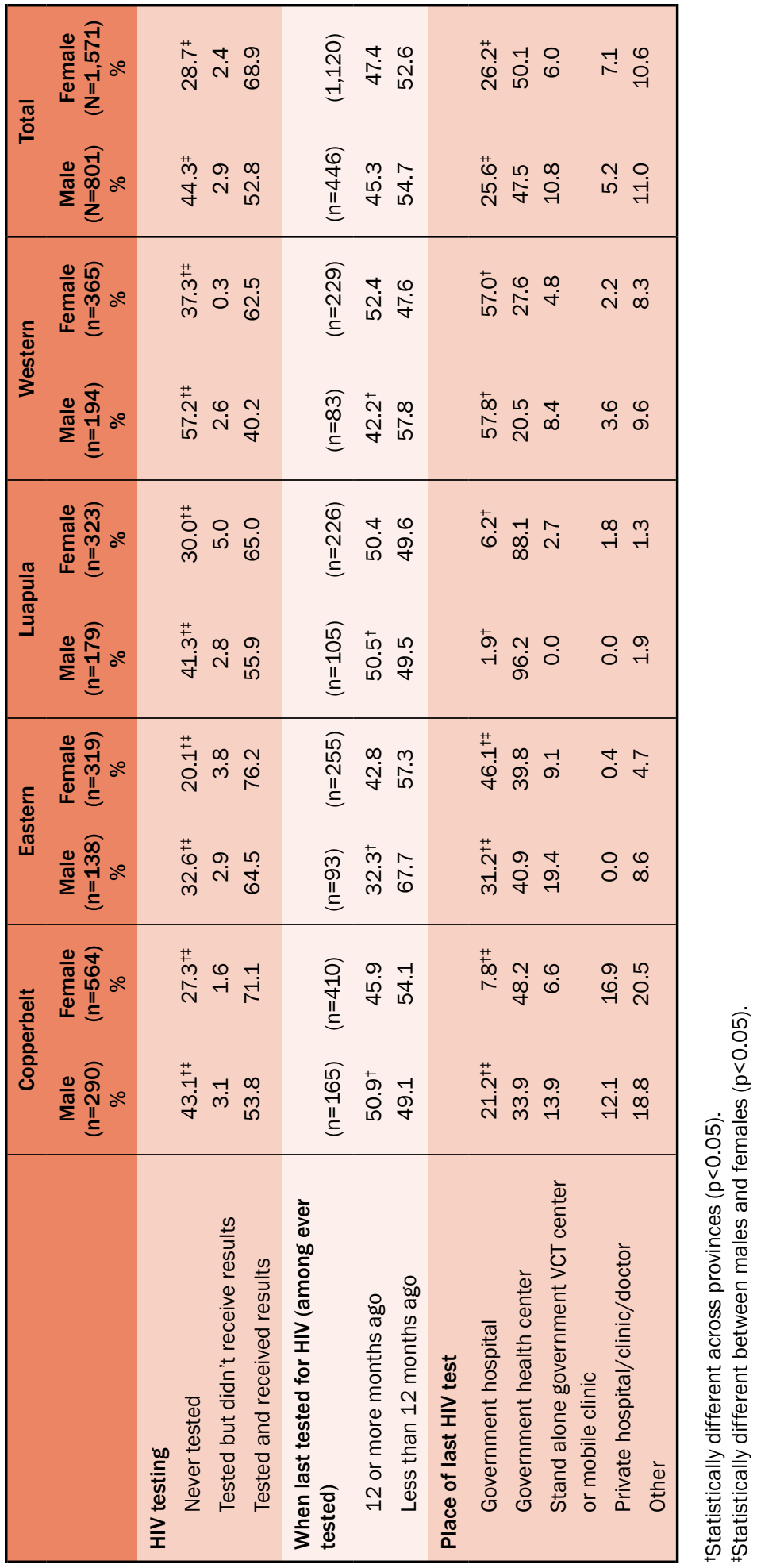




\section{APPENDIX 5. SEXUAL BEHAVIORS}

\begin{tabular}{|c|c|c|c|c|c|c|c|c|c|c|}
\hline & 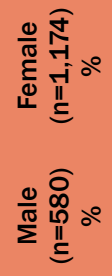 & $\begin{array}{l}\stackrel{0}{\stackrel{\dot{D}}{\infty}} \\
\\
\infty \\
\dot{\infty} \\
\infty\end{array}$ & 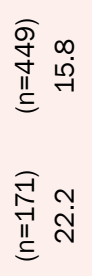 & $\begin{array}{c}\stackrel{-1}{0} \\
\infty \\
\infty \\
\infty \\
\infty \\
\infty\end{array}$ & 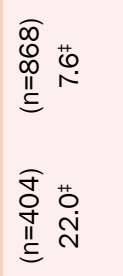 & 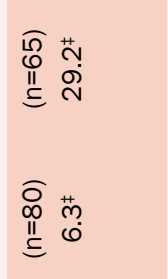 & 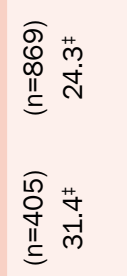 & 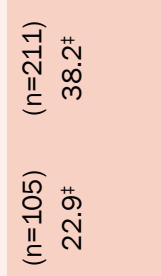 & 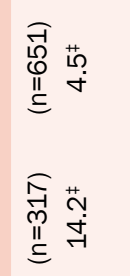 & \\
\hline & 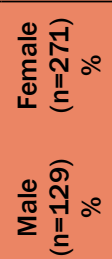 & $\begin{array}{l}+ \\
\infty \\
\dot{8} \\
\\
\infty \\
0 \\
\infty\end{array}$ & 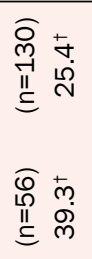 & $\begin{array}{l}0 \\
0 \\
0 \\
0 \\
0 \\
0\end{array}$ & 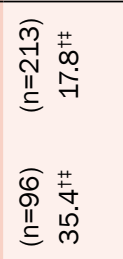 & 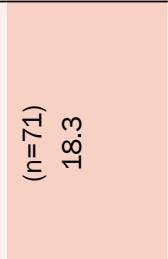 & 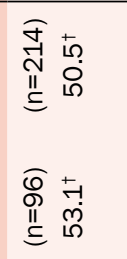 & 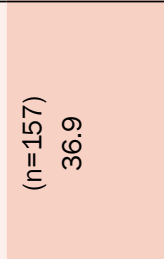 & 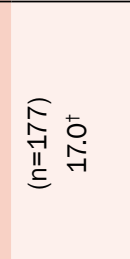 & \\
\hline & 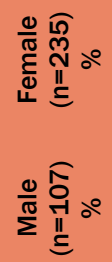 & 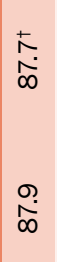 & 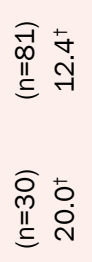 & $\begin{array}{l}\stackrel{\hat{D}}{0} \\
\stackrel{+}{\infty}\end{array}$ & 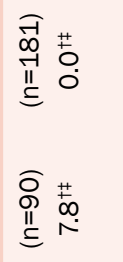 & 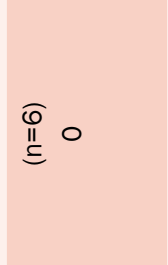 & 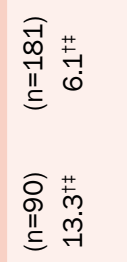 & 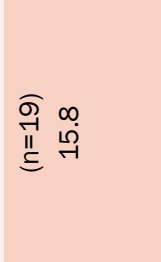 & 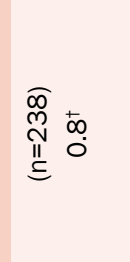 & \\
\hline & 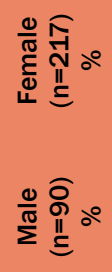 & $\begin{array}{l}\dot{m} \\
\dot{0} \\
\dot{8} \\
\hat{0} \\
\infty\end{array}$ & 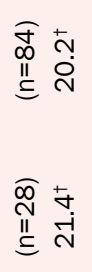 & $\begin{array}{l}\stackrel{\sim}{\infty} \\
\infty \\
\infty \\
\hat{\phi}\end{array}$ & 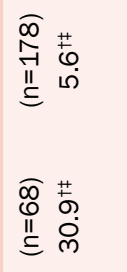 & 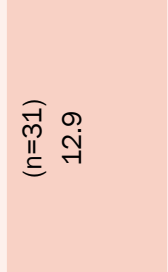 & 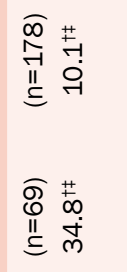 & 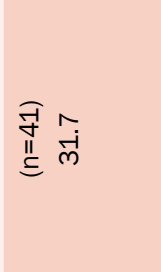 & 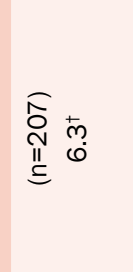 & $\dot{\bar{\omega}} \stackrel{\dot{N}}{\omega}$ \\
\hline है & 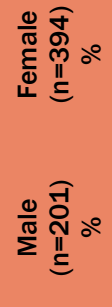 & 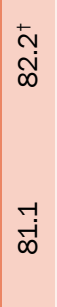 & 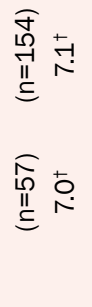 & $\underset{\substack{\infty \\
\infty}}{\stackrel{0}{\wedge}}$ & 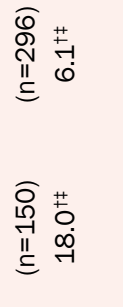 & $\begin{array}{ll}\widehat{N} & 0 \\
\mathbb{N} & \infty \\
& \infty\end{array}$ & 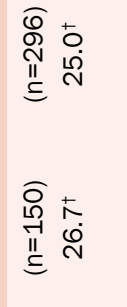 & 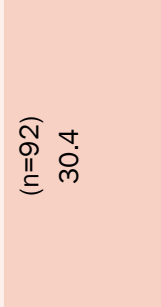 & 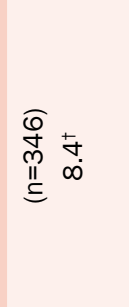 & 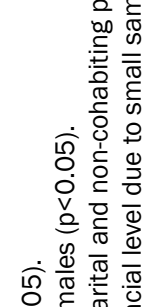 \\
\hline & & 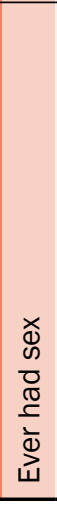 & 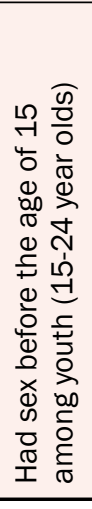 & 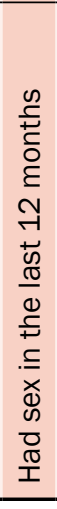 & 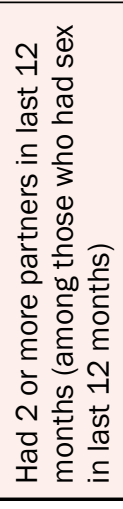 & 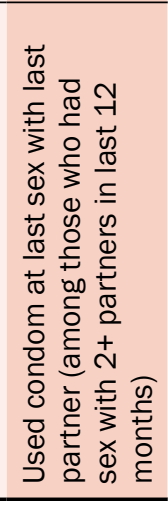 & 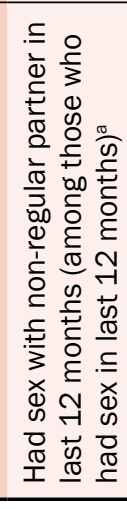 & 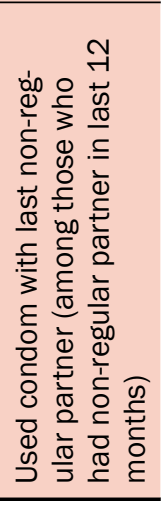 & 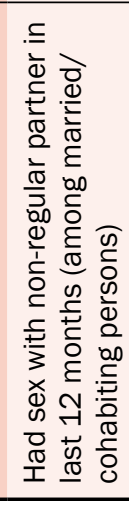 & 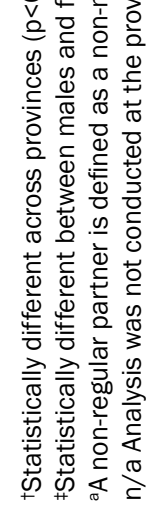 \\
\hline
\end{tabular}




\section{APPENDIX 6. ECONOMIC EMPOWERMENT AMONG MARRIED OR COHABITING MEN AND WOMEN}

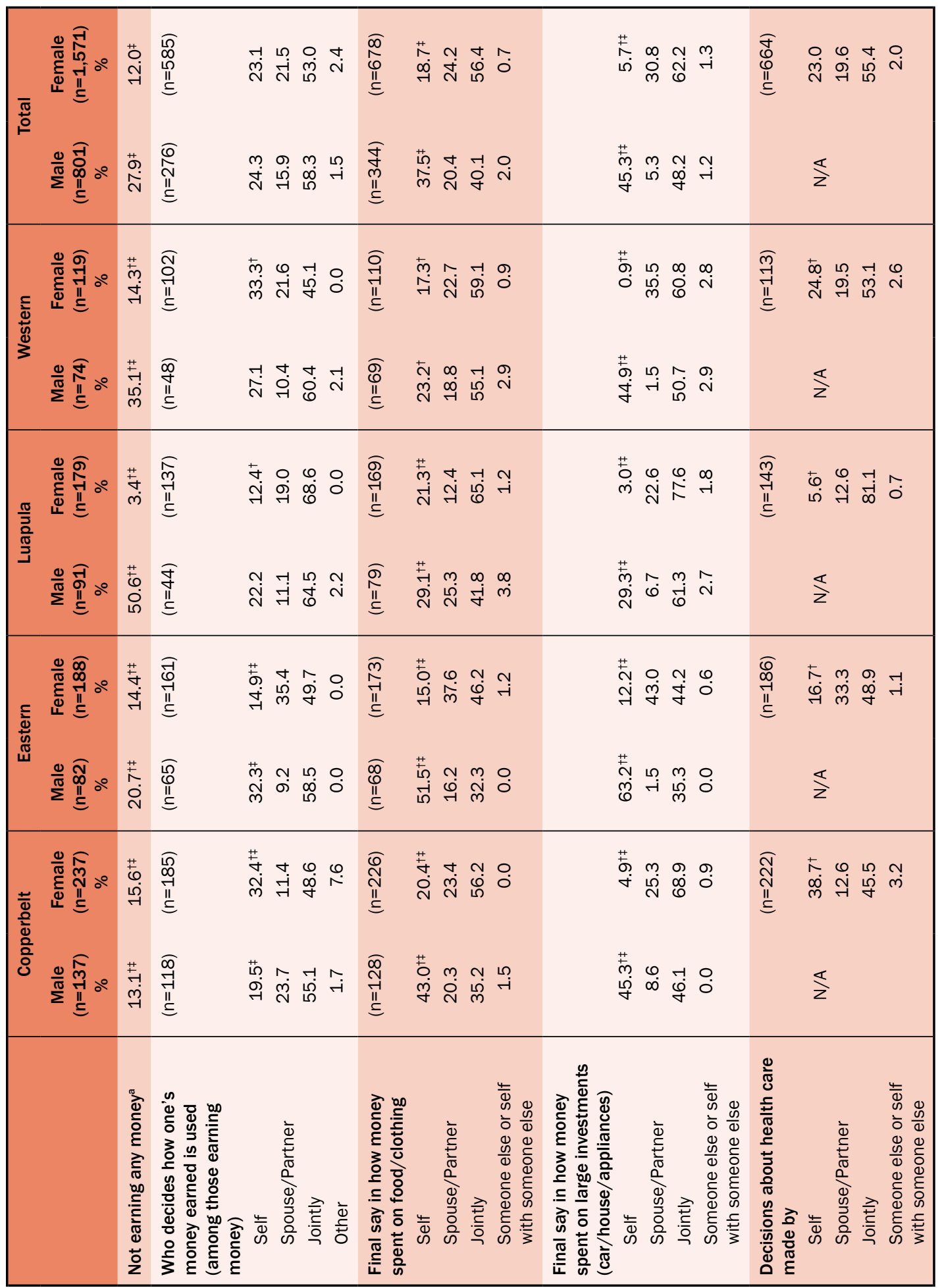




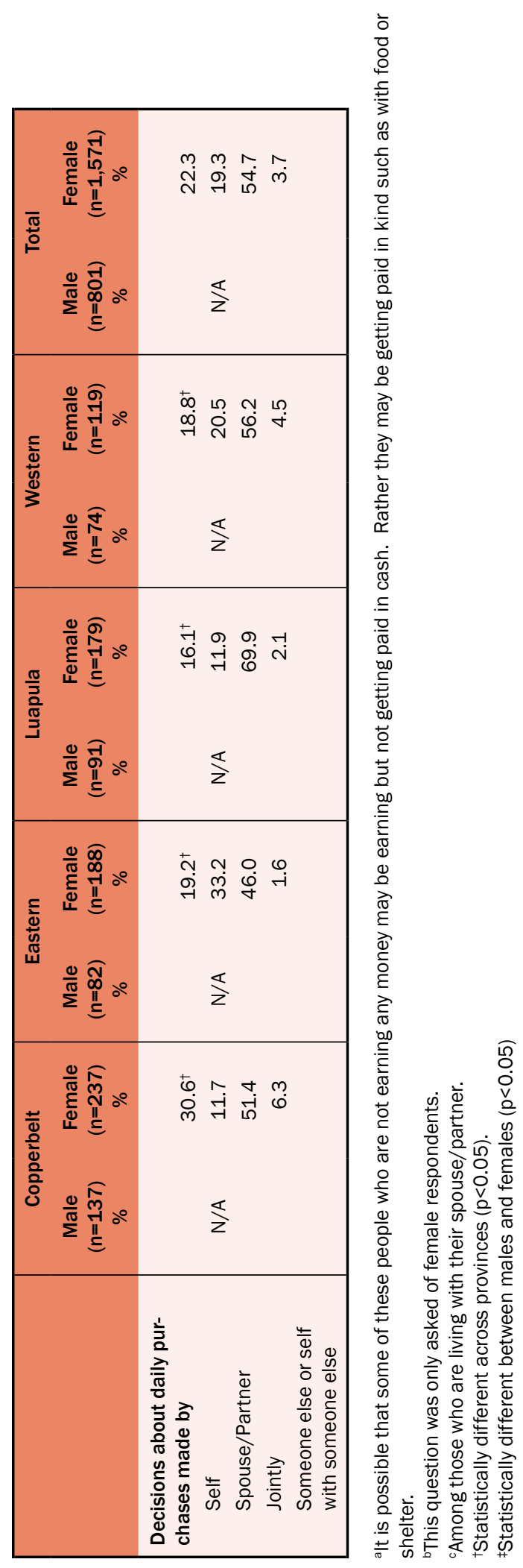


74 - ZPI Baseline Household Survey 

